\title{
ipen
}

AUTARQUIA ASSOCIADA À UNIVERSIDADE DE SÃO PAULO

\section{DESENVOLVIMENTO DE PROCEDIMENTOS E METODOLOGIA DE CONTROLE PARA APLICAÇÃO DE BOAS PRÁTICAS DE FABRICAÇÃO (BPF) NA IRRADIAÇÃO DE SANGUE HUMANO}

\section{CLÁUDIO BOGHI}

\begin{abstract}
Dissertação apresentada como parte dos requisitos para obtenção do Grau de Mestre em Ciências na Área de Tecnologia Nuclear - Aplicações.
\end{abstract}

Orientador:

Prof. Dr. Paulo Roberto Rela

SÃO PAULO

2008 
INSTITUTO DE PESQUISAS ENERGÉTICAS E NUCLEARES AUTARQUIA ASSOCIADA À UNIVERSIDADE DE SÃO PAULO

DESENVOLVIMENTO DE PROCEDIMENTOS E METODOLOGIA DE CONTROLE PARA APLICAÇÃO DE BOAS PRÁTICAS DE FABRICAÇÃO (BPF) NA IRRADIAÇÃO DE SANGUE HUMANO

\section{CLÁUDIO BOGHI}

Dissertação apresentada como parte dos requisitos para obtenção do Grau de Mestre em Ciências na Área de Tecnologia Nuclear - Aplicações.

Orientador:

Prof. Dr. Paulo Roberto Rela 


\section{AGRADECIMENTOS}

Como forma de expressar minha gratidão pela ajuda e incentivo recebido na realização deste trabalho, desejo agradecer:

Ao meu orientador Prof. Dr. Paulo Roberto Rela e a Prof ${ }^{\mathrm{a}}$. Dr ${ }^{\mathrm{a}}$. Maria Helena de Oliveira Sampa.

Especialmente ao meu grande amigo Ricardo Shitsuka.

Aos meus amigos que muito me ajudaram no laboratório de dosimetria do CTR-IPEN: Prof ${ }^{a}$ MsC. Célia M. Napolitano, Danilo C. Ferreira e Herman S. Zarate (o nosso amigo do Chile). Aos funcionários que me proporcionaram todo suporte e apoio necessários para operar na prática o irradiador Gammacell 220: Elizabeth S. R. Somessari ("Beth") e Carlos Gaia da Silveira ("Sr. Carlos"). Ao Prof. Dr. Fabio E. da Costa que sempre me forneceu sugestões importantes para este trabalho.

Aos meus amigos do CMR - IPEN: Prof ${ }^{\mathrm{a}}$. Dr ${ }^{\mathrm{a} .}$ Letícia Lucente Campos Rodrigues, pelo apoio na explicação sobre os dosímetros de $\mathrm{CaSO}_{4}$ :Dy (TLD), Prof ${ }^{\mathrm{a}}$. Dr ${ }^{\mathrm{a}}$. Linda V. E. Caldas pelas orientações sobre dosimetria e Linda Theresse ao me ensinar a ler as doses absorvidas nos dosímetros $\mathrm{CaSO}_{4}$ :Dy (TLD) no equipamento Harshaw.

A todos os professores do IPEN pela dedicação e carinho com que lecionaram suas disciplinas.

À minha esposa Silvana S. de Almeida Boghi e meus filhos Gianlucca Almeida Boghi e Henry Almeida Boghi. 


\section{DESENVOLVIMENTO DE PROCEDIMENTOS E METODOLOGIA DE CONTROLE PARA APLICAÇÃO DE BOAS PRÁTICAS DE FABRICAÇÃO (BPF) NA IRRADIAÇÃO DE SANGUE HUMANO}

\section{Cláudio Boghi}

\section{RESUMO}

A irradiação do sangue humano é usada para evitar a TA-DECH ("transfusão associada a doença do enxerto contra hospedeiro"), um raro mas devastador efeito adverso dos leucócitos presentes em componentes de sangue de doadores. Normalmente esta prática de irradiação é executada para a eliminação física de leucócitos. A implementação de procedimentos permitirá que a dose apropriada, dentro de uma faixa de 25 Gy a 50 Gy, seja absorvida pelas bolsas de sangue coletadas em um banco de sangue. Os estudos para estabelecer os procedimentos de BPF (Boas Práticas de Fabricação) foram desenvolvidos baseados na norma ISO 11137 Esterilização de produtos médicos - Requisitos para validação e controle de rotina - Esterilização por radiação. Dois sistemas dosimétricos foram usados para o mapeamento de dose durante os estudos da qualificação do irradiador, carregamento de produto, validação de processo de irradiação e auditoria. O dosímetro $\mathrm{CaSO}_{4}: \mathrm{Dy}$ apresentou dificuldades em relação à incerteza na medição da dose, estabilidade, rastreabilidade e calibração. Os dosímetros PMMA e Gafchromic mostraram uma melhor performance e foram adotados para estudos de qualificação de irradiadores necessários para a implantação de BPF. Os testes de irradiação foram realizados em um irradiador Gammacell 220. Os procedimentos desenvolvidos podem ser adaptados para diferentes tipos de irradiadores gama, permitindo a implantação de um programa de garantia da qualidade e BPF para irradiação de sangue. 


\title{
PROCEDURES DEVELOPMENT AND METHODOLOGY OF CONTROL FOR APPLICATION OF GOOD MANUFACTURE PRACTICES (GMP) ON HUMAN BLOOD IRRADIATION
}

\section{Cláudio Boghi}

\begin{abstract}
The irradiation of human blood is used to avoid the TA-GVHD (transfusion-associated graft-versus-host-disease), a rare but devastating adverse effect of leukocytes present in blood components for a immunocompetent transfusion recipients. Usually this irradiation practice is performed to a physical elimination of leukocytes. The implementation of the procedures will assure that the properly dose in a range of 25 Gy to 50 Gy will be delivered to the blood in the bag collected in a blood tissue bank. The studies of the procedures in order to establish a GMP (Good Manufacturing Practices) were developed under the guidelines of the standard ISO 11137 - Sterilization of health care products - Requirements for validation and routine control Radiation sterilization. In this work, two dosimetric systems were used for dose mapping during the studies of irradiator qualification, loading pattern, irradiation process validation and auditing. The $\mathrm{CaSO}_{4}$ :Dy dosimeter presented difficulties concerning to uncertainty on dose measurement, stability, traceability and calibration. The PMMA and Gafchromic dosimetric systems have shown a better performance and were adopted on studies of irradiators qualification that are necessary to implementation of GMP. The irradiation tests have been done in a Gammacell 220 irradiator. The developed procedures can be adapted for different kinds of gamma irradiators, allowing implanting a quality assurance program and a GMP for blood irradiation.
\end{abstract}




\section{SUMÁRIO}

Página

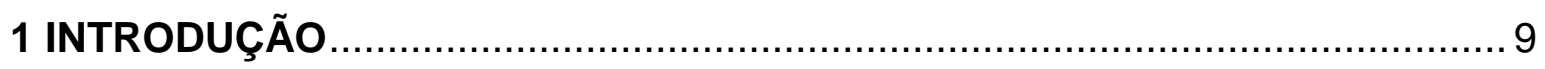

1.1 Relevância do estudo ......................................................................... 11

1.2 Procedimentos para coleta de sangue ………......................................... 14

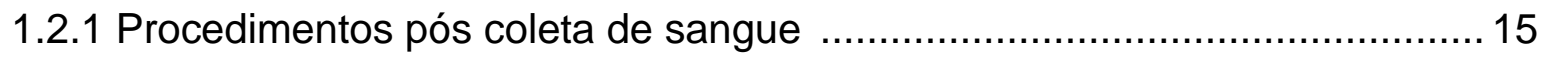

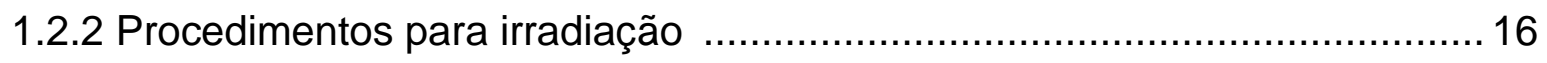

2 OBJETIVO

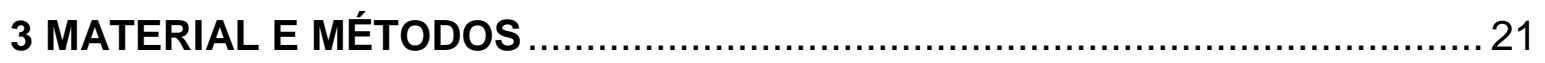

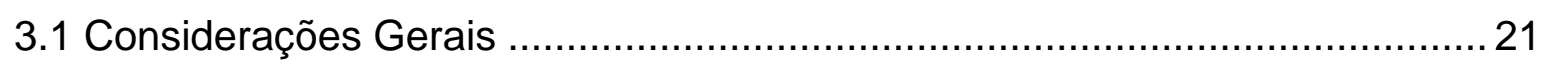

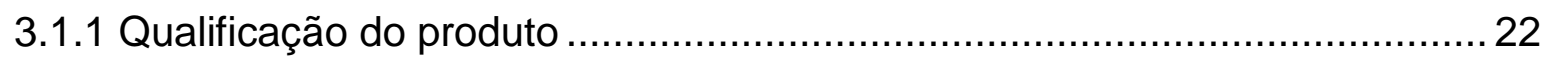

3.1.1.1 Avaliação do produto e do material da embalagem ................................. 22

3.1.1.2 Determinação da dose de irradiação ...................................................... 23

3.2 Qualificação do irradiador .................................................................... 23

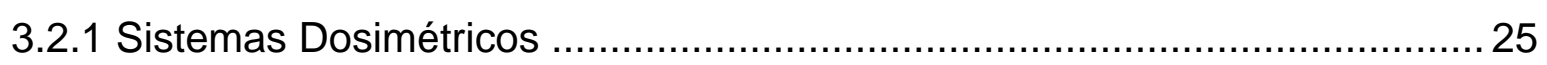

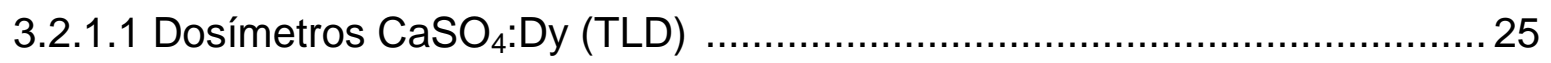

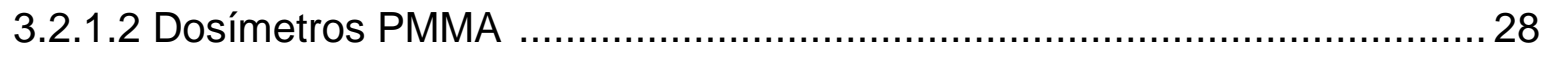

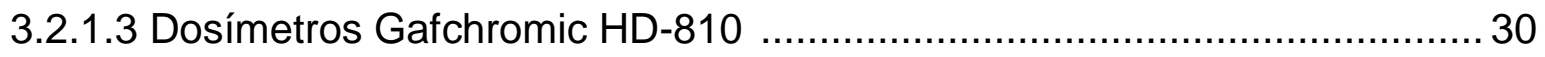

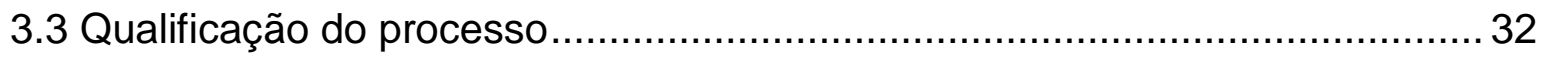

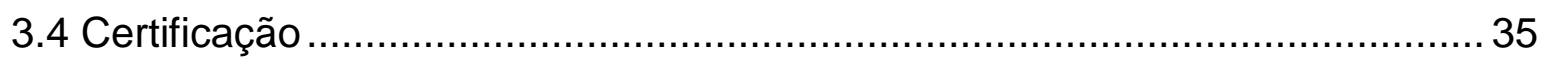

3.5 Testes para verificação da validade do processo ....................................... 36

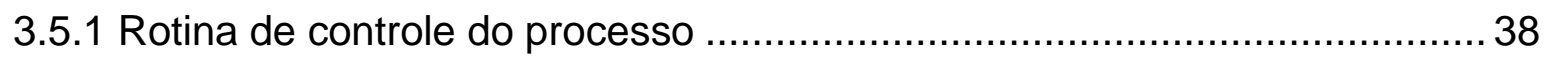

4 RESULTADOS E DISCUSSÃO

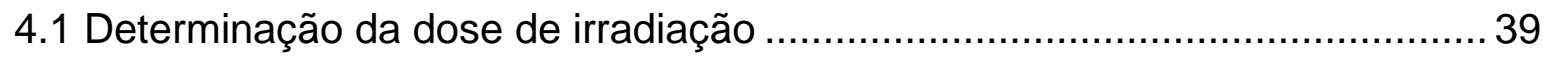

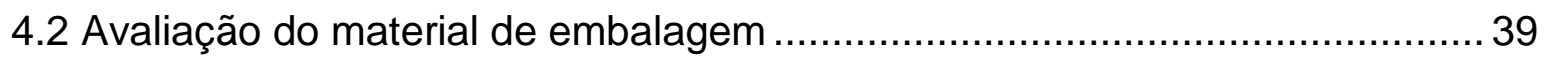

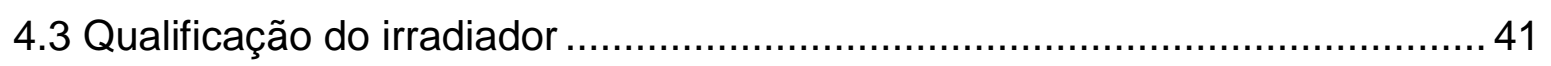

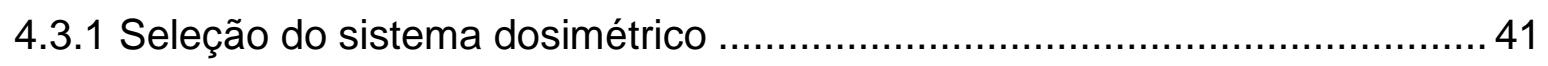

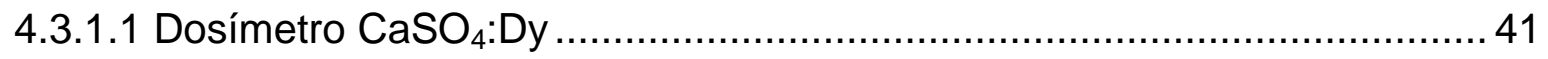

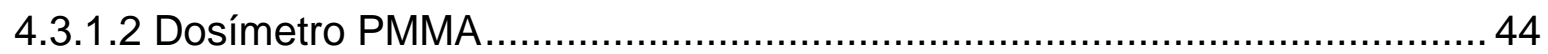

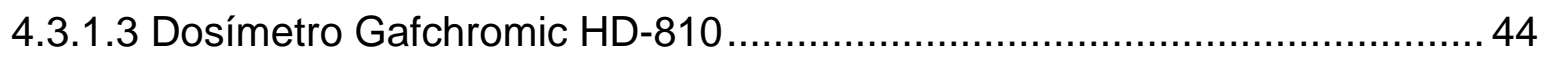

4.3.1.4 Curva de calibração para o dosímetro Gafchromic HD-810 ..................... 48

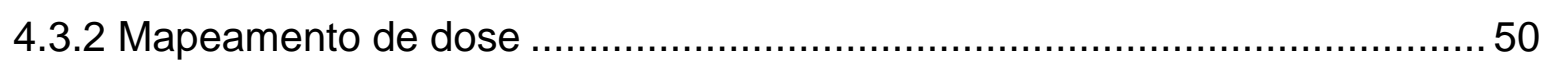




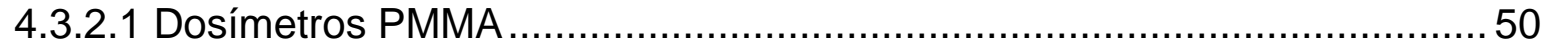

4.3.2.2 Dosímetros Gafchromic HD-810 ….............................................. 56

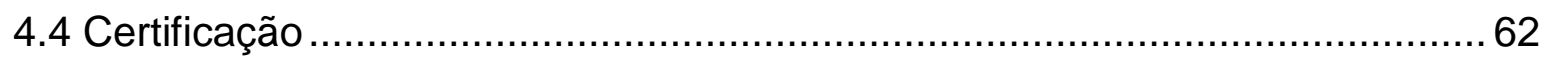

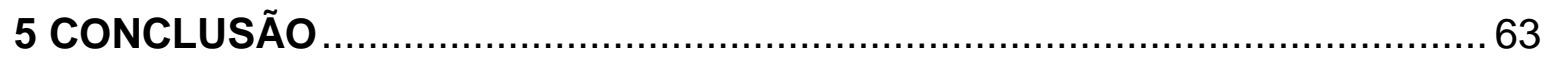

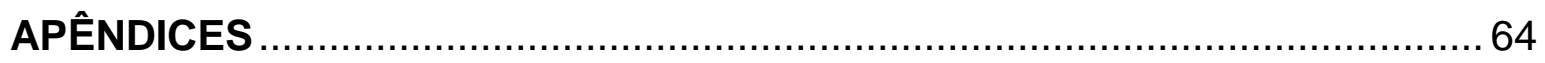

APÊNDICE A - Fluxograma da rotina de coleta e irradiação de sangue ....... 64

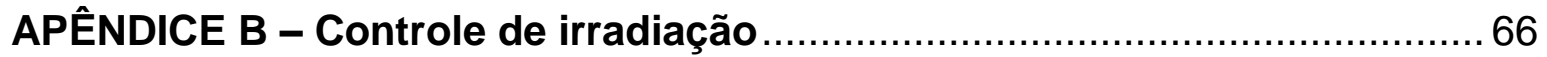

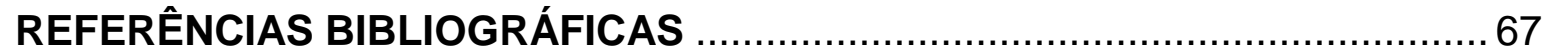




\section{INDICE DE TABELAS}

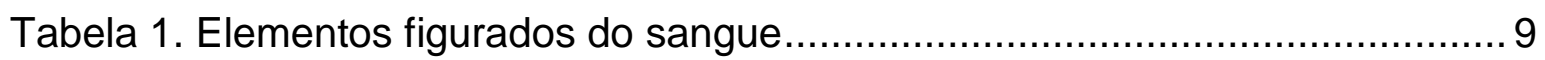

Tabela 2. Tipagem conforme grupo sangüíneo ……....................................... 10

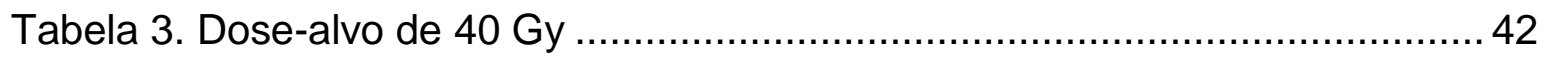

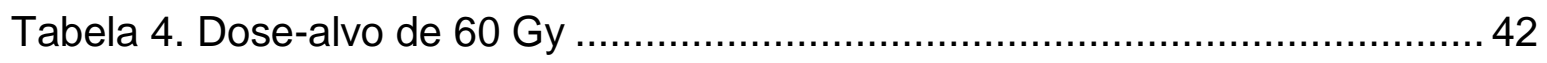

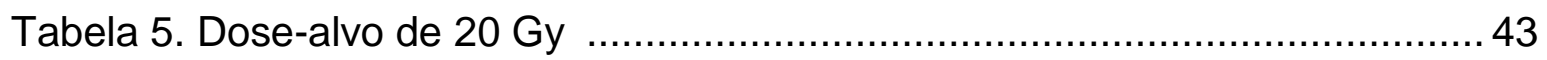

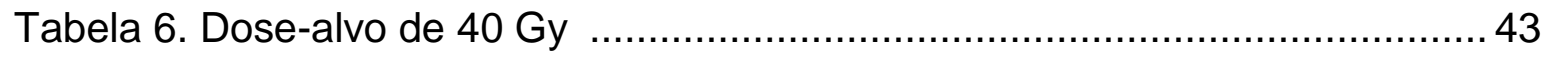

Tabela 7. Cálculo do Coeficiente de Variação para Experimento 1 ....................... 46

Tabela 8. Cálculo do Coeficiente de Variação para Experimento 2 .......................4 47

Tabela 9. Valores de kmédio e desvio-padrão .................................................... 48

Tabela 10. Cálculo Final do Coeficiente de Variação (CV) .................................. 49

Tabela 11. Dose absorvida no dosímetro PMMA na posição 0 ํ...........................50

Tabela 12. Dose absorvida no dosímetro PMMA na posição $90^{\circ}$......................... 52

Tabela 13. Dose absorvida no dosímetro PMMA na posição 45…..................... 54

Tabela 14. Posição 0 을 do dosímetro Gafchromic............................................... 56

Tabela 15. Posição 90ำ do dosímetro Gafchromic ............................................ 58

Tabela 16. Posição 45o do dosímetro Gafchromic............................................ 60 


\section{INDICE DE FIGURAS}

Figura 1. Indicador de processo da empresa Rad Tag ..................................... 17

Figura 2. Indicador de processo irradiado a 25 Gy ......................................... 17

Figura 3. Procedimentos seguidos conforme AAMI/ISO11137 ........................... 21

Figura 4. Gammacell 220 instalado no CTR - IPEN ............................................. 24

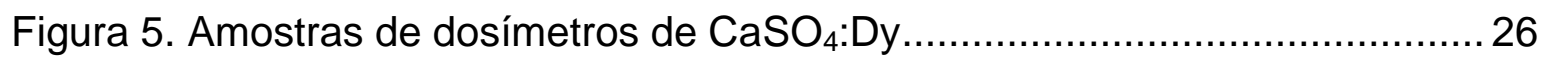

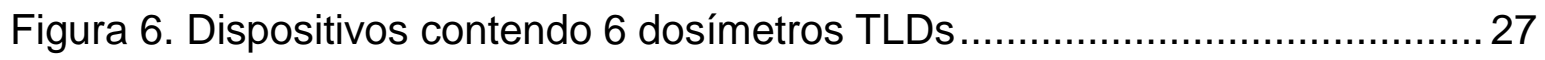

Figura 7. Harshaw Nuclear System e o gráfico da leitura do dosímetro ................ 28

Figura 8. Espectrofotômetro Thermo Spectronic, modelo Genesys 20................. 29

Figura 9. Micrômetro Mitutoyo ……......................................................... 30

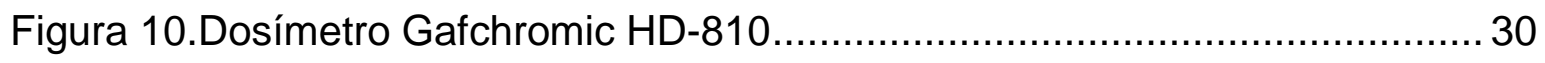

Figura 11. Película do dosímetro Gafchromic HD-810 da ISP ............................ 31

Figura 12. Coloração do dosímetro Gafchromic depois de irradiado ..................... 31

Figura 13. Espectrofotômetro Shimadzu UV-1601 PC...................................... 32

Figura 14. Dosímetros PMMA distribuídos no dispositivo de irradiação para

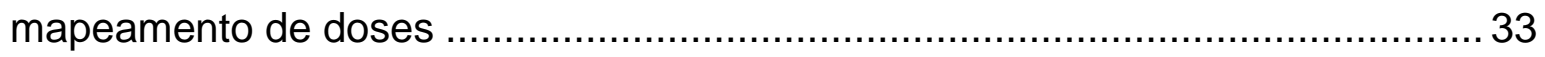

Figura 15. Arranjo utilizado para mapeamento de dose .................................... 34

Figura 16. Distribuição das bolsas e dosímetros na prática de irradiação

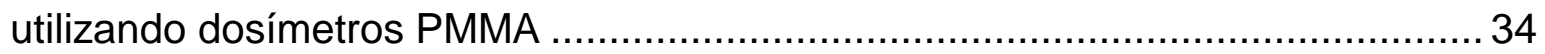

Figura 17. Visão do arranjo dentro do Gammacell 220...................................... 34

Figura 18. Marcação do dosímetro Gafchromic e o arranjo final ......................... 35

Figura 19. Análise de árvore de falhas ........................................................ 37

Figura 20. Posicionamento dos dosímetros Gafchromic no arranjo

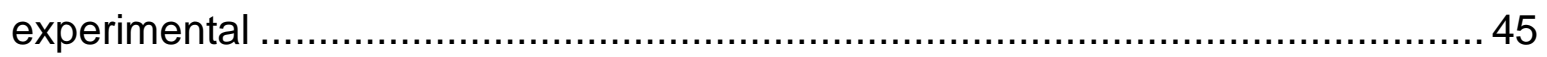

Figura 21. Curva de calibração do dosímetro Gafchromic .................................. 49

Figura 22. Representação gráfica do dosímetro PMMA na posição 으...................51

Figura 23. Representação gráfica do dosímetro PMMA na posição $90^{\circ}$................ 53

Figura 24. Representação gráfica do dosímetro PMMA na posição $45^{\circ}$................ 55

Figura 25. Representação gráfica do dosímetro Gafchromic na posição 0 …...... 57

Figura 26. Representação gráfica do dosímetro Gafchromic na posição $90^{\circ}$........ 59

Figura 27. Representação gráfica do dosímetro Gafchromic na posição $45^{\circ}$........61 


\section{INTRODUÇÃO}

O sangue humano é um tecido que circula ao longo do corpo, carregando nutrientes, abastecendo de oxigênio as células e participando da remoção do gás carbônico e em diversos processos, como é o caso do controle da temperatura do corpo (homeostasia), defesa e integridade. ${ }^{(1)}$

A composição sangüínea pode dividir-se em duas partes principais: os elementos figurados e o plasma. $O$ primeiro é formado por elementos que possuem morfologia, tamanho e funções. Na TAB. 1 são apresentados os elementos figurados do sangue e as suas principais características. ${ }^{(2)}$

TABELA 1 - Elementos figurados do sangue

\begin{tabular}{|c|c|c|c|}
\hline \multicolumn{3}{|c|}{ NOME } & CARACTERÍSTICAS \\
\hline \multicolumn{3}{|c|}{ Eritrócitos (glóbulos vermelhos) } & $\begin{array}{l}\text { Forma discoidal, bicôncava, repleta de } \\
\text { hemoglobina; transporta oxigênio para os } \\
\text { tecidos. }\end{array}$ \\
\hline \multirow{5}{*}{$\begin{array}{l}\text { Leucócitos } \\
\text { (glóbulos } \\
\text { brancos) }\end{array}$} & \multirow{3}{*}{ Granulosos } & Neutrófilo & $\begin{array}{l}\text { Forma esférica, núcleo trilobulado; fagocita } \\
\text { bactérias e corpos estranhos. }\end{array}$ \\
\hline & & $\begin{array}{l}\text { Eosinófilo } \\
\text { (acidófilo) }\end{array}$ & $\begin{array}{l}\text { Forma esférica, núcleo bilobulado; participa } \\
\text { das reações alérgicas, produzindo histamina. }\end{array}$ \\
\hline & & Basófilo & $\begin{array}{l}\text { Forma esférica, núcleo irregular. Acredita-se } \\
\text { que também participe de processos } \\
\text { alérgicos; produz histamina e heparina. }\end{array}$ \\
\hline & \multirow{2}{*}{ Agranulosos } & $\begin{array}{l}\text { Linfócitos } \\
\text { (B e T) }\end{array}$ & $\begin{array}{l}\text { Forma esférica, núcleo também esférico; } \\
\text { participam dos processos de defesa } \\
\text { imunitária, produzindo e regulando a } \\
\text { produção de anticorpos. }\end{array}$ \\
\hline & & Monócito & $\begin{array}{l}\text { Forma esférica, núcleo oval ou reniforme, } \\
\text { origina macrófagos e osteoclastos, células } \\
\text { especializadas em fagocitar. }\end{array}$ \\
\hline \multicolumn{3}{|c|}{ Plaquetas (trombócitos) } & $\begin{array}{l}\text { Forma irregular, sem núcleo, participam dos } \\
\text { processos de coagulação do sangue. }\end{array}$ \\
\hline
\end{tabular}

O plasma é a parte líquida do tecido sangüíneo com uma constituição de aproximadamente $90 \%$ de água em que estão dissolvidas as numerosas substâncias existentes no sangue tais como os sais como sódio, cloro, fósforo, potássio, magnésio, cálcio e outros. As proteínas, que também estão dissolvidas no plasma, são de grande importância para o corpo humano. Em cada litro de 
sangue existem de 60 a 80 gramas de proteínas, entre elas, a albumina e, em menor proporção, as globulinas, relacionadas com a formação de anticorpos, e o fibrinogênio, fundamental no processo de coagulação ${ }^{(2)}$.

Os glóbulos brancos, também denominados leucócitos, podem ser classificados em cinco variedades como já mencionado na TAB.1, com funções importantes para o corpo humano.

Os tipos sangüíneos são classificados em A, B, O e AB. A descrição do sistema Rh ocorreu em 1940, pelos pesquisadores Wiener e Landsteiner ${ }^{(3)}$. Para se determinar o grupo sangüíneo, normalmente são realizados dois tipos de testes ${ }^{(2)}$ :

1) Tipagem direta: ocorre por meio da identificação da presença de antígenos nos eritrócitos, utilizando reativos compostos de anticorpos conhecidos (anti-A, anti-B, anti-AB).

2) Tipagem reversa: identifica a presença de anticorpos no soro/plasma utilizando reativos compostos de antígenos conhecidos (hemácias $A$ e hemácias B).

Na TAB. 2 são apresentadas as tipagens conforme o grupo sangüíneo. ${ }^{(2)}$

TABELA 2 - Tipagem conforme grupo sanguíneo

\begin{tabular}{c|c|c|c|c|c|c}
\hline $\begin{array}{c}\text { GRUPO } \\
\text { SANGUÍNEO }\end{array}$ & \multicolumn{2}{|c|}{$\begin{array}{c}\text { SORO DE } \\
\text { TIPAGEM }\end{array}$} & \multicolumn{2}{c|}{$\begin{array}{c}\text { HEMÁCIAS DE } \\
\text { TIPAGEM }\end{array}$} & ANTÍGENO & ANTICORPO \\
& Anti-A & Anti-B & A & B & & \\
\hline A & + & - & - & + & A & Anti-B \\
\hline B & - & + & + & - & B & Anti-A \\
\hline AB & + & + & - & - & A e B & Ausente \\
\hline O & - & - & + & + & - & Anti-A e Anti-B \\
\hline
\end{tabular}

Para efeito de transfusão, é considerado que pacientes Rh positivos podem receber sangue $\mathrm{Rh}$ positivo ou negativo, e que pacientes $\mathrm{Rh}$ negativos podem receber somente sangue $\mathrm{Rh}$ negativo. ${ }^{(4)}$ 
As transfusões de sangue ou de seus componentes são semelhantes aos transplantes. As primeiras, geralmente, são procedimentos de urgência e não podem ser classificadas como um tratamento. Após uma transfusão, devem ser observados todos os cuidados, pois, como em um transplante, podem ocorrer reações e rejeições. A maioria dos casos de transfusão sangüínea está associada à anemia crítica ou perdas sangüíneas, devido a problemas hepáticos ou renais e a infecções por parasitas do sangue.

Os leucócitos provenientes de transfusão sanguínea podem causar a doença transfusion-associated graft-versus-host disease (TA-GVHD) ${ }^{(5)}$, que é conhecida no Brasil, como doença do enxerto contra o hospedeiro (DECH). Segundo a Resolução da ANVISA-RDC 153 de 14 de junho de 2004 ${ }^{(6)}$, esta doença é mediada imunologicamente pelos linfócitos do sangue doador e pode causar a morte do receptor.

Atualmente, é muito grande a aceitação da irradiação de componentes de sangue por ser segura e por ser um dos mais eficientes métodos para eliminação física de linfócitos com o propósito de inibir seu potencial de proliferação para evitar a TA-GVHD. ${ }^{(5)}$

Geralmente se utilizam como fonte de radiação os isótopos de cobalto-60 ou de césio-137, mas também podem ser empregados os aceleradores de elétrons. A radiação proveniente destas fontes, possuem devido às suas elevadas energias, propriedades ionizantes que interferem diretamente na estrutura de átomos e moléculas. O processo causa a eliminação das células, as quais perdem a capacidade de multiplicação. A principal vantagem é que a irradiação é realizada no material contido dentro de bolsas lacradas e prontas para uso, diminuindo assim, o processo de recontaminação.

\subsection{Relevância do estudo}

O procedimento de irradiação de sangue humano é obrigatório para pacientes submetidos ao transplante de medula óssea e é indicado para pessoas que sofram de leucemia, linfomas, doença de Hodgkin, anemia aplástica e 
imunodeficiência congênita. Ainda é obrigatório, por lei, para crianças recém nascidas ou prematuras, caso a transfusão não seja entre parentes de primeiro grau. ${ }^{(7)}$

Atualmente, poucos hospitais no Brasil, assim como hemocentros, possuem um irradiador próprio para bolsas de sangue, pois este equipamento ainda é de alto custo para os hospitais que necessitam deste tipo de irradiação. Há alguns hospitais no País que possuem irradiadores como é o caso do Hospital Albert Einstein em São Paulo, o Instituto Nacional do Câncer (INCA), no Rio de Janeiro, e o Hospital do Servidor Público Estadual de São Paulo, sendo que esses equipamentos foram adquiridos do exterior.

No Brasil, o Instituto de Pesquisas Energéticas e Nucleares através do Centro de Tecnologia das Radiações (IPEN-CTR) está desenvolvendo um irradiador nacional, dedicado a bancos de sangue, que utilizará fontes radioativas decaídas de ${ }^{60} \mathrm{Co}$, modelo Nordion $\mathrm{C} 188$, provenientes de irradiadores industriais de grande porte. As fontes, ao decaírem para a atividade radioativa da ordem de $1.000 \mathrm{Ci}\left(3,7 \times 10^{13} \mathrm{~Bq}\right)$ normalmente são substituídas por fontes com atividade da ordem de $10.000 \mathrm{Ci}\left(3,7 \times 10^{14} \mathrm{~Bq}\right)$.

Para um irradiador de sangue a atividade necessária seria da ordem de $3.000 \mathrm{Ci}\left(11,1 \times 10^{13} \mathrm{~Bq}\right)$. A possibilidade de utilização de três fontes industriais C188 já decaídas ao serem tratadas como rejeitos, favoreceria a construção com baixo custo do irradiador com tecnologia nacional, viabilizando a utilização dessa técnica em um número maior de bancos de sangue no País, principalmente os pertencentes a hospitais e entidades governamentais.

A Resolução ANVISA RDC 153 de 14 de junho de $2004^{(6)}$ no seu item C-6 estabelece que "a irradiação de componentes de sangue deve ser feita preferencialmente, em irradiador de células, próprio para a irradiação de sangue e componentes". Segundo informações obtidas junto à Coordenação de Instalações Radiativas (CORAD) - Unidade da Comissão Nacional de Energia Nuclear (CNEN), responsável pelo licenciamento no País de instalações radioativas, existem atualmente 12 unidades em operação concentradas na Região Sudeste. 
Para a utilização de um equipamento com tecnologia nacional na irradiação de componentes de sangue tornar-se-ia necessária a sua qualificação a fim de assegurar a realização deste processo de modo apropriado. De acordo com a Resolução ANVISA RDC 153 de 14 de junho de $2004^{(6)}$ notou-se a necessidade da implantação de códigos de Boas Práticas de Fabricação (BPF), internacionalmente conhecidos como GMP - Good Manufacturing Practice.

Na BPF estão incorporadas atividades devidamente registradas em um programa de trabalho para demonstração do processo de irradiação dentro dos limites especificados, possibilitando que os produtos tratados (bolsas de sangue e os dosímetros) absorvam as doses de radiação no intervalo previamente definido.

É importante mencionar que a Resolução ANVISA RDC 153 de 14 de junho de $2004^{(6)}$ é a legislação mais atualizada referentemente à regulamentação técnica para os procedimentos de hemoterapia para coleta, processamento, testes, armazenamento, transporte, utilização e controle de qualidade do sangue e seus componentes e nela, não estão estabelecidas as boas práticas a serem adotadas para validação do processamento por irradiação. Consta de modo bastante genérico que "o controle de qualidade da fonte radioativa do equipamento deve ser realizado e documentado no mínimo, anualmente".

A AABB - American Association of Blood Bank ${ }^{(8)}$-, apresenta orientações gerais para o processo de irradiação de componentes de sangue. A norma AAMI/ISO11137 ${ }^{(9)}$ da Association for Advancement of Medical Instrumentation e International Standards Organization estabelece os requisitos para validação e controle de rotina, utiliza-se da radiação ionizante para esterilização de produtos para saúde e estabelece, com detalhes e rigor, todos os procedimentos necessários para implantação de BPF voltada para a esterilização.

Em um processo de irradiação, a dosimetria é a metodologia aceita para assegurar que esse processo siga as especificações, medindo-se a quantidade de radiação depositada em um meio em que os resultados obtidos em laboratório possam ser reproduzidos e, então, transferidos para uma aplicação industrial ${ }^{(10)}$. Para ser efetuada a dosimetria das radiações são utilizados dosímetros que são instrumentos para medir a dose absorvida de radiação em produtos industriais, 
médicos e de agricultura. $\mathrm{O}$ fator mais importante em dosimetria do processamento por radiação é a dose absorvida $\mathrm{D}^{(10)}$.

Utiliza-se o dosímetro nos seguintes tipos de radiação ionizante $(X, \gamma, \alpha, \beta)$ e em qualquer tipo de material absorvedor. Atualmente, a unidade medida de dose absorvida é o gray (Gy), que equivale a $1 \mathrm{~J} / \mathrm{kg}$. A unidade antiga é o rad, que equivale a $10^{-2} \mathrm{~J} / \mathrm{kg}$, ou seja, $1 \mathrm{~Gy}=100 \mathrm{rad}$. A medida da taxa de dose absorvida tem por definição a medida de dose absorvida por unidade de tempo como, por exemplo, Gy/h ${ }^{(11)}$.

Na norma AAMI/ISO 11137 incluem-se os procedimentos para a definição da dose de esterilização, que são da ordem de 25 kGy a 50 kGy. No caso da irradiação de sangue, a literatura disponível e a AABB definem o intervalo das doses requeridas de 25 Gy a 50 Gy, cabendo observar que a magnitude é 1000 vezes inferior à dose de esterilização de produtos médico-cirúrgicos.

\subsection{Procedimentos para coleta de sangue adotados atualmente por banco de sangue}

Para o procedimento de coleta de sangue faz-se necessário que o candidato à doação informe os seguintes dados: nome, endereço completo, data de nascimento, filiação e documento de identidade. A seguir, ele recebe um código emitido via software a ser adicionado à etiqueta do código de barras acoplada à bolsa de sangue que o acompanha durante todo o processo. Este não permite que o candidato seja identificado nem mesmo pelos funcionários da instituição, ocorrendo apenas a conferência dos dados, principalmente o CEP, para que o cartão de doador chegue à sua residência.

Segundo a Resolução ANVISA-RDC 153 de 14 de junho de 2004 ${ }^{(6)}$, portadores de anemia, de pressão arterial alta e baixa, de baixo peso e pertencentes ao grupo de risco da Síndrome da Imunodeficiência Adquirida (que do inglês deriva a sigla AIDS, Acquired Immune Deficiency Syndrome) não estão qualificados para a doação de sangue. 
No caso do doador inserido no grupo de risco de AIDS e Hepatite C, a bolsa é descartada, e com a retirada dos resultados oficiais, o candidato será direcionado para orientação médica e tratamento adequado.

A coleta de sangue compreenderá cerca de $450 \mathrm{ml}$ com armazenamento em bolsa de uso único e estéril, sendo, portanto, totalmente segura. Para esse fim o Instituto do $\mathrm{PVC}^{(12)}$, a portaria $\mathrm{n}$ ․ 1376 da $\operatorname{ANVISA}^{(13)}$ e a norma AAMI/ISO11137 ${ }^{(9)}$ indicam o Policloreto de Vinila (PVC).

\subsubsection{Procedimentos pós coleta de sangue}

A bolsa de sangue é encaminhada ao fracionamento para ser separada em até quatro componentes com armazenamentos específicos sendo estes: hemácias, plasma, plaquetas e o crioprecipitado (fator de coagulação). A seguir, cada componente recebe mais uma etiqueta com código de barras, a qual se acrescenta à etiqueta inicial, que contém o código emitido no início do processo referente ao cadastramento. Esse código adicional distingue cada hemocomponente e o acompanha durante todo o processo de irradiação e pode ser elaborado da seguinte maneira: 01 - hemácias; 02 - plasma; 03 crioprecipitado e 04 - plaquetas. Sendo assim, em cada bolsa de sangue é constado o código de cadastramento do doador e o código do hemocomponente.

Assim que as bolsas de sangue receberem as etiquetas com os respectivos códigos de barras, cada bolsa de sangue dos hemocomponentes segue para o local apropriado e, antes de ser armazenada, tem seu registro via software para controle de entrada e saída. Após todos os procedimentos serem concluídos, cada hemocomponente está pronto para irradiação e transfusões de sangue.

Em caso de necessidade de armazenamento as hemácias são armazenadas em refrigeradores com temperaturas entre 2 a 6 graus Celsius por até 35 dias; o plasma e o crioprecipitado são mantidos em freezers em temperatura de 18 graus Celsius negativos ou menos, no período máximo de um ano e as plaquetas são guardadas em temperatura ambiente entre 20 e 24 graus Celsius, sob agitação constante, por três a cinco dias. 


\subsubsection{Procedimentos para irradiação}

A partir da leitura computadorizada do código de barras da bolsa de sangue é possível verificar todo histórico do sangue em questão, desde a coleta até seu destino final. Essa verificação compreende ainda, a data de coleta, a validade da bolsa, a tipificação (ABO), a determinação do fator Rh (Rhesus), o tipo de fracionamento submetido (hemácias, plasma, plaquetas e o crioprecipitado), as condições de armazenamento e a identificação da instituição que fez a coleta do sangue.

Uma vez feito o registro de saída dos locais de armazenamento para irradiação, a partir dos dados lidos no código de barras da bolsa de sangue, o funcionário colocará um indicador de processo na bolsa conforme a FIG. 1.

Segundo AAMI/ISO11140-1 ${ }^{(14)}$, os indicadores de processo são projetados para o uso em unidades individuais (ex: pacotes, caixas cirúrgicas, bolsa de sangue entre outros), demonstrando que a unidade foi exposta ao processo de irradiação e distingue entre unidades processadas e não processadas.

Para a etapa seguinte, o funcionário deverá digitar seu número de registro de identificação para que o sistema possa relacionar o funcionário com as bolsas irradiadas por ele.

No caso de confirmação de irradiação em uma bolsa de sangue, o indicador de processo identificará se a bolsa foi de fato irradiada e quem a realizou.

Para implementações futuras pode ser utilizada uma câmera acoplada ao monitor do computador para registro da identificação visual do funcionário, ou ainda, um sistema de Circuito Fechado de Televisão (CFTV) para monitoramento do ambiente de irradiação das bolsas.

A bolsa de sangue será registrada no sistema através da leitura de seu código de barras logo que a irradiação for concluída.

Para garantir maior segurança e controle do processo de irradiação serão utilizadas duas etapas distintas: uma via software e outra por relatório escrito. Neste último deverá constar a assinatura do responsável pela irradiação conforme 
modelo no apêndice $B$. Feito isso, a bolsa de sangue será novamente armazenada ou seguirá para uso.

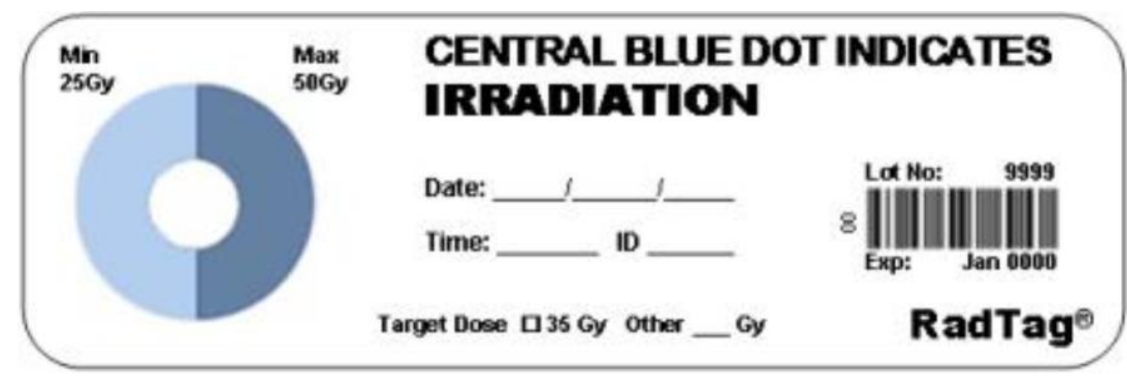

FIGURA 1 - Indicador de processo da empresa Rad Tag ${ }^{(15)}$

Conforme ilustração da FIG. 1, antes da bolsa ser irradiada, a etiqueta do indicador de processo apresentará dois semicírculos com as colorações azul-claro e azul-escuro. Ocorrendo a irradiação a 25 Gy, os dois semicírculos da etiqueta assumirão a cor azul-claro; na dose de irradiação a 50 Gy, os dois semicírculos assumirão a cor azul-escuro.

O indicador de processo contém materiais radiocrômicos sensíveis que mudam a cor quando irradiado ${ }^{(15)}$ e que indicam sua irradiação. Na FIG. 2 é apresentado o indicador de processo depois da irradiação absorvendo a dose de 25 Gy.

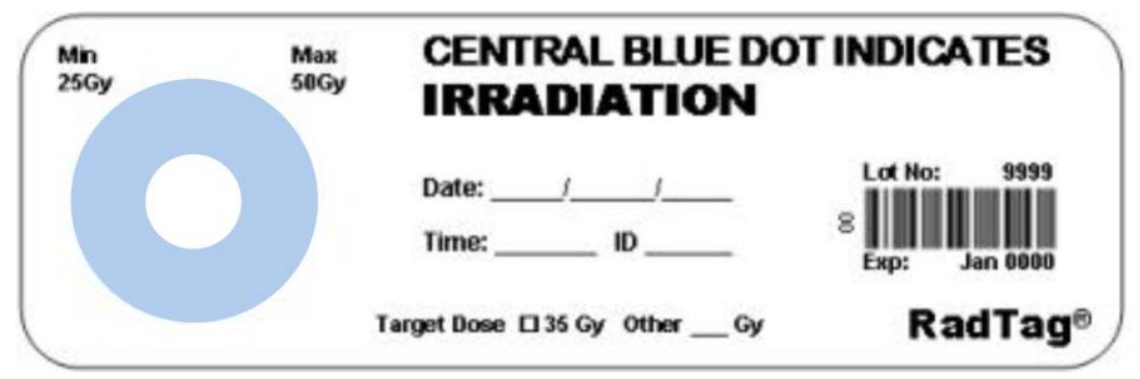

FIGURA 2 - Indicador de processo irradiado a 25 Gy

Nas irradiações com doses intermediárias entre 25 Gy e 50 Gy as colorações assumirão tons intermediários entre o azul-claro e o azul-escuro.

Nos procedimentos adotados atualmente, o funcionário tem papel fundamental no manuseio da bolsa de sangue e na alimentação dos dados para processamento via software das informações pertinentes. 
Após a irradiação, caso ocorra um extravio da bolsa de sangue, outro funcionário conseguirá saber através do indicador de processo e da leitura do código de barras se a mesma foi irradiada ou não.

No caso de ocorrer algum problema ou falha no irradiador, o funcionário deverá retirar as bolsas de sangue e descartá-las.

No apêndice $A$, é encontrado o fluxograma completo para irradiação das bolsas de sangue.

Outra opção para manipulação das bolsas de sangue poderia ser realizada com a implantação de um sistema de etiquetas inteligentes com identificação por meio de radiofreqüência ou RFID (Radio Frequency Identification), que suportam as doses de radiação utilizadas no processamento das bolsas de sangue.

Basicamente, o RFID é uma tecnologia que utiliza uma comunicação por radiofreqüência, sem fios, para transmitir dados de um dispositivo móvel, como uma simples etiqueta ou um chaveiro (normalmente chamado de tag), para um leitor ${ }^{(16)}$.

O RFID funciona basicamente através de dois componentes. O primeiro é um identificador anexado ao item a ser rastreado, e o segundo, um dispositivo que reconhece a presença de identificadores RFID ${ }^{(17)}$.

Algumas vantagens relacionam-se à utilização deste tipo de sistema. Uma delas refere-se à desobrigatoriedade da utilização de uma leitora de código de barras, possibilitando, por exemplo, rastrear itens dentro de uma sacola ou de uma sala sem a intervenção humana.

Por meio dessas etiquetas, é possível acessar informações relevantes sobre cada bolsa de sangue, já que sua identificação ocorre utilizando-se um "chip". As informações contidas em cada bolsa de sangue são armazenadas em chips RFID, e sua leitura possibilita o acesso aos dados pelos funcionários. A implantação de etiquetas RFID pode melhorar os processos internos de uma organização.

À proporção que os componentes ficarem mais baratos e a infra-estrutura de informação se tornar mais definida e segura, o RFID será usado em um grupo 
cada vez maior de tarefas ${ }^{(17)}$. Sendo assim, a implantação de um software específico com o sistema de RFID com a etiqueta colada à bolsa de sangue irá aperfeiçoar a BPF em todo o processo, desde a coleta até a irradiação. 


\section{OBJETIVO}

O objetivo do estudo é desenvolver procedimentos e metodologia de controle para aplicação de BPF na irradiação de sangue humano, no Centro de Tecnologia das Radiações (CTR) - IPEN. Os procedimentos deverão ter 0 mesmo rigor, conforme os já estabelecidos na norma AAMI/ISO $11137^{(9)}$ no que tange à qualificação do irradiador, à qualificação do processo e à certificação do processo. 


\section{MATERIAL E MÉTODOS}

\subsection{Considerações Gerais}

O desenvolvimento de procedimentos e metodologia de controle para aplicação de boas práticas de fabricação (BPF) na irradiação de sangue humano tem como referência as normas AAMI $/ \mathrm{ISO} 11137^{(9)}$, Guidance for Industry FDA $^{(18)}$ e a resolução o 153 da ANVISA ${ }^{(6)}$. Foram estudados os elementos que contribuem para o programa de validação para irradiação rotineira proposto pela AAMI/ISO11137 apresentado na FIG.3 testando-os conforme a necessidade.

\section{Qualificação do Produto}

1.1

Avaliação do produto e do material da embalagem

\section{Qualificação do Irradiador}

\begin{tabular}{|c|}
\hline 2.1 \\
Documentação \\
do \\
equipamento
\end{tabular}

\begin{tabular}{|c|}
\hline 2.2 \\
Teste \\
do \\
equipamento
\end{tabular}

2.3
Calibração
do
equipamento

\section{Qualificação do Processo}

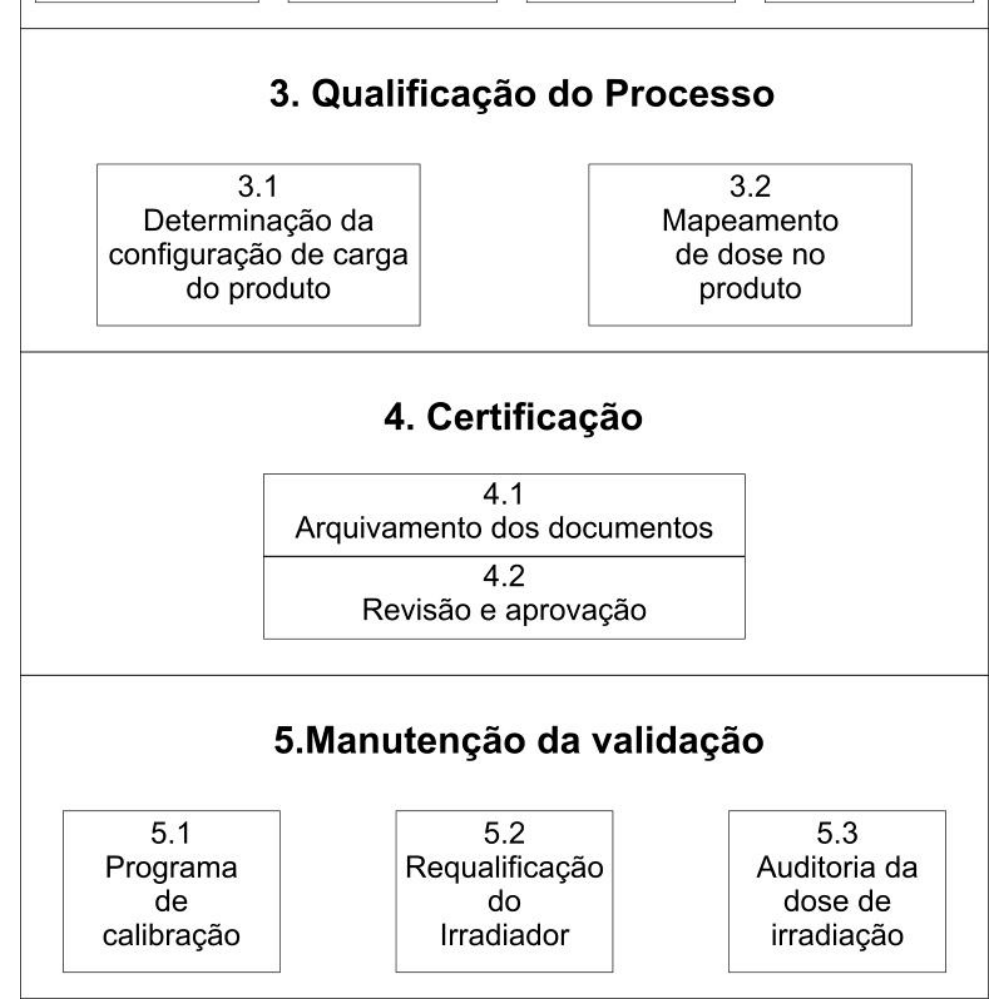

FIGURA 3 - Procedimentos seguidos conforme AAMI/ISO11137 


\subsubsection{Qualificação do produto}

Foi elaborado estudo de acordo com a resolução no 153 da ANVISA e da norma AAMI/ISO11137 para a qualificação do produto, a qual se divide em: avaliação do produto e do material da embalagem, e determinação da dose de irradiação.

\subsubsection{Avaliação do produto e do material da embalagem}

Com relação ao produto (sangue) deve-se seguir os ensaios preconizados pela resolução № 153 da ANVISA com ênfase nos testes para verificação de patologia dos doadores.

Antes do processo de irradiação da bolsa de sangue, torna-se necessário obter a certificação do material da embalagem por parte de uma certificadora ou órgão competente com base nas normas ISO 9001 e/ou 9002.

A certificação compreende a avaliação por meio de testes a respeito da qualidade e segurança da embalagem.

Estes testes avaliarão o efeito da irradiação sobre a estabilidade do material que compõe a embalagem quanto à variação dos processos de produção, tolerâncias, doses de radiação, qualidade da matéria-prima e condições de armazenamento. Ainda, deve-se testar a integridade da embalagem quanto à visibilidade e biocompatibilidade ${ }^{(9)}$.

Obrigatoriamente, torna-se necessário a aplicação de testes de biocompatibilidade para observação de prováveis mudanças na estrutura química do polímero e/ou seus aditivos, bem como, bioprodutos gasosos liberados durante irradiação que podem alterar o material. Estes testes devem também demonstrar a biocompatibilidade relacionada ao vencimento da embalagem.

Aos testes mencionados acima, torna-se necessária a adição de avaliações físicas e mecânicas em forma de ensaios que avaliarão prováveis deformações e rompimento da bolsa. 


\subsubsection{Determinação da dose de irradiação}

Para determinação da dose de irradiação, seguem-se os critérios adotados pela resolução o 153 da ANVISA $^{(6)}$ e por Baldwin e Jefferies ${ }^{(8)}$ - American Association of Blood Bank (AABB).

\subsection{Qualificação do irradiador}

Com base na norma AAMI/ISO11137 ${ }^{(9)}$ e no Guidance for Industry ${ }^{(18)}$ foram analisados os critérios necessários para qualificar o irradiador.

a) Estudo das características adequadas para um irradiador de bolsas de sangue, principalmente com relação à taxa de dose, à configuração da câmara de irradiação e ao arranjo físico das bolsas de sangue no interior da câmara de irradiação.

b) Estudo das rotinas de testes a serem submetidos ao irradiador $\mathrm{e}$ definição dos parâmetros e suas respectivas faixas de aceitação.

c) Estudo de metodologia e dos processos apropriados e normalizados para calibração de componentes que permitirão a operação automática do irradiador e que influenciarão no processo de irradiação.

d) Estudo da distribuição da dose no interior do irradiador, com o propósito de definir pontos críticos (doses máximas e mínimas) para diferentes configurações de carregamento.

e) Estudos e testes do sistema dosimétrico mais adequado para a verificação das doses na câmara de irradiação.

Para os estudos de qualificação do irradiador foi utilizada a unidade Gammacell 220, fabricada pela Atomic Energy of Canada Limited (AECL), Ottawa-Canada e instalada na Coordenadoria de Aplicações na Engenharia e 
Indústria, IPEN-CNEN/SP conforme apresentado na FIG. 4. Durante as irradiações, apresentava uma atividade de $3849 \mathrm{Ci}$ e uma taxa de dose de 3,18 kGy/h no dia 19 de julho de 2006.

Segundo $A E C L{ }^{(19)}$, o irradiador possui 48 lápis de ${ }^{60} \mathrm{Co}$ de $20 \mathrm{~cm}$ de altura que circundam internamente a câmara primária totalmente isolada. As amostras são colocadas na câmara secundária com dimensões limitadas à altura de 20,30 $\mathrm{cm}$ por diâmetro de 15,40 cm.

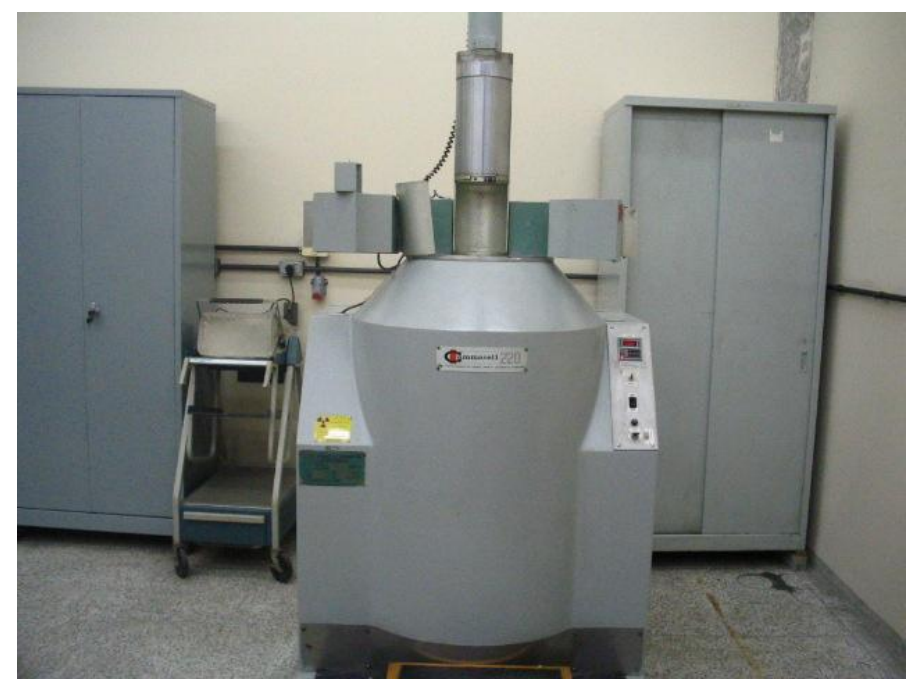

FIGURA 4 - Irradiador Gammacell 220 instalado no CTR - IPEN

Para a seleção do sistema dosimétrico, foram seguidos os seguintes critérios estabelecidos na AAMI/ISO11137 ${ }^{(9)}$, pertinentes ao produto (bolsa de sangue):

a) Adequação dos dosímetros à escala de dose absorvida de interesse e ao uso com o produto estudado;

b) Adequação da estabilidade e reprodutibilidade do sistema;

c) Facilidade da calibração do sistema;

d) Sistema consistente em relação aos padrões nacionais;

e) Capacidade de controlar ou corrigir a resposta do sistema no caso de erros sistemáticos, relacionados à temperatura e à umidade;

f) Facilidade e simplicidade do uso; 
g) Avaliação se o tempo e o trabalho requeridos para o desenvolvimento da resposta do dosímetro, leitura e a interpretação estão dentro dos limites aceitáveis para a finalidade proposta;

h) Avaliação da variação dos dados da resposta do sistema dosimétrico de acordo com os limites estabelecidos para a curva de calibração amoldada sobre a escala de dose absorvida de interesse.

Métodos apropriados de análise de regressão devem ser usados para ajustar a curva e poderiam incluir funções lineares, polinomiais ou exponenciais;

i) Dependência da resposta do dosímetro sobre a taxa de dose absorvida e/ou fracionamento da entrega da dose absorvida no uso da calibração e do processo em uso;

j) Estabilidade da resposta do dosímetro, antes, e depois da irradiação.

Para estudos de mapeamento de dose, foram utilizados três tipos de dosímetros: $\mathrm{CaSO}_{4}: \mathrm{Dy}$ (TLD), PMMA Amber e filme padrão Gafchromic HD-810.

\subsubsection{Sistemas Dosimétricos}

\subsubsection{Dosímetros $\mathrm{CaSO}_{4}: \mathrm{Dy}(\mathrm{TLD})$}

A dosimetria termoluminescente tende a ser uma ferramenta versátil para avaliação da dose de radiação ionizante. Foram estudadas suas características e observadas suas vantagens e desvantagens. O dosímetro em questão foi o $\mathrm{CaSO}_{4}$ :Dy (TLD), em inglês Termoluminescence-Dosimetry, desenvolvido no Centro de Metrologia das Radiações no IPEN.

Para calibração dos dosímetros TLD, foi aplicada a norma ASTM E668 $97^{(20)}$, que segue procedimentos para o uso de dosímetros termoluminescentes. Estes utilizados na medida da dose absorvida em materiais irradiados por raios gama, por raios $X$ e por elétrons. A faixa da dose absorvida coberta por este tipo de dosímetro é aproximadamente de $10^{-2}$ a $10^{4}$ Gy ( 1 a $10^{6} \mathrm{rad}$ ), e aplicável para taxas de dose absorvidas de aproximadamente de $10^{-2}$ a $10^{10} \mathrm{~Gy} / \mathrm{s}$ (1 a $10^{12}$ $\mathrm{rad} / \mathrm{s}$ ), valores compatíveis com a dose requerida para irradiação de sangue e com a taxa de dose apresentada no irradiador estudado (0,9 Gy/s). 
Na FIG. 5 são mostrados os dosímetros de $\mathrm{CaSO}_{4}$ :Dy (TLD) com diâmetro de $5,92 \mathrm{~mm}$ e espessura de $0,88 \mathrm{~mm}$ antes de serem irradiados.

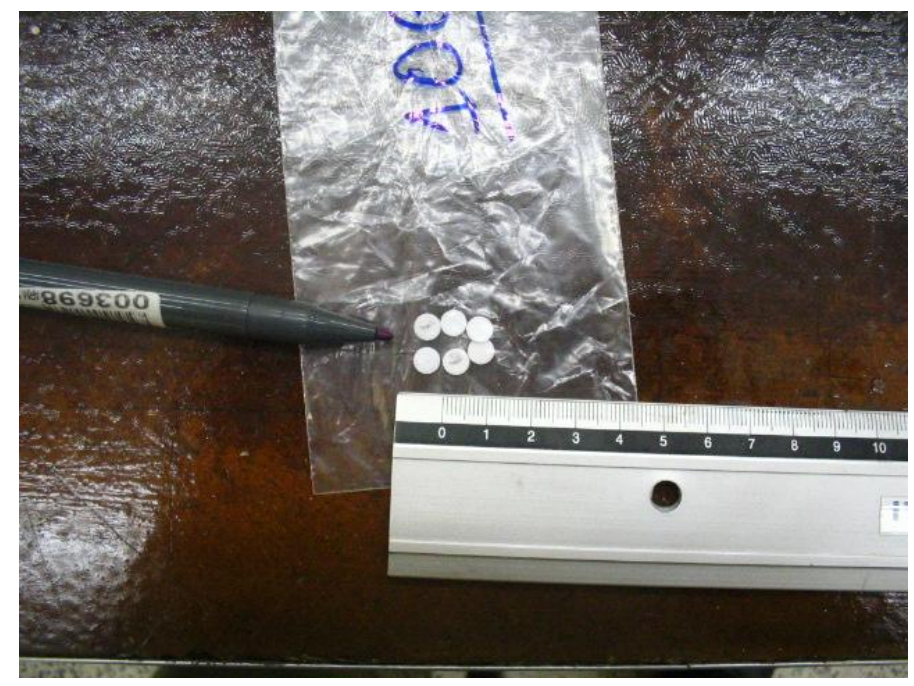

FIGURA 5 - Amostras de dosímetros de $\mathrm{CaSO}_{4}$ :Dy

Considerando-se a existência, a facilidade, o custo e a fabricação no próprio IPEN, utilizou-se, inicialmente, o dosímetro $\mathrm{CaSO}_{4}$ :Dy (TLD).

De acordo com as vantagens observadas, percebeu-se que o TLD pode ser considerado:

- $\quad$ de baixo custo de fabricação;

- pequeno;

- $\quad$ possui alta sensibilidade;

- $\quad$ pode ser reutilizado.

Como desvantagens pode-se citar:

- $\quad$ dependência energética;

- perda da informação.

No procedimento de calibração do sistema dosimétrico foi utilizado um lote com 60 dosímetros que, inicialmente, foram verificados quanto à uniformidade da resposta para a mesma dose de irradiação, seguindo o item 8 da norma ASTM E668 - $97^{(20)}$, que estabelece para aceitação do lote a condição do desvio padrão das respostas de 30 dosímetros escolhidos aleatoriamente, não podendo exceder $8 \%$ do valor da média das leituras desses dosímetros. 
As doses-alvo utilizadas para ensaios de uniformidade de resposta foram: 20, 40 e 60 Gy. As amostras foram irradiadas tendo como referência a ASTM $\mathrm{E} 668-97^{(20)}$.

Foram numerados todos os dosímetros de 1 a 60 , a saber: o primeiro lote de 30 dosímetros ( 1 a 30) foi irradiado com dose-alvo de 40 Gy; o segundo lote (31 a 60) com dose-alvo de 60 Gy. Posteriormente, foi repetido o experimento com o primeiro lote de 30 dosímetros (1 a 30), que foi irradiado com dose-alvo de 20 Gy. Em seguida, foi repetido o experimento com o segundo lote (31 a 60), irradiado com dose-alvo de 40 Gy. Esta dose foi repetida porque, nos experimentos acima, os dosímetros não apresentaram uniformidade da resposta de leitura das doses. Sendo assim, com o objetivo de encontrar uniformidade nas taxas de dose, a dose de 40 Gy foi utilizada como valor médio entre 20 Gy e 60 Gy.

$\mathrm{Na}$ prática de irradiação, os dosímetros foram posicionados em um dispositivo construído para alojar 6 unidades e permitir a irradiação simultânea dessas unidades no interior do irradiador tipo Gammacell 220 do CTR. Na FIG. 6 , é mostrado o dispositivo de irradiação com o posicionamento dos dosímetros na posição central que coincide com a região de isodose no interior da câmara do irradiador utilizado.

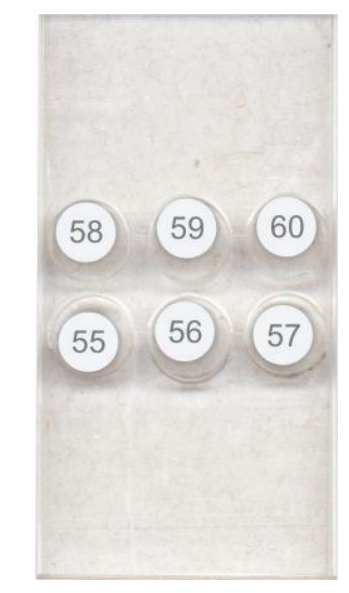

FIGURA 6 - Dispositivo contendo 6 dosímetros TLDs

Os dosímetros, após a leitura, passaram por um processo de aquecimento para serem reutilizados na determinação da curva de calibração. 
Para leitura dos dosímetros TLD foi utilizado a leitora Harshaw Nuclear System, modelo Bicron QS 3500 conectado a um microcomputador com sistema operacional Windows $98 \mathrm{com}$ uma taxa de aquecimento linear de $10^{\circ} \mathrm{C} . \mathrm{s}^{-1}$, ciclo de leitura de $50 \mathrm{~s}$ e um fluxo constante de $\mathrm{N}_{2}$ de $4.01 . \mathrm{min}^{-1}$.
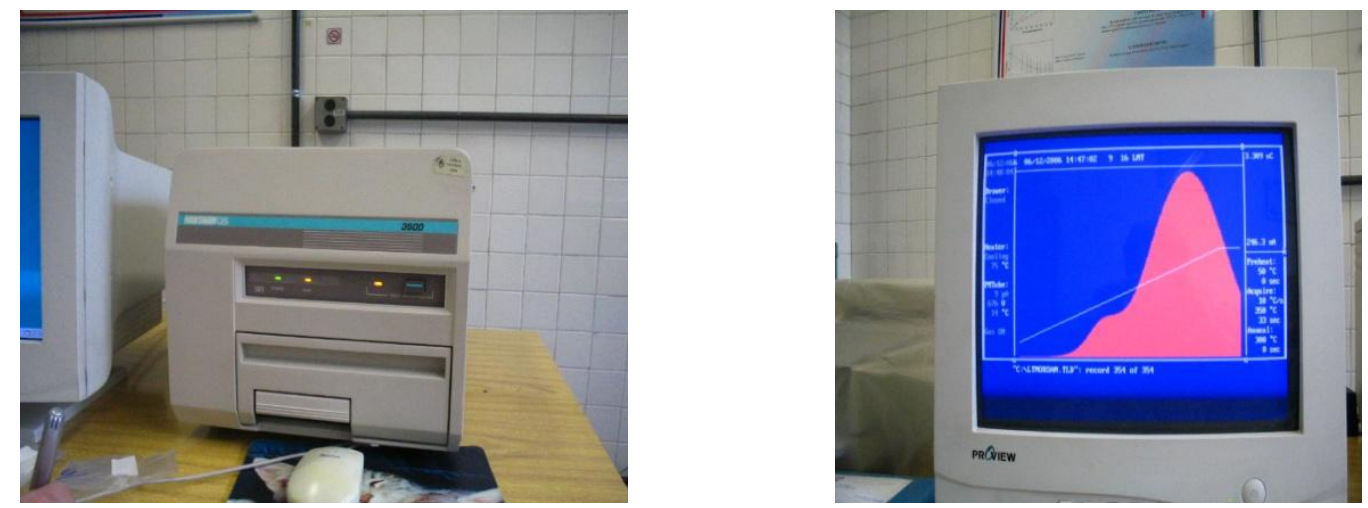

FIGURA 7 - Harshaw Nuclear System e o gráfico da leitura do dosímetro

Cabe ressaltar que foram necessárias cinco leituras do equipamento com gaveta aberta e cinco leituras com gaveta semi aberta para analisar se ocorreu estabilidade na leitora, conforme o manual de operações da Harshaw.

Uma vez que a leitora se estabilizou, inicia-se a leitura dos dosímetros, e o software desenvolvido pela Harshaw permite a visualização no monitor do valor de cada dose absorvida pelos dosímetros. Na FIG. 7 o equipamento Harshaw e o monitor apresentam a curva característica de leitura do dosímetro. Os dosímetros são lidos um a um, identificando sua numeração. Assim, um dosímetro que obtiver um valor muito acima ou muito abaixo da média conforme a norma ASTM E668 - $97^{(20)}$ poderá ser tratado novamente para futuras leituras.

\subsubsection{Dosímetros PMMA}

O dosímetro de PMMA (polimetil metacrilato) é utilizado rotineiramente pelo Centro de Tecnologia das Radiações (CTR) no controle das atividades de irradiação voltadas para pesquisas e prestação de serviço.

Os dosímetros utilizados no presente trabalho foram do tipo PMMA Amber, de fabricação inglesa, da empresa Harwell Dosimeter. Foram previamente 
calibrados pelo CTR de acordo com a norma ASTM - E1276/93 "Standard practice for use of polymethy/methacrylate Dosimetry System" e com rastreabilidade realizada junto ao IDAS (International Dose Assurance Service) da IAEA (International Atomic Energy Agency - Vienna - Áustria).

Foi utilizado o lote P Amber tipo 3042 e com data de calibração de julho de 2004.

Para o presente trabalho, a faixa estudada é de 10 Gy a 100 Gy, e neste caso o PMMA no início de sua faixa de aplicação ultrapassa em 200 vezes o valor inicial estudado. Entretanto, sua utilização foi aceita aumentando-se o tempo de irradiação por um fator correspondente. Esse aumento não afetou a realização dos experimentos de mapeamento de dose do irradiador, uma vez que os materiais utilizados para simular a bolsa de sangue suportam valores acima de 25 kGy (dose usual para esterilização de produtos médicos descartáveis).

O espectrofotômetro utilizado na leitura dos dosímetros de PMMA foi o Thermo Spectronic modelo Genesys 20, da Spectronic Instruments Inc., dos Estados Unidos. A absorbância dos dosímetros foi lida com comprimento de onda de $603 \mathrm{~nm}$ seguindo recomendação do fabricante Harwell. Para medida da espessura dos dosímetros PMMA com o propósito de se obter a absorbância específica foi utilizado o micrômetro da marca Mitutoyo com data de calibração de dezembro de 2005. As FIG. 8 e 9 ilustram o espectrofotômetro e o micrômetro utilizados, respectivamente.

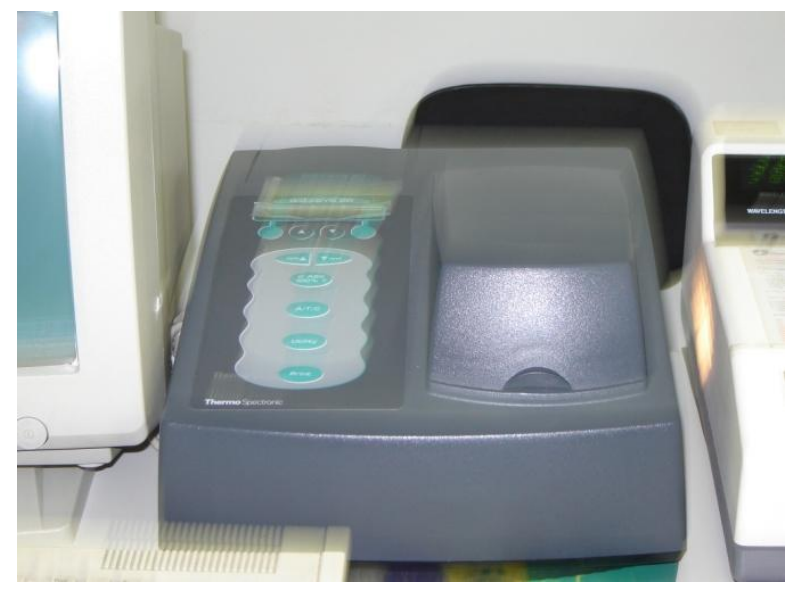

FIGURA 8 - Espectrofotômetro Thermo Spectronic, modelo Genesys 20 


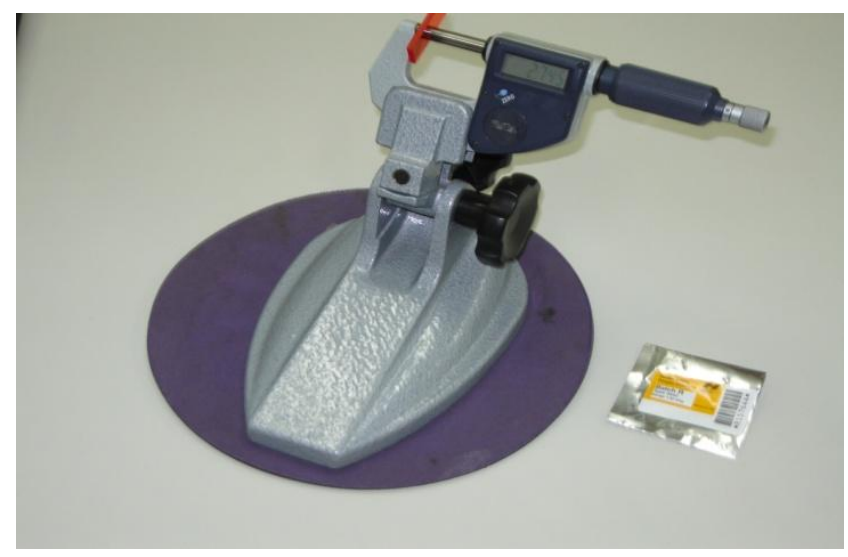

FIGURA 9 - Micrômetro Mitutoyo

\subsubsection{Dosímetros Gafchromic HD-810}

Estudou-se também a utilização do dosímetro Gafchromic HD-810 como sistema dosimétrico, por ser considerado ideal para medir a dose absorvida em irradiação de bolsa de sangue humano ${ }^{(21)}$. Para calibração, foi utilizada como referência a norma ASTM E1310 - 89(22). A faixa de aplicação para este tipo de dosímetro para fótons é aproximadamente de 1 a $10^{3}$ Gy e taxas de dose de 0,001 a $1000 \mathrm{~Gy} / \mathrm{s}^{(22)}$. A FIG. 10 ilustra o dosímetro Gafchromic HD-810 da empresa ISP (International Specialty Products) utilizado nos experimentos.

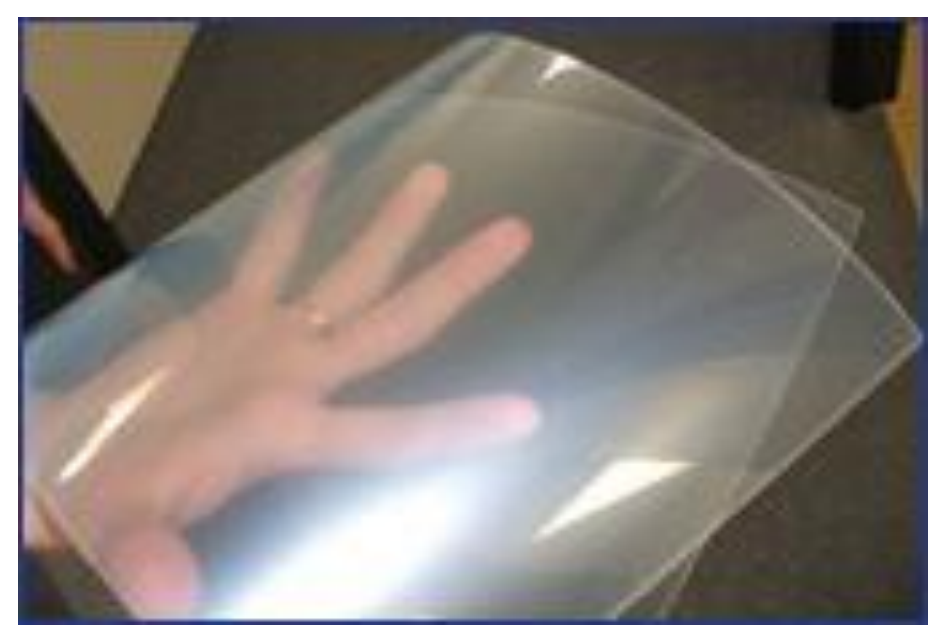

FIGURA 10 - Dosímetro Gafchromic HD-810 
A estrutura da película do dosímetro Gafchromic HD-810 pode ser vista na FIG. 11.

Surface layer -0.75 microns

Active layer -6.5 microns

Clear Polyester - 3.8 mils

FIGURA 11 - Película do dosímetro Gafchromic HD-810 da ISP ${ }^{(23)}$

A camada ativa, aproximadamente 6,5 $\mu \mathrm{m}$ (microns), é revestida por poliéster transparente de 3,8 milésimo de polegadas (aproximadamente 97 microns) e por uma camada de superfície gelatinosa de 0,75 microns ${ }^{(23)}$.

Quando a película é exposta à radiação ionizante, uma reação de polimerização tem início, resultando na mudança da coloração para o azul. A quantidade de polímero produzida e a profundidade da mudança da cor são proporcionais à dose absorvida na camada ativa. Na FIG. 12 são mostrados os dosímetros no dispositivo utilizado para irradiação com doses-alvo de 5 Gy, 10 Gy, 20 Gy, 25 Gy, 30 Gy, 50 Gy, 70 Gy, 100 Gy, 120 Gy, 140 Gy, 160 Gy, 180 Gy e 200 Gy.

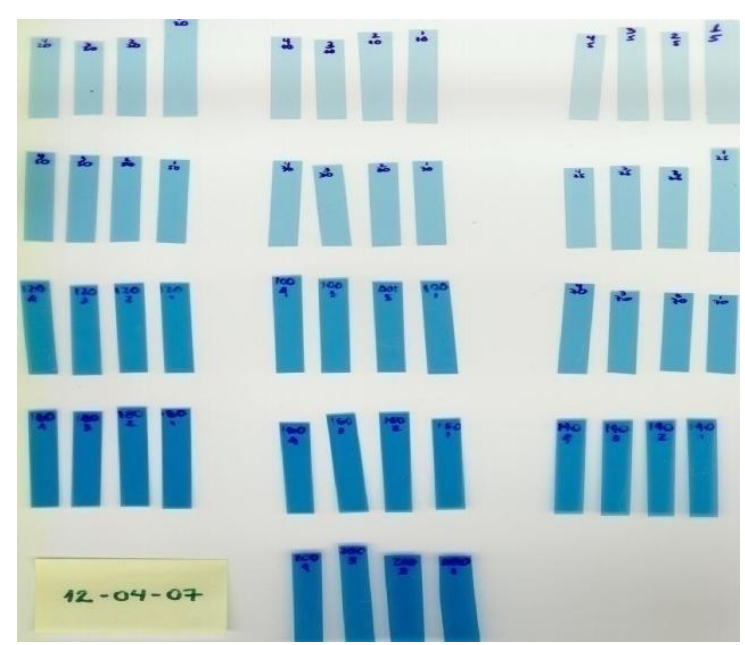

FIGURA 12 - Coloração do dosímetro Gafchromic depois de irradiado 
O espectrofotômetro utilizado na leitura dos dosímetros Gafchromic HD810 foi o Spectrophotometer, modelo Shimadzu UV-1601 PC do fabricante Shimadzu Corporation Analytical Instruments Division, de Kyoto, Japão, mostrado na FIG.13. A absorbância dos dosímetros foi lida com comprimento de onda de $603 \mathrm{~nm}$, seguindo recomendação do fabricante. Para medida da espessura com o propósito de se obter a absorbância específica foi utilizado o micrômetro da marca Mitutoyo.

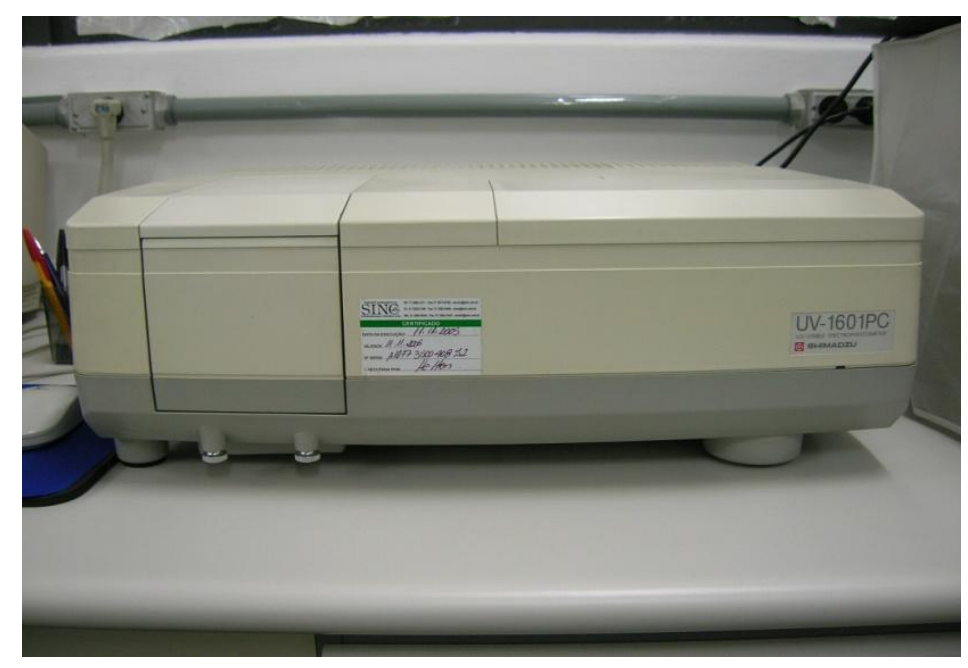

FIGURA 13 - Espectrofotômetro Shimadzu UV-1601 PC

\subsection{Qualificação do processo}

Com base na norma AAMI/ISO11137(9) e Guidance for Industry ${ }^{(18)}$, as seguintes atividades foram realizadas para qualificar o processo:

a) Estudos para determinação do melhor modo de carregamento de produtos (bolsas de sangue e dosímetros) no interior da câmara de irradiação, com o propósito de se obter a menor relação entre a dose máxima e a mínima absorvida.

b) Para o mapeamento da dose absorvida pelo produto, utilizando-se dosímetros PMMA e Gafchromic, foram desenvolvidos dispositivos com geometria que não interferem no carregamento da câmara de irradiação com bolsas de sangue de mesma densidade. Os dispositivos permitem alojar em seu interior quantidade de dosímetros suficiente para indicar com precisão as regiões de dose 
mínima e máxima absorvida pelo produto. $\mathrm{Na}$ FIG.14 são mostrados os dosímetros numerados e posicionados no dispositivo para depois serem irradiados. Na FIG.15 apresenta-se o arranjo utilizado para o mapeamento de dose da câmara de irradiação da Gammacell 220 do CTR. O arranjo utilizado permite a irradiação simultânea de quatro bolsas de sangue. As bolsas de sangue utilizadas são da empresa Baxter, que tem capacidade de armazenar 450 $\mathrm{ml}$ de sangue por bolsa. Durante a irradiação as bolsas foram preenchidas com água.

Com o propósito de verificar a distribuição em distintos planos da câmara de irradiação, os ensaios de mapeamento foram realizados em três posições com os seguintes ângulos de rotação: 0, 90ำ e 45․ A FIG. 16 ilustra como as bolsas de sangue mais os dosímetros PMMA numerados ficaram distribuídos na prática de irradiação.

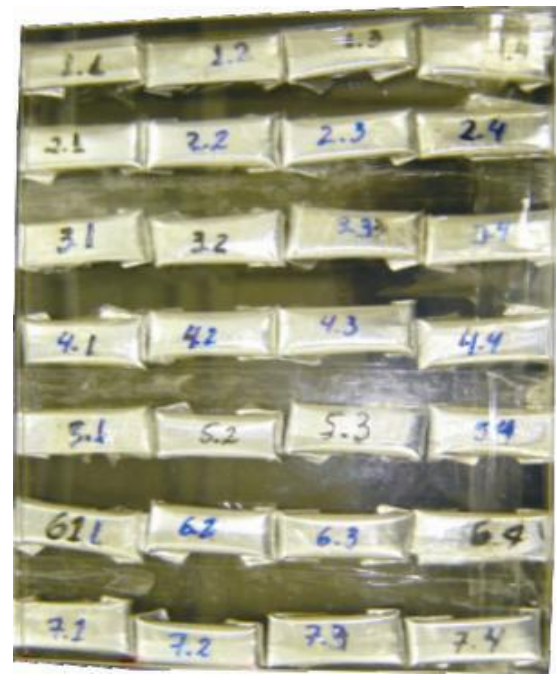

FIGURA 14 - Dosímetros PMMA distribuídos no dispositivo de irradiação para mapeamento de doses 


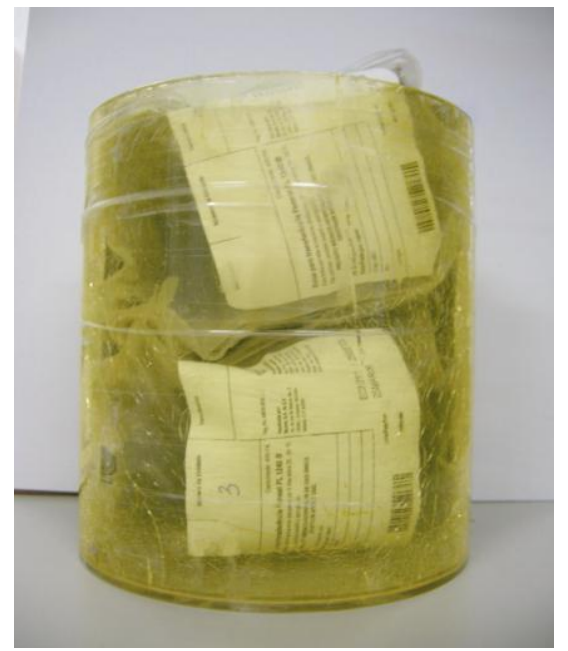

FIGURA 15 - Arranjo utilizado para mapeamento de dose

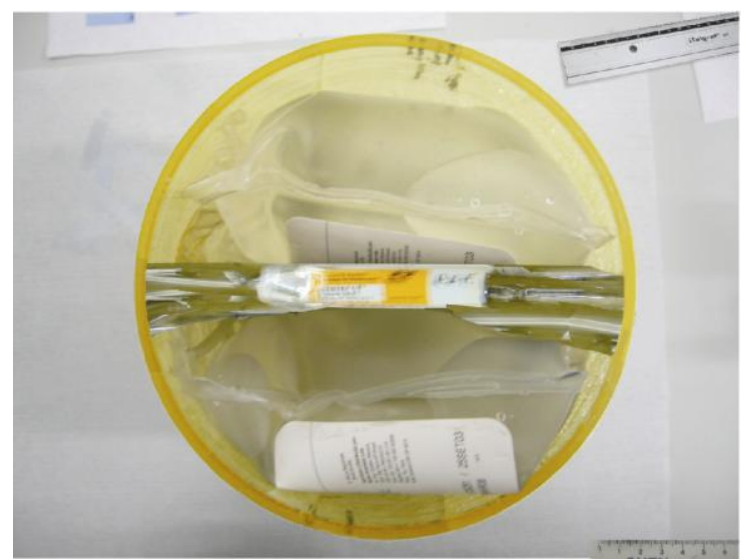

FIGURA 16 - Distribuição das bolsas e dosímetros na prática de irradiação utilizando dosímetros PMMA

Na FIG. 17 é mostrado o posicionamento do arranjo utilizado no interior da câmara de irradiação do irradiador Gammacell 220 do CTR-IPEN.

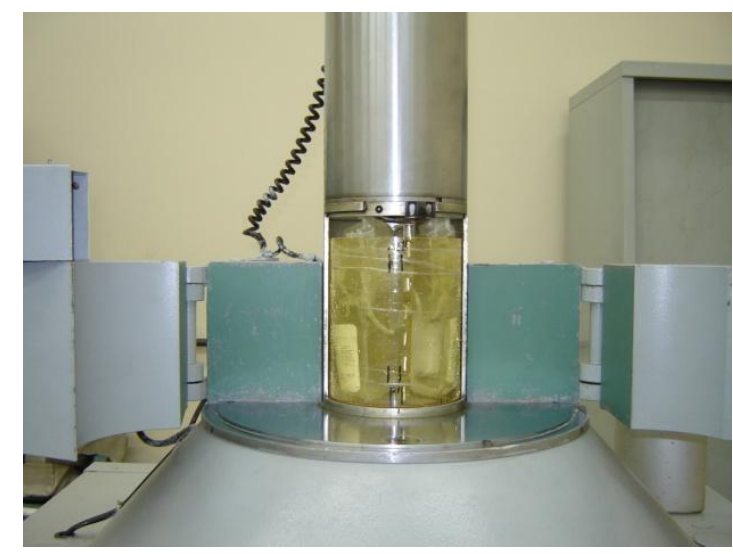

FIGURA 17 - Visão do arranjo dentro do Gammacell 220 
A FIG. 18 ilustra o dispositivo utilizado para os ensaios utilizando-se o dosímetro Gafchromic para logo em seguida serem numerados para distribuição no arranjo.
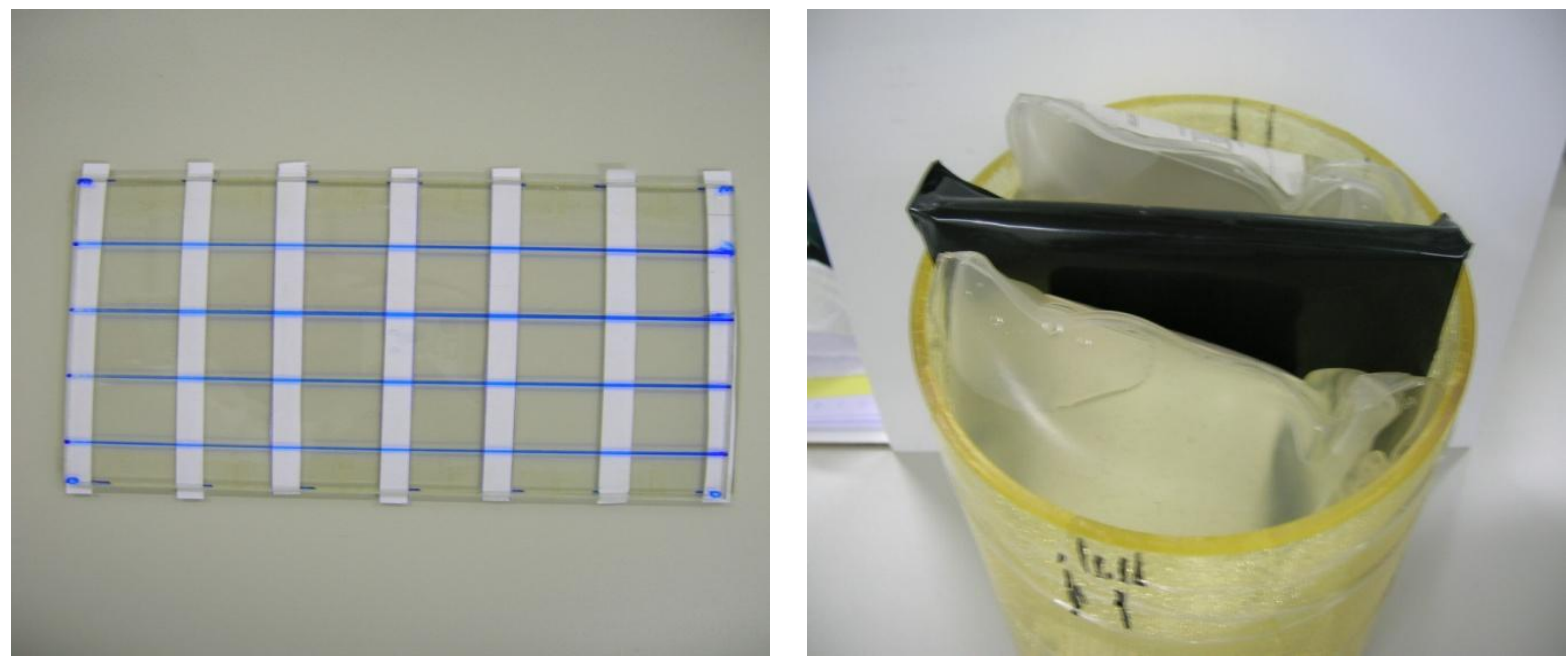

FIGURA 18 - Marcação do dosímetro Gafchromic e o arranjo final

Os dosímetros foram numerados e separados em tiras para serem colocados no arranjo e, em seguida, serem irradiados conforme a FIG. 18.

Foi necessária a utilização de um filme de plástico não transparente, com a coloração preta, devido ao fato dos dosímetros serem sensíveis à luz.

\subsection{Certificação}

A certificação é o registro e a análise de todos os testes e controles da qualificação do produto, do irradiador e do processo, com a finalidade de validar a irradiação nas bolsas de sangue. A norma AAMI/ISO11137(9) recomenda que sejam feitas sempre documentações e revisões para aprovação da certificação. Após serem realizados todos os passos indicados no item 1.2, deverá ser gerado um relatório final com a devida assinatura do funcionário responsável pela irradiação. Esse relatório deverá conter todas as etapas envolvidas no processo de irradiação da bolsa de sangue, desde a coleta até a irradiação. As nãoconformidades observadas durante a validação, a calibração, e a manutenção preventiva devem ser adequadamente registradas, assim como as correções 
efetuadas. Deve haver, ainda, um registro dos defeitos apresentados pelo equipamento, com a respectiva data de conserto ${ }^{(6)}$.

\subsection{Testes para verificação da validação do processo}

Para os testes de validação foram utilizados os seguintes tópicos:

a) Programa de calibração dos instrumentos e estudo do sistema dosimétrico a serem utilizados no processo de irradiação, estabelecendo procedimentos de rotina; e

b) Análise de risco. Para a análise de riscos do processo de irradiação de sangue foi utilizada uma abordagem considerando a seleção de eventos iniciadores e a modelagem da seqüência até a situação de bolsa de sangue não irradiada ou com dose de irradiação absorvida durante o processamento não adequado para sua aplicação final. Para os dois casos adotou-se uma escalada para o evento final que pode ser considerado como o acidente bolsa de sangue não irradiada, uma vez que qualquer uma das situações ocasionam graves conseqüências para a saúde do usuário final.

Na FIG. 19 são apresentadas as indicações para os eventos iniciadores com a utilização do método de Análise de Árvore de Falhas. Este método é uma técnica a ser utilizada para prevenir ou para analisar não-conformidades em projetos, processos e produtos ${ }^{(24)}$. Nesta análise foram considerados os modos de falhas associados, de falha simples e de modo comum e também as interações humanas segundo uma ordem lógica de prioridade de ocorrência dos eventos. 


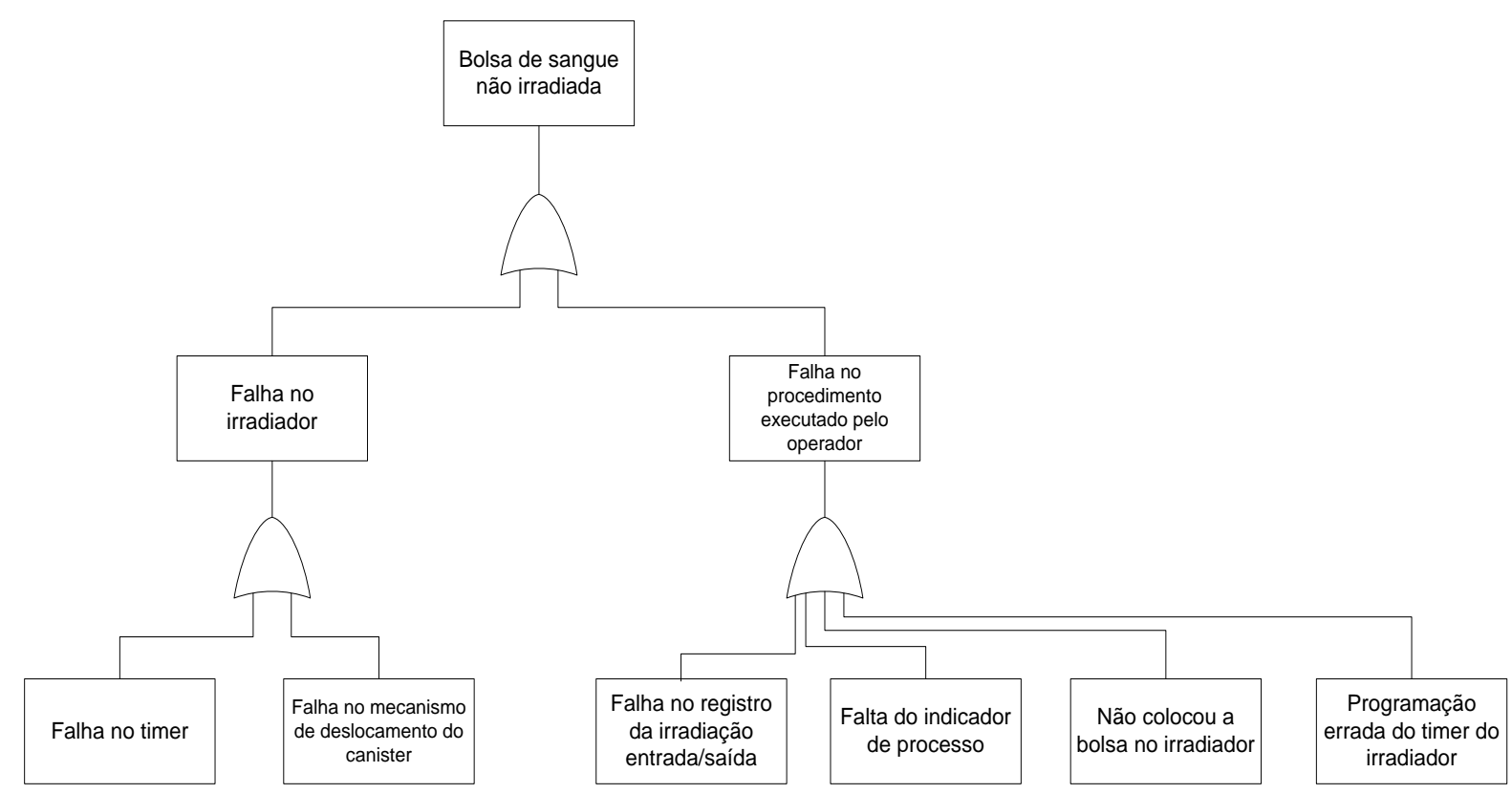

FIGURA 19 - Análise de árvore de falhas

A partir desta análise, para cada evento iniciador devem ser implementados sistemas de segurança e procedimentos operacionais que evitam ou mitigam as conseqüências desses eventos.

O procedimento de irradiação está montado para irradiar simultaneamente quatro bolsas de sangue. Se houver a necessidade de irradiar uma quantidade menor, será necessária a utilização de bolsas com as mesmas características contendo água no seu interior ("dummies") para uniformização da distribuição de dose. 


\subsubsection{Rotina de controle do processo}

A rotina do processo inclui o controle e a monitoração dos equipamentos, manuseio do produto antes, durante e após a irradiação, manutenção, monitoração da dose de produção, continuidade do processo e os seguintes cuidados e registros pertinentes:

a) A documentação deve ser estabelecida e mantida, descrevendo o manuseio das bolsas de sangue antes, durante e depois da irradiação e armazenamento, de modo a assegurar sua eficácia. Um sistema de contagem deve ser mantido durante 0 recebimento do produto, carga, descarga, pós-irradiação e liberação;

b) Rotinas de manutenção preventiva com procedimentos (normalmente recomendados pelo fornecedor do equipamento) documentados devem ser implementados em conformidade com a ISO 9001 e/ou 9002 (apud norma AAMI/ISO 11137(9));

c) Processo de documentação com informações registradas e revisadas por pessoas autorizadas; e

d) Aceitação da irradiação quando os registros forem avaliados e demonstrarem que o processo está de acordo com os requisitos previamente estabelecidos. 


\section{RESULTADOS E DISCUSSÃO}

\subsection{Determinação da dose de irradiação}

De acordo com os dados disponíveis na literatura e principalmente com o Guidance for Industry ${ }^{(18)}$ e Baldwin e Jefferies ${ }^{(8)}$ - American Association of Blood Bank (AABB), a dose ideal para irradiação em bolsas de sangue deve variar entre 25 Gy a 50 Gy, sem perder suas características ${ }^{(8)}$.

\subsection{Avaliação do material da embalagem}

Existem vários produtos que podem ser utilizados para embalagem neste tipo de aplicação. A norma AAMI/ISO11137 ${ }^{(9)}$ recomenda, em seu anexo (tabela A4 "A general guide to radiation stability of materials"), materiais como poliestireno, polietileno, poliamidas, poliimidas e polisulfonas, os quais são excelentes quanto à estabilidade. Por serem de custo maior, existem alternativas como o PVC, que apresenta boa estabilidade à irradiação com custos menores.

A portaria $n^{0} 1376$ da ANVISA $^{(13)}$, a norma AAMI/ISO11137(9) e Neto $^{(12)}$ indicam o produto Policloreto de Vinila (PVC) para esse fim. O PVC passou por todos os passos que o programa de teste exige, conforme supracitado ${ }^{(12)}$.

Conforme Anexo A da norma AAMI/ISO11137(9), o PVC é um material satisfatório na utilização com radiação de ${ }^{60} \mathrm{Co}$ para doses abaixo de $10 \mathrm{kGy}$.

Segundo Neto ${ }^{(12)}$, as vantagens do PVC para a aplicação na área médica são:

a-) Versatilidade - Por suas múltiplas aplicações, o PVC pode se adaptar às exigências específicas do uso às quais se destina, como as características de proteção a medicamentos delicados (impermeabilidade a odores e proteção contra oxidação, maleabilidade, entre outras);

b) Confiabilidade - Durante mais de 50 anos, o setor médico acumulou larga experiência em produtos feitos à base de PVC. É um dos materiais mais 
pesquisados do planeta e aprovado pelos órgãos de controle dos países desenvolvidos mais exigentes;

c) Segurança - A alta transparência do produto permite saber, com precisão, o que se passa dentro de um sistema à base de PVC. Bolhas de ar, entupimentos ou incrustações são facilmente identificados e instantaneamente corrigidos, evitando complicações. O PVC pode ser soldado com segurança, à prova de vazamentos e contaminações provenientes do ambiente externo;

d) Praticidade - O conforto no uso é muito importante tanto para os profissionais de saúde, como para os pacientes. Em atendimentos de emergência fora dos hospitais, a facilidade de empilhamento, estocagem e movimentação dos artigos médicos à base de PVC viabiliza os trabalhos nas unidades móveis;

e) Resistência - O PVC, que é inerte, é um dos materiais que apresenta maior resistência aos métodos de esterilização (vaporização, óxido de etileno ou raios gama);

f) Leveza - O PVC é extremamente leve, o que permite importantes economias de transporte e instalação, sem contar seu fácil manuseio pelo corpo clínico.

Em função de inúmeros pontos positivos do PVC e das recomendações técnicas da ANVISA-RDC 153 de 14 de junho de 2004, pode-se afirmar que o material é extremamente útil para a aplicação desejada. Sendo assim, pode-se utilizar com segurança a bolsa de sangue fabricada com PVC em um irradiador de raios gama, no caso do presente trabalho com fonte de ${ }^{60} \mathrm{Co}$. 


\subsection{Qualificação do irradiador}

\subsubsection{Seleção do sistema dosimétrico}

\subsubsection{Dosímetro $\mathrm{CaSO}_{4}: \mathrm{Dy}$ (TLD)}

Foram realizados ensaios de uniformidade de resposta com o dosímetro de $\mathrm{CaSO}_{4}$ :Dy (TLD), seguindo o estabelecido na norma ASTM E668 - 97 ${ }^{(20)}$. Utilizouse 60 dosímetros com numeração de 1 a 60 e divididos em dois lotes com 30 dosímetros, conforme item 3.2.1.1. Irradiou-se o primeiro lote com dose-alvo de 40 Gy e o segundo, com dose-alvo de 60 Gy obtendo-se os resultados da leitura dos dosímetros apresentados conforme as TAB. 3 e TAB. 4.

Após a obtenção da resposta da leitura dos dois primeiros lotes, os 60 dosímetros foram reutilizados através de um processo de aquecimento realizado pelo CMR-IPEN (Centro de Metrologia das Radiações) para continuidade do processo de irradiação.

Nas TAB. 5 encontram-se os resultados da resposta da leitura dos dosímetros com a dose-alvo de 20 Gy.

Conforme item 3.2.1.1, para avaliação da uniformidade da resposta da leitura dos dosímetros foi necessário a repetição da dose-alvo de 40 Gy representando a média entre 20 Gy e 60 Gy. Na TAB. 6 mostram-se os resultados da resposta da leitura dos dosímetros.

Em cada tabela encontra-se o número do dosímetro e sua respectiva carga em nC (nanocoulomb) utilizada na leitura dos dosímetros. 
TABELA 3 - Dose-alvo de 40 Gy

\begin{tabular}{cc}
\hline Dosímetros & Carga nC \\
\hline 1 & 6,076 \\
\hline 2 & 6,972 \\
\hline 3 & 5,621 \\
\hline 4 & 4,431 \\
\hline 5 & 5,782 \\
\hline 6 & 6,300 \\
\hline 7 & 6,430 \\
\hline 8 & 6,598 \\
\hline 9 & 6,560 \\
\hline 10 & 5,320 \\
\hline 11 & 8,075 \\
\hline 12 & 7,631 \\
\hline 13 & 7,431 \\
\hline 14 & 7,155 \\
\hline 15 & 4,754 \\
\hline
\end{tabular}

\begin{tabular}{cc}
\hline Dosímetros & Carga nC \\
\hline 16 & 5,939 \\
\hline 17 & 5,907 \\
\hline 18 & 7,334 \\
\hline 19 & 6,459 \\
\hline 20 & 4,583 \\
\hline 21 & 6,456 \\
\hline 22 & FT \\
\hline 23 & 3,729 \\
\hline 24 & 7,046 \\
\hline 25 & 8,194 \\
\hline 26 & 3,894 \\
\hline 27 & 5,063 \\
\hline 28 & 6,259 \\
\hline 29 & 4,903 \\
\hline 30 & 5,465 \\
\hline
\end{tabular}

Média $=6,082 \mathrm{nC}$

Desvio-Padrão = 1,178262

Relação: Desvio-Padrão/Média = 0,19 (19\%)

FT = Falha Técnica - problema com o dosímetro

TABELA 4 - Dose-alvo de 60 Gy

\begin{tabular}{cc}
\hline Dosímetros & Carga nC \\
\hline 31 & 11,870 \\
\hline 32 & 11,320 \\
\hline 33 & 8,935 \\
\hline 34 & 11,080 \\
\hline 35 & 11,780 \\
\hline 36 & 11,270 \\
\hline 37 & 8,367 \\
\hline 38 & 6,320 \\
\hline 39 & 11,690 \\
\hline 40 & 12,030 \\
\hline 41 & 8,246 \\
\hline 42 & 5,622 \\
\hline 43 & 11,660 \\
\hline 44 & 11,090 \\
\hline 45 & 8,443 \\
\hline
\end{tabular}

\begin{tabular}{cc}
\hline Dosímetros & Carga nC \\
\hline 46 & 8,736 \\
\hline 47 & 9,674 \\
\hline 48 & 9,282 \\
\hline 49 & 11,910 \\
\hline 50 & 11,180 \\
\hline 51 & 11,620 \\
\hline 52 & 12,940 \\
\hline 53 & 11,340 \\
\hline 54 & 7,046 \\
\hline 55 & 7,112 \\
\hline 56 & 10,560 \\
\hline 57 & 12,300 \\
\hline 58 & 7,998 \\
\hline 59 & 11,540 \\
\hline 60 & 10,230 \\
\hline
\end{tabular}

Média $=10,11 \mathrm{nC}$

Desvio-Padrão = 1,975764

Relação: Desvio-Padrão/Média = 0,19 (19\%) 
TABELA 5 - Dose-alvo de 20 Gy

\begin{tabular}{cc}
\hline Dosímetros & Carga $\mathbf{n C}$ \\
\hline 1 & 2,582 \\
\hline 2 & 2,954 \\
\hline 3 & 1,630 \\
\hline 4 & 1,884 \\
\hline 5 & 2,301 \\
\hline 6 & 2,260 \\
\hline 7 & 2,486 \\
\hline 8 & 2,389 \\
\hline 9 & 2,748 \\
\hline 10 & 2,002 \\
\hline 11 & 3,199 \\
\hline 12 & 3,097 \\
\hline 13 & 2,982 \\
\hline 14 & 2,809 \\
\hline 15 & 2,179 \\
\hline
\end{tabular}

\begin{tabular}{cc}
\hline Dosímetros & Carga nC \\
\hline 16 & 2,249 \\
\hline 17 & 2,845 \\
\hline 18 & 2,946 \\
\hline 19 & 2,741 \\
\hline 20 & 2,321 \\
\hline 21 & 2,418 \\
\hline 22 & 2,258 \\
\hline 23 & 2,615 \\
\hline 24 & 3,020 \\
\hline 25 & 3,061 \\
\hline 26 & 2,148 \\
\hline 27 & 1,305 \\
\hline 28 & 2,877 \\
\hline 29 & 2,682 \\
\hline 30 & 2,809 \\
\hline
\end{tabular}

Média $=2,526 \mathrm{nC}$

Desvio-Padrão $=0,454118$

Relação: Desvio-Padrão/Média = 0,18 ( 18\%)

TABELA 6 - Dose-alvo de 40 Gy

\begin{tabular}{cc}
\hline Dosímetros & Carga nC \\
\hline 31 & 6,871 \\
\hline 32 & 6,252 \\
\hline 33 & 4,816 \\
\hline 34 & 5,787 \\
\hline 35 & 6,133 \\
\hline 36 & 5,925 \\
\hline 37 & 5,764 \\
\hline 38 & 3,895 \\
\hline 39 & 5,836 \\
\hline 40 & 5,949 \\
\hline 41 & 4,286 \\
\hline 42 & 4,636 \\
\hline 43 & 6,159 \\
\hline 44 & 5,509 \\
\hline 45 & 4,751 \\
\hline
\end{tabular}

\begin{tabular}{cc}
\hline Dosímetros & Carga nC \\
\hline 46 & 5,307 \\
\hline 47 & 4,549 \\
\hline 47 & 4,408 \\
\hline 49 & 6,411 \\
\hline 50 & 5,520 \\
\hline 51 & 6,153 \\
\hline 52 & 6,201 \\
\hline 53 & 6,559 \\
\hline 54 & 5,984 \\
\hline 55 & 5,410 \\
\hline 56 & 5,754 \\
\hline 57 & 6,576 \\
\hline 58 & 4,916 \\
\hline 59 & 5,625 \\
\hline 60 & 6,011 \\
\hline
\end{tabular}

Média $=5,598 \mathrm{nC}$

Desvio-Padrão = 0,755396

Relação: Desvio-Padrão/Média = 0,13 (13\%) 
Houve problemas operacionais no laboratório do Centro de Dosimetria do IPEN, que dava suporte na realização das leituras dos TLDs. As medidas de doses lidas eram muito dispersas e impediam a realização dos ensaios de calibração e o mapeamento de dose do irradiador para o dosímetro.

Observa-se que as respostas das leituras para os ensaios realizados apresentam os desvios-padrão com valor que excedem em $8 \%$ o valor da média das leituras. De acordo com a norma ASTM E668 - $97^{(20)}$, o lote deve ser rejeitado, sendo necessário um melhor critério de seleção dos dosímetros, de modo a apresentar uma resposta uniforme para as doses de irradiação.

\subsubsection{Dosímetro PMMA}

Por se tratar de dosímetro utilizado rotineiramente no CTR-IPEN que segue procedimentos de calibração com rastreabilidade junto ao IDAS (International Dose Assurance Service - da Agência Internacional de Energia Atômica) e a norma ASTM E1276 - 93 ${ }^{(25)}$, não houve a necessidade de estudar a adequação deste sistema dosimétrico.

\subsubsection{Dosímetro Gafchromic HD-810}

Determinou-se a quantidade de dosímetros utilizados na irradiação observando-se a norma ASTM E1275-93 ${ }^{(26)}$ item 7.3.2 que orienta a realização de no mínimo, quatro valores de dose absorvida.

Optou-se por utilizar quatro amostras por questões operacionais em virtude do ajuste necessário para a realização das irradiações como ilustra a FIG. 20. 


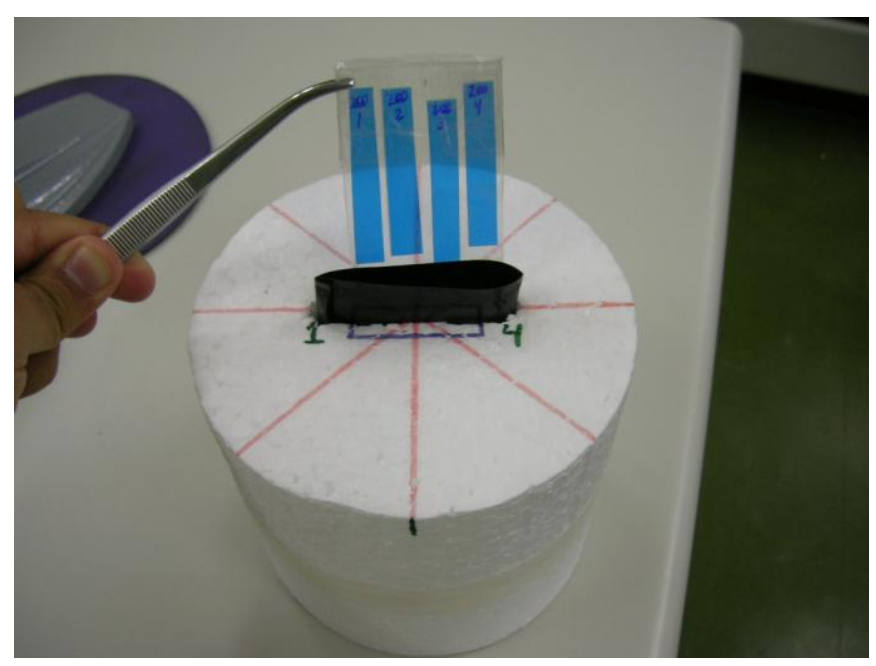

FIGURA 20 - Posicionamento dos dosímetros Gafchromic no arranjo experimental

Apesar da norma ASTM E1275-93 ${ }^{(26)}$ indicar cinco amostras, o uso das mesmas no arranjo experimental mostrou-se inadequado, pois essa quantidade não adaptaria ao tamanho do dispositivo de irradiação, ocasionando o surgimento de sombra e prejudicando a leitura dos dosímetros.

Definiu-se a quantidade de quatro dosímetros para a irradiação nas dosesalvo de 5 Gy, 10 Gy, 20 Gy, 25 Gy, 30 Gy, 50 Gy, 70 Gy, 100 Gy, 120 Gy, 140 Gy, 160 Gy, 180 Gy e 200 Gy.

Determinou-se a curva de calibração com o dosímetro tipo filme Gafchromic HD 810, realizando-se dois ensaios em dois dias distintos, sendo, no dia 03 (Experimento 1) e dia 12 (Experimento 2) de abril de 2007, seguindo o estabelecido na norma ASTM E1310 - 89 (22), ambos no Centro das Tecnologias das Radiações (CTR) - IPEN e com as mesmas doses descritas.

Nas TAB. 7 e TAB. 8 mostram-se os resultados do coeficiente de variação para cada dose solicitada. 
TABELA 7 - Cálculo do Coeficiente de Variação para Experimento 1

\begin{tabular}{|c|c|c|c|c|c|c|c|c|c|c|}
\hline $\begin{array}{c}\text { Dose Solic. } \\
\text { (Gy) }\end{array}$ & $\begin{array}{l}\text { D. } \\
\text { no }\end{array}$ & Data & $\begin{array}{c}\text { Timer } \\
\text { (s) }\end{array}$ & $\begin{array}{c}\text { Espes. } \\
(\mathrm{cm})\end{array}$ & AO & A & $\begin{array}{c}k \\
\left(\mathrm{~cm}^{-1}\right)\end{array}$ & $\begin{array}{l}k_{\text {médio }} \\
\left(\mathrm{cm}^{-1}\right)\end{array}$ & $\begin{array}{l}\text { Desvio } \\
\text { Padrão }\end{array}$ & $\begin{array}{l}\text { C.V. } \\
\text { (\%) }\end{array}$ \\
\hline \multirow{4}{*}{5,0} & 1 & \multirow{4}{*}{$3 / 4 / 07$} & \multirow{4}{*}{ 2'40" } & 0,0101 & 0,0945 & 0,1272 & 3,238 & \multirow{4}{*}{3,2351} & \multirow{4}{*}{0,0485} & \multirow{4}{*}{1,5} \\
\hline & 2 & & & 0,0098 & 0,0970 & 0,1285 & 3,214 & & & \\
\hline & 3 & & & 0,0096 & 0,1000 & 0,1306 & 3,188 & & & \\
\hline & 4 & & & 0,0093 & 0,0970 & 0,1277 & 3,301 & & & \\
\hline \multirow{4}{*}{10,0} & 1 & \multirow{4}{*}{$3 / 4 / 07$} & \multirow{4}{*}{ 6'12" } & 0,0097 & 0,1002 & 0,1506 & 5,196 & \multirow{4}{*}{5,2524} & \multirow{4}{*}{0,0550} & \multirow{4}{*}{1,0} \\
\hline & 2 & & & 0,0094 & 0,1030 & 0,1520 & 5,213 & & & \\
\hline & 3 & & & 0,0092 & 0,0988 & 0,1477 & 5,315 & & & \\
\hline & 4 & & & 0,0096 & 0,0980 & 0,1482 & 5,229 & & & \\
\hline \multirow{4}{*}{20,0} & 1 & \multirow{4}{*}{$3 / 4 / 07$} & \multirow{4}{*}{ 10'19" } & 0,0093 & 0,0992 & 0,1855 & 9,280 & \multirow{4}{*}{9,3170} & \multirow{4}{*}{0,2243} & \\
\hline & 2 & & & 0,0096 & 0,1007 & 0,1926 & 9,573 & & & 24 \\
\hline & 3 & & & 0,0094 & 0,0986 & 0,1853 & 9,223 & & & \\
\hline & 4 & & & 0,0097 & 0,1016 & 0,1904 & 9,155 & & & \\
\hline & 1 & & & 0,0093 & 0,1019 & 0,2080 & 11,409 & & & \\
\hline 25.0 & 2 & $3 / 4 / 07$ & $16^{\prime} 30^{\prime \prime}$ & 0,0092 & 0,1021 & 0,2072 & 11,424 & 113445 & 0.1705 & 1.5 \\
\hline$<v, 0$ & 3 & $0 / 4 / 01$ & 1000 & 0,0095 & 0,1057 & 0,2114 & 11,126 & 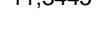 & 0,1700 & (1, \\
\hline & 4 & & & 0,0093 & 0,1024 & 0,2086 & 11,419 & & & \\
\hline & 1 & & & 0,0097 & 0,1016 & 0,2242 & 12,639 & & & \\
\hline 30.0 & 2 & $3 / 4 / 07$ & 20'42" & 0,0101 & 0,1003 & 0,2228 & 12,129 & 12,2514 & 0,2617 & 2,1 \\
\hline & 3 & & & 0,0101 & 0,1010 & 0,2239 & 12,168 & & & \\
\hline & 4 & & & 0,0101 & 0,1062 & 0,2281 & 12,069 & & & \\
\hline & 1 & & & 0,0100 & 0,0962 & 0,2926 & 19,640 & & & \\
\hline 50.0 & 2 & $3 / 4 / 07$ & $30^{\prime}$ & 0,0100 & 0,0999 & 0,2919 & 19,200 & 19,1311 & 0,4638 & 2,4 \\
\hline & 3 & & & 0,0100 & 0,1010 & 0,2927 & 19,170 & & & \\
\hline & 4 & & & 0,0103 & 0,1015 & 0,2922 & 18,515 & & & \\
\hline & 1 & & & 0,0102 & 0,0961 & 0,3599 & 25,863 & & & \\
\hline 70,0 & 2 & $3 / 4 / 07$ & $41 ' 18 "$ & 0,0100 & 0,1025 & 0,3622 & 25,970 & 26.2307 & 0.4615 & 18 \\
\hline & 3 & & & 0,0100 & 0,0980 & 0,3600 & 26,200 & & & \\
\hline & 4 & & & 0,0100 & 0,0972 & 0,3661 & 26,890 & & & \\
\hline & 1 & & & 0,0099 & 0,1013 & 0,4568 & 35,909 & & & \\
\hline 100.0 & 2 & $3 / 4 / 07$ & 51'36" & 0,0100 & 0,0975 & 0,4683 & 37,080 & 36.2769 & 0.6963 & 1.9 \\
\hline & 3 & & & 0,0102 & 0,1018 & 0,4489 & 34,029 & (2) & 0,0000 & \\
\hline & 4 & & & 0,0101 & 0,1047 & 0,4667 & 35,842 & & & \\
\hline & 1 & & & 0,0101 & 0,1011 & 0,5425 & 43,703 & & & \\
\hline 120.0 & 2 & $3 / 4 / 07$ & $57^{\prime} 48^{\prime \prime}$ & 0,0103 & 0,0996 & 0,5430 & 43,049 & 43,7038 & 0,6557 & 1,5 \\
\hline & 3 & & & 0,0100 & 0,1017 & 0,5453 & 44,360 & 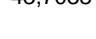 & & \\
\hline & 4 & & & 0,0106 & 0,1025 & 0,5360 & 40,896 & & & \\
\hline & 1 & & & 0,0101 & 0,0985 & 0,5735 & 47,030 & & & \\
\hline 140,0 & 2 & $3 / 4 / 07$ & $57^{\prime} 48^{\prime \prime}$ & 0,0102 & 0,1040 & 0,5834 & 47,000 & 46,9197 & 0,1244 & 0,3 \\
\hline & 3 & & & 0,0104 & 0,1024 & 0,5901 & 46,894 & & & \\
\hline & 4 & & & 0,0106 & 0,1024 & 0,5980 & 46,755 & & & \\
\hline & 1 & & & 0,0101 & 0,1005 & 0,6321 & 52,634 & & & \\
\hline 160,0 & 2 & $3 / 4 / 07$ & $57^{\prime} 48^{\prime \prime}$ & 0,0104 & 0,0992 & 0,6313 & 51,163 & 52,0483 & 0,6247 & 1,2 \\
\hline & 3 & & & 0,0103 & 0,1019 & 0,6394 & 52,184 & & & \\
\hline & 4 & & & 0,0104 & 0,1082 & 0,6512 & 52,212 & & & \\
\hline & 1 & & & 0,0103 & 0,1064 & 0,7307 & 60,612 & & & \\
\hline 180.0 & 2 & $3 / 4 / 07$ & $57^{\prime} 48 "$ & 0,0103 & 0,1035 & 0,7251 & 60,350 & 60.2910 & 0.3536 & 0.6 \\
\hline & 3 & & & 0,0101 & 0,1102 & 0,7546 & 63,802 & 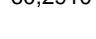 & & \\
\hline & 4 & & & 0,0102 & 0,0981 & 0,7092 & 59,912 & & & \\
\hline & 1 & & & 0,0101 & 0,1066 & 0,8206 & 70,693 & & & \\
\hline 200,0 & 2 & $3 / 4 / 07$ & $57^{\prime} 48^{\prime \prime}$ & 0,0103 & 0,1096 & 0,8180 & 68,777 & 69,1615 & 1,2412 & 1,8 \\
\hline & 3 & & ט דו & 0,0101 & 0,1063 & 0,8077 & 69,446 & & & \\
\hline & 4 & & & 0,0104 & 0,1061 & 0,8105 & 67,731 & & & \\
\hline
\end{tabular}

\section{Legenda:}

Dose $(G y)=$ dose alvo

D = número do dosímetro

Data $=$ data da irradiação

Timer $=$ tempo de irradiação
Espes. = espessura do dosímetro Grafchromic

$\mathbf{A O}=$ leitura inicial do dosímetro antes da irradiação

$\mathbf{A}=$ leitura do dosímetro após irradiação

$\mathbf{k}=(\mathrm{A}-\mathrm{A} 0) /$ Espes. $\mathbf{k}_{\text {médio }}=$ é o valor médio encontrado a partir dos quatro valores fornecidos na coluna $\mathrm{k}\left(\mathrm{cm}^{-1}\right)$ de cada dose apresentada

Desvio-Padrão $=\sqrt{\frac{\sum\left(k-k_{\text {médio }}\right)^{2}}{(n-1)}}$ onde $\mathrm{n}$ é quantidade de leitura dos dosímetros

CV $=\left(\right.$ Desvio-Padrão/ $\left.k_{\text {médio }}\right) \times 100$ 
TABELA 8 - Cálculo do Coeficiente de Variação para Experimento 2

\begin{tabular}{|c|c|c|c|c|c|c|c|c|c|c|}
\hline $\begin{array}{c}\text { Dose Solic. } \\
\text { (Gy) }\end{array}$ & $\begin{array}{l}\text { D. } \\
\text { no }\end{array}$ & Data & $\begin{array}{c}\text { Timer } \\
\text { (s) }\end{array}$ & $\begin{array}{c}\text { Espes. } \\
(\mathrm{cm})\end{array}$ & A0 & A & $\begin{array}{c}k \\
\left(\mathrm{~cm}^{-1}\right)\end{array}$ & $\begin{array}{l}k_{\text {médio }} \\
\left(\mathrm{cm}^{-1}\right)\end{array}$ & $\begin{array}{l}\text { Desvio } \\
\text { Padrão }\end{array}$ & $\begin{array}{l}\text { C.V. } \\
\text { (\%) }\end{array}$ \\
\hline \multirow{4}{*}{5,0} & 1 & \multirow{4}{*}{$12 / 4 / 07$} & \multirow{4}{*}{$2^{\prime} 40^{\prime \prime}$} & 0,0104 & 0,1036 & 0,1307 & 2,606 & \multirow{4}{*}{2,7015} & \multirow{4}{*}{0,1501} & \multirow{4}{*}{5,6} \\
\hline & 2 & & & 0,0106 & 0,1090 & 0,1396 & 2,887 & & & \\
\hline & 3 & & & 0,0106 & 0,1075 & 0,1346 & 2,557 & & & \\
\hline & 4 & & & 0,0107 & 0,1067 & 0,1362 & 2,757 & & & \\
\hline \multirow{4}{*}{10,0} & 1 & \multirow{4}{*}{$12 / 4 / 07$} & \multirow{4}{*}{ 6'12" } & 0,0107 & 0,1099 & 0,1511 & 3,850 & \multirow{4}{*}{4,5409} & \multirow{4}{*}{0,0791} & \multirow{4}{*}{1,7} \\
\hline & 2 & & & 0,0106 & 0,1140 & 0,1616 & 4,491 & & & \\
\hline & 3 & & & 0,0106 & 0,1057 & 0,1548 & 4,632 & & & \\
\hline & 4 & & & 0,0106 & 0,1110 & 0,1587 & 4,500 & & & \\
\hline \multirow{4}{*}{20,0} & 1 & \multirow{4}{*}{$12 / 4 / 07$} & \multirow{4}{*}{ 16'30" } & 0,0106 & 0,1063 & 0,1823 & 7,170 & \multirow{4}{*}{8,1715} & \multirow{4}{*}{0,1815} & \\
\hline & 2 & & & 0,0105 & 0,1083 & 0,1943 & 8,190 & & & 2.2 \\
\hline & 3 & & & 0,0107 & 0,1052 & 0,1906 & 7,981 & & & \\
\hline & 4 & & & 0,0105 & 0,1062 & 0,1938 & 8,343 & & & \\
\hline & 1 & & & 0,0107 & 0,1115 & 0,1963 & 7,925 & & & \\
\hline 25.0 & 2 & $12 / 4 / 07$ & 20'42" & 0,0107 & 0,1083 & 0,2106 & 9,561 & 9.0924 & 0.1337 & 1.5 \\
\hline $2 \sigma, v$ & 3 & $12 / 4 / 01$ & $204 \angle$ & 0,0106 & 0,1101 & 0,2114 & 9,557 & , $00<4$ & , & \\
\hline & 4 & & & 0,0107 & 0,1077 & 0,2075 & 9,327 & & & \\
\hline & 1 & & & 0,0106 & 0,1060 & 0,2278 & 11,491 & & & \\
\hline 30.0 & 2 & $12 / 4 / 07$ & $30^{\prime}$ & 0,0107 & 0,1069 & 0,2280 & 11,318 & 11,4420 & 0,2302 & 2,0 \\
\hline 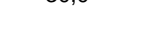 & 3 & 政 & & 0,0105 & 0,1077 & 0,2310 & 11,743 & 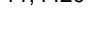 & & \\
\hline & 4 & & & 0,0106 & 0,1080 & 0,2269 & 11,217 & & & \\
\hline & 1 & & & 0,0105 & 0,1028 & 0,2933 & 18,143 & & & \\
\hline 50.0 & 2 & $12 / 4 / 07$ & 41'18" & 0,0104 & 0,1060 & 0,2944 & 18,115 & 18,2422 & 0,1791 & 1.0 \\
\hline & 3 & & & 0,0105 & 0,1073 & 0,3016 & 18,505 & & & \\
\hline & 4 & & & 0,0107 & 0,1071 & 0,3019 & 18,206 & & & \\
\hline & 1 & & & 0,0107 & 0,1030 & 0,3613 & 24,140 & & & \\
\hline 70,0 & 2 & $12 / 4 / 07$ & 51'36" & 0,0106 & 0,1010 & 0,3582 & 24,264 & 24,3212 & 0,1667 & 0,7 \\
\hline & 3 & & & 0,0106 & 0,1128 & 0,3729 & 24,538 & & & \\
\hline & 4 & & & 0,0105 & 0,1077 & 0,3633 & 24,343 & & & \\
\hline & 1 & & & 0,0106 & 0,1077 & 0,4290 & 30,311 & & & \\
\hline 100.0 & 2 & $12 / 4 / 07$ & $57^{\prime} 48^{\prime \prime}$ & 0,0104 & 0,1152 & 0,4349 & 30,740 & 30.6868 & 0.6667 & 22 \\
\hline & 3 & 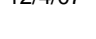 & & 0,0103 & 0,1044 & 0,4299 & 31,602 & 00,0000 & 0,000 & \\
\hline & 4 & & & 0,0107 & 0,1094 & 0,4314 & 30,093 & & & \\
\hline & 1 & & & 0,0107 & 0,1117 & 0,4937 & 35,701 & & & \\
\hline 120.0 & 2 & $12 / 4 / 07$ & 57'48" & 0,0106 & 0,1102 & 0,4844 & 35,302 & 35,4498 & 0,5211 & 1,5 \\
\hline & 3 & & & 0,0108 & 0,1055 & 0,4813 & 34,796 & ט, דוד, & 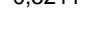 & ( \\
\hline & 4 & & & 0,0106 & 0,1141 & 0,4957 & 36,000 & & & \\
\hline & 1 & & & 0,0105 & 0,1118 & 0,5432 & 41,086 & & & \\
\hline 140,0 & 2 & $12 / 4 / 07$ & 57'48" & 0,0105 & 0,1143 & 0,5422 & 40,752 & 41,3619 & 0,6453 & 1,6 \\
\hline & 3 & & & 0,0105 & 0,1080 & 0,5422 & 41,352 & & & \\
\hline & 4 & & & 0,0105 & 0,1039 & 0,5476 & 42,257 & & & \\
\hline & 1 & & & 0,0104 & 0,1058 & 0,6056 & 48,058 & & & \\
\hline 160,0 & 2 & $12 / 4 / 07$ & $57^{\prime} 48^{\prime \prime}$ & 0,0104 & 0,1072 & 0,5938 & 46,788 & 46,7583 & 1,1761 & 2,5 \\
\hline & 3 & & & 0,0107 & 0,1094 & 0,5931 & 45,206 & & & \\
\hline & 4 & & & 0,0107 & 0,1075 & 0,6102 & 46,981 & & & \\
\hline & 1 & & & 0,0104 & 0,1057 & 0,6650 & 53,779 & & & \\
\hline 180,0 & 2 & $12 / 4 / 07$ & $57^{\prime} 48^{\prime \prime}$ & 0,0104 & 0,1155 & 0,6615 & 52,500 & 52,5604 & 0,9068 & 1,7 \\
\hline 100,0 & 3 & 作 & & 0,0107 & 0,1067 & 0,6587 & 51,589 & & & \\
\hline & 4 & & & 0,0107 & 0,1085 & 0,6689 & 52,374 & & & \\
\hline & 1 & & & 0,0106 & 0,1208 & 0,7083 & 55,425 & & & \\
\hline 200,0 & 2 & $12 / 4 / 07$ & $57^{\prime} 48^{\prime \prime}$ & 0,0106 & 0,1167 & 0,7644 & 61,104 & 59,3733 & 4,0874 & 6.9 \\
\hline & 3 & & & 0,0106 & 0,1157 & 0,7164 & 56,670 & & & \\
\hline & 4 & & & 0,0105 & 0,1064 & 0,7815 & 64,295 & & & \\
\hline
\end{tabular}

\section{Legenda:}

Dose $(G y)=$ dose alvo

D = número do dosímetro

Data $=$ data da irradiação

Timer $=$ tempo de irradiação
Espes. $=$ espessura do dosímetro Grafchromic

$\mathbf{A O}=$ leitura inicial do dosímetro antes da irradiação

A = leitura do dosímetro após irradiação

$\mathbf{k}=(\mathrm{A}-\mathrm{A} 0) /$ Espes. $\mathbf{k}_{\text {médio }}=$ é o valor médio encontrado a partir dos quatro valores fornecidos na coluna $\mathrm{k}\left(\mathrm{cm}^{-1}\right)$ de cada dose apresentada

Desvio-Padrão $=\sqrt{\frac{\sum\left(k-k_{\text {médio }}\right)^{2}}{(n-1)}}$ onde $\mathrm{n}$ é quantidade de leitura dos dosímetros

CV $=\left(\right.$ Desvio-Padrão $\left./ k_{\text {médio }}\right) \times 100$ 


\subsubsection{Curva de calibração para o dosímetro Gafchromic HD-810}

Para a construção da curva de calibração, utilizou-se como referência a norma ASTM E1310 - 89(22).

Foram selecionados das duas tabelas (TAB. 7 e TAB. 8) os valores do $\mathrm{k}_{\text {médio }}$ e o desvio-padrão conforme TAB. 9 para calcular em seguida a média do $k_{\text {médio }}$ e a média dos desvios-padrão para calcular o coeficiente de variação (CV) conforme TAB. 10. O coeficiente de variação é calculado da seguinte maneira:

$$
C V=\left(\text { Média do desvio-padrão / Média do } k_{\text {médio }}\right) \times 100
$$

TABELA 9 - Valores de $k_{\text {médio }}$ e desvio-padrão (D.P.)

\begin{tabular}{c|cc|cc}
\hline \multirow{2}{*}{$\begin{array}{c}\text { Dose } \\
\text { (Gy) }\end{array}$} & \multicolumn{2}{|c|}{ Experimento 1 } & \multicolumn{2}{c}{ Experimento 2 } \\
\hline 5 & 3,2351 & 0,0485 & 2,7015 & 0,1501 \\
10 & 5,2383 & 0,0531 & 4,5409 & 0,0791 \\
20 & 9,3076 & 0,1841 & 8,2222 & 0,1083 \\
25 & 11,3445 & 0,1456 & 9,5716 & 0,1495 \\
30 & 12,2514 & 0,2617 & 11,3613 & 0,2143 \\
50 & 19,1311 & 0,4638 & 18,1153 & 0,4078 \\
70 & 26,2307 & 0,4615 & 24,4975 & 0,4130 \\
100 & 36,2769 & 0,6963 & 30,3907 & 0,3469 \\
120 & 43,7038 & 0,6557 & 36,0419 & 0,3384 \\
140 & 46,9197 & 0,1244 & 40,6870 & 0,7840 \\
160 & 52,0483 & 0,6247 & 46,9714 & 0,8995 \\
180 & 60,2910 & 0,3536 & 52,5604 & 0,9068 \\
200 & 69,1615 & 0,2412 & 59,3733 & 4,0874 \\
\hline
\end{tabular}


TABELA 10 - Cálculo Final do Coeficiente de Variação (CV)

\begin{tabular}{c|c|c}
\hline Média $\mathbf{k}_{\text {médio }}$ & Média do D.P. & CV\% \\
\hline 2,9683 & 0,0789 & 2,7 \\
4,8896 & 0,0476 & 1,0 \\
8,7649 & 0,1068 & 1,2 \\
10,4581 & 0,1043 & 1,0 \\
11,8063 & 0,1691 & 1,4 \\
18,6232 & 0,3088 & 1,7 \\
25,3641 & 0,3096 & 1,2 \\
33,3338 & 0,3890 & 1,2 \\
39,8728 & 0,3689 & 0,9 \\
43,8033 & 0,3969 & 0,9 \\
49,5099 & 0,5476 & 1,1 \\
56,4257 & 0,4867 & 0,9 \\
64,2674 & 2,0473 & 3,2 \\
\hline
\end{tabular}

Segundo a norma ASTM E1310 - 89 ${ }^{(15)}$, se o coeficiente de variação (CV) for maior que $2 \%$, pode-se ou não rejeitar tais valores. Sendo assim, optou-se pela não rejeição dos valores marcados com fundo na cor amarela na TAB.10, os quais não afetaram a curva de calibração. A equação polinomial obtida pela curva de calibração foi $y=-1,2268 \mathrm{E}-05 \mathrm{x}^{4}+1,1369 \mathrm{E}-03 \mathrm{x}^{3}-1,7439 \mathrm{E}-02 \mathrm{x}^{2}+$ 2,8445E+00x - 3,5631E+00. A curva de calibração do dosímetro Gafchromic é mostrada na FIG. 21.

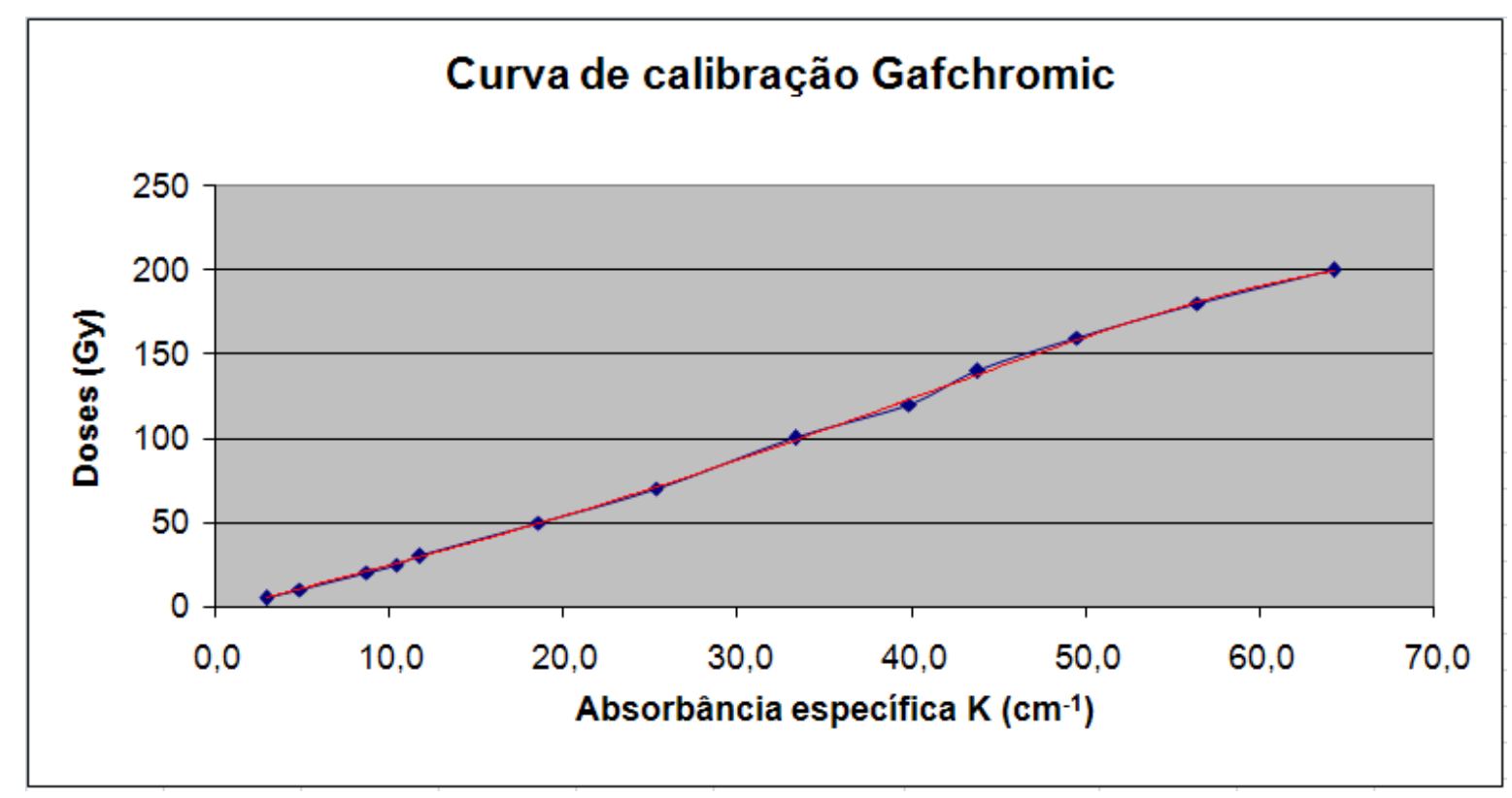

FIGURA 21 - Curva de calibração do dosímetro Gafchromic 


\subsubsection{Mapeamento de dose}

\subsubsection{Dosímetros PMMA}

Os dosímetros PMMA numerados e apresentados conforme FIG. 14 foram calibrados de acordo a norma ASTM E1276 - 93 ${ }^{(25)}$. Através da curva de calibração medida, calculou-se o valor da dose absorvida em cada dosímetro na posição $0^{\circ}$ conforme TAB. 11.

TABELA 11 - Dose absorvida no dosímetro PMMA na posição $0^{0}$

\begin{tabular}{c|c|c|c|c|c}
\hline \multicolumn{2}{|c|}{ Dosímetros } & $\begin{array}{c}\text { Dose-alvo } \\
\text { (kGy) }\end{array}$ & Abs & $\mathbf{k}\left(\mathbf{c m}^{-1} \mathbf{)}\right.$ & $\begin{array}{c}\text { Dose } \\
\mathbf{k G y}\end{array}$ \\
\hline No & Espessura (cm) & 2 & 0,220 & 0,837 & 2,10 \\
$1-1$ & 0,2630 & 2 & 0,152 & 0,556 & 1,43 \\
$1-2$ & 0,2736 & 2 & 0,150 & 0,591 & 1,51 \\
$1-3$ & 0,2536 & 2 & 0,180 & 0,619 & 1,58 \\
$1-4$ & 0,2908 & 2 & 0,220 & 0,691 & 1,75 \\
$2-1$ & 0,3184 & 2 & 0,215 & 0,642 & 1,64 \\
$2-2$ & 0,3347 & 2 & 0,181 & 0,629 & 1,60 \\
$2-3$ & 0,2878 & 2 & 0,220 & 0,796 & 2,00 \\
$2-4$ & 0,2764 & 2 & 0,231 & 0,719 & 1,82 \\
$3-1$ & 0,3211 & 2 & 0,191 & 0,700 & 1,77 \\
$3-2$ & 0,2730 & 2 & 0,233 & 0,696 & 1,76 \\
$3-3$ & 0,3348 & 2 & 0,229 & 0,823 & 2,07 \\
$3-4$ & 0,2782 & 2 & 0,253 & 0,855 & 2,15 \\
$4-1$ & 0,2958 & 2 & 0,188 & 0,739 & 1,87 \\
$4-2$ & 0,2545 & 2 & 0,227 & 0,716 & 1,81 \\
$4-3$ & 0,3169 & 2 & 0,238 & 0,738 & 1,87 \\
$4-4$ & 0,3223 & 2 & 0,203 & 0,770 & 1,94 \\
$5-1$ & 0,2636 & 2 & 0,203 & 0,660 & 1,68 \\
$5-2$ & 0,3077 & 2 & 0,218 & 0,701 & 1,78 \\
$5-3$ & 0,3112 & 2 & 0,209 & 0,743 & 1,88 \\
$5-4$ & 0,2814 & 2 & 0,194 & 0,758 & 1,91 \\
$6-1$ & 0,2559 & 2 & 0,206 & 0,622 & 1,59 \\
$6-2$ & 0,3312 & 2 & 0,177 & 0,671 & 1,71 \\
$6-3$ & 0,2636 & 2 & 0,220 & 0,820 & 2,06 \\
$6-4$ & 0,2683 & 0,211 & 0,784 & 1,98 \\
$7-1$ & 0,2692 & 0,170 & 0,612 & 1,56 \\
$7-2$ & 0,2779 & 0,158 & 0,572 & 1,47 \\
$7-3$ & 0,2762 & 0,209 & 0,721 & 1,82 \\
\hline $7-4$ & 0,2900 & 2 & & &
\end{tabular}

Legenda:

$\begin{array}{ll}\text { № = Número do dosímetro } & \begin{array}{l}\text { Espessura = Espessura do } \\ \text { dosímetro medido em } \mathrm{cm}\end{array} \\ \text { Abs = Absorbância } & \mathbf{k}=\text { Abs / Espessura }\end{array}$

Dose-alvo = Quantidade de dose que o dosímetro recebeu em kGy

Dose kGy = Dose absorvida pelo dosímetro conforme equação da curva de calibração 
Os dados da TAB. 11 foram utilizados para construção da representação gráfica na FIG. 22. Pode-se observar nesta figura, por meio das cores, as regiões que receberam uma determinada dose de irradiação em kGy.

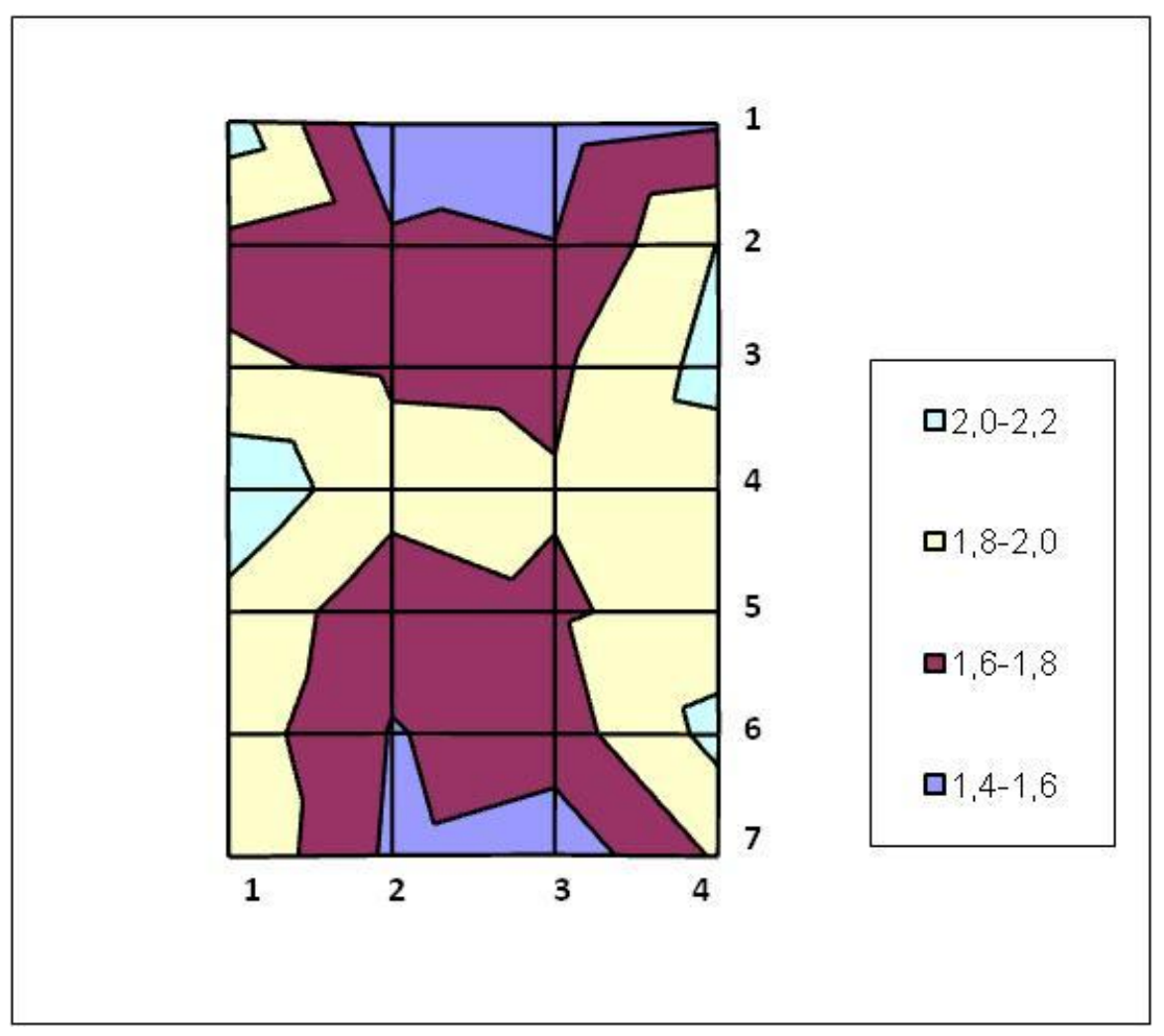

FIGURA 22 - Representação gráfica do dosímetro PMMA na posição 0ำ

A cor azul-claro corresponde aos locais que receberam doses de radiação entre 2,0 e 2,2 kGy.

A cor amarela corresponde aos locais que receberam doses de radiação na faixa entre 1,8 kGy e 2,0 kGy.

$\mathrm{Na}$ faixa de doses de radiação entre 1,6 kGy e 1,8 kGy utilizou-se a representação por meio da cor bordô.

A região azul-escuro que corresponde a faixa de doses de radiação entre 1,4 kGy e 1,6 kGy ficou dividida entre as partes inferior e superior da figura. 
A seguir, apresentam-se os resultados obtidos na posição $90^{\circ}$ conforme a

TAB. 12.

TABELA 12 - Dose absorvida no dosímetro PMMA na posição 90ำ

\begin{tabular}{c|c|c|c|c|c}
\hline \multicolumn{2}{|c|}{ Dosímetros } & $\begin{array}{c}\text { Dose-alvo } \\
\text { (kGy) }\end{array}$ & Abs & $\mathbf{k}\left(\mathbf{c m}^{-1} \mathbf{)}\right.$ & $\begin{array}{c}\text { Dose } \\
\mathbf{k G y}\end{array}$ \\
\hline $\mathbf{N}$ No & Espessura (cm) & 4 & 0,392 & 1,490 & 3,69 \\
$1-1$ & 0,2630 & 4 & 0,320 & 1,170 & 2,90 \\
$1-2$ & 0,2736 & 4 & 0,305 & 1,203 & 2,98 \\
$1-3$ & 0,2536 & 4 & 0,399 & 1,372 & 3,40 \\
$1-4$ & 0,2908 & 4 & 0,465 & 1,460 & 3,61 \\
$2-1$ & 0,3184 & 4 & 0,459 & 1,371 & 3,40 \\
$2-2$ & 0,3347 & 4 & 0,381 & 1,324 & 3,28 \\
$2-3$ & 0,2878 & 4 & 0,470 & 1,700 & 4,21 \\
$2-4$ & 0,2764 & 4 & 0,521 & 1,623 & 4,01 \\
$3-1$ & 0,3211 & 4 & 0,399 & 1,462 & 3,62 \\
$3-2$ & 0,2730 & 4 & 0,494 & 1,476 & 3,65 \\
$3-3$ & 0,3348 & 4 & 0,448 & 1,610 & 3,98 \\
$3-4$ & 0,2782 & 4 & 0,503 & 1,700 & 4,21 \\
$4-1$ & 0,2958 & 4 & 0,385 & 1,513 & 3,74 \\
$4-2$ & 0,2545 & 4 & 0,473 & 1,493 & 3,69 \\
$4-3$ & 0,3169 & 4 & 0,526 & 1,632 & 4,04 \\
$4-4$ & 0,3223 & 4 & 0,448 & 1,700 & 4,21 \\
$5-1$ & 0,2636 & 4 & 0,427 & 1,388 & 3,44 \\
$5-2$ & 0,3077 & 4 & 0,452 & 1,452 & 3,59 \\
$5-3$ & 0,3112 & 4 & 0,478 & 1,699 & 4,20 \\
$5-4$ & 0,2814 & 4 & 0,439 & 1,716 & 4,25 \\
$6-1$ & 0,2559 & 4 & 0,434 & 1,310 & 3,25 \\
$6-2$ & 0,3312 & 4 & 0,353 & 1,339 & 3,32 \\
$6-3$ & 0,2636 & 0,452 & 1,685 & 4,17 \\
$6-4$ & 0,2683 & 0,429 & 1,594 & 3,94 \\
$7-1$ & 0,2692 & 0,325 & 1,169 & 2,90 \\
$7-2$ & 0,2779 & 0,329 & 1,191 & 2,96 \\
$7-3$ & 0,2762 & 4 & & & \\
$7-4$ & 0,2900 & 4,43 & 1,483 & 3,67 \\
\hline
\end{tabular}

Legenda:

№ = Número do dosímetro

Abs = Absorbância
Espessura $=$ Espessura do dosímetro medido em $\mathrm{cm}$

$\mathbf{k}=$ Abs $/$ Espessura
Dose-alvo = Quantidade de dose que o dosímetro recebeu em kGy

Dose kGy = Dose absorvida pelo dosímetro conforme equação da curva de calibração 
$\mathrm{Na}$ FIG. 23 apresentam-se graficamente os pontos correspondentes aos valores obtidos na TAB.12.

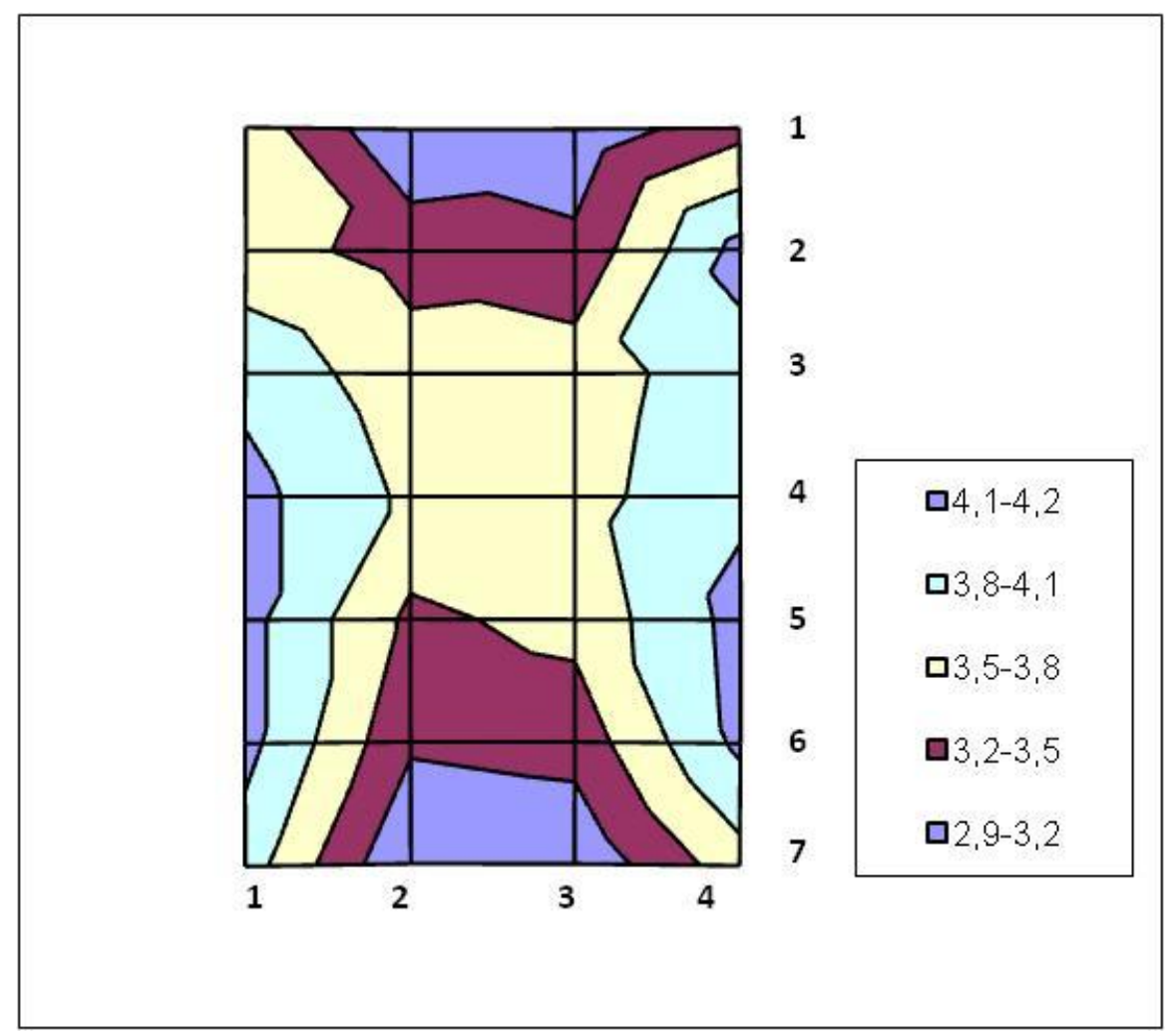

FIGURA 23 - Representação gráfica do dosímetro PMMA na posição 90ํำ

Nesta figura pôde-se observar que ocorreu uma alteração da configuração gráfica em relação a FIG.22, embora existam semelhanças.

A faixa de doses de radiação entre 4,1 kGy e 4,2 kGy é representada pela cor roxa.

A faixa de doses radiações entre 3,8 kGy e 4,1 kGy corresponde a cor azulclaro.

A cor amarela representa as regiões que receberam doses de radiação na faixa entre 3,5 kGy e 3,8 kGy.

$\mathrm{Na}$ faixa de doses de radiação entre 3,2 kGy e 3,5 kGy utilizou-se a representação por meio da cor bordô. 
A região azul-escuro corresponde a faixa de doses de irradiação entre 2,9 kGy e 3,2 kGy.

A seguir, apresentam-se os resultados obtidos na posição $45^{\circ}$ conforme apresentado na TAB. 13.

TABELA 13 - Dose absorvida no dosímetro PMMA na posição 45ำ

\begin{tabular}{|c|c|c|c|c|c|}
\hline \multicolumn{2}{|r|}{ Dosímetros } & \multirow{2}{*}{$\begin{array}{c}\text { Dose-alvo } \\
\text { (kGy) }\end{array}$} & \multirow{2}{*}{ Abs } & \multirow{2}{*}{$\mathrm{k}\left(\mathrm{cm}^{-1}\right)$} & \multirow{2}{*}{$\begin{array}{l}\text { Dose } \\
\text { kGy }\end{array}$} \\
\hline № & Espessura (cm) & & & & \\
\hline $1-1$ & 0,2630 & 6 & 0,583 & 2,217 & 5,53 \\
\hline $1-2$ & 0,2736 & 6 & 0,481 & 1,758 & 4,35 \\
\hline $1-3$ & 0,2536 & 6 & 0,445 & 1,755 & 4,35 \\
\hline $1-4$ & 0,2908 & 6 & 0,581 & 1,998 & 4,96 \\
\hline $2-1$ & 0,3184 & 6 & 0,790 & 2,481 & 6,24 \\
\hline $2-2$ & 0,3347 & 6 & 0,649 & 1,939 & 4,81 \\
\hline $2-3$ & 0,2878 & 6 & 0,573 & 1,991 & 4,95 \\
\hline $2-4$ & 0,2764 & 6 & 0,633 & 2,290 & 5,73 \\
\hline $3-1$ & 0,3211 & 6 & 0,751 & 2,339 & 5,86 \\
\hline $3-2$ & 0,2730 & 6 & 0,575 & 2,106 & 5,24 \\
\hline $3-3$ & 0,3348 & 6 & 0,696 & 2,079 & 5,17 \\
\hline $3-4$ & 0,2782 & 6 & 0,680 & 2,444 & 6,14 \\
\hline $4-1$ & 0,2958 & 6 & 0,735 & 2,485 & 6,25 \\
\hline $4-2$ & 0,2545 & 6 & 0,547 & 2,149 & 5,36 \\
\hline $4-3$ & 0,3169 & 6 & 0,671 & 2,117 & 5,27 \\
\hline $4-4$ & 0,3223 & 6 & 0,767 & 2,380 & 5,97 \\
\hline 5-1 & 0,2636 & 6 & 0,644 & 2,443 & 6,14 \\
\hline $5-2$ & 0,3077 & 6 & 0,666 & 2,164 & 5,40 \\
\hline 5-3 & 0,3112 & 6 & 0,643 & 2,066 & 5,14 \\
\hline $5-4$ & 0,2814 & 6 & 0,664 & 2,360 & 5,91 \\
\hline $6-1$ & 0,2559 & 6 & 0,613 & 2,395 & 6,01 \\
\hline $6-2$ & 0,3312 & 6 & 0,685 & 2,068 & 5,15 \\
\hline $6-3$ & 0,2636 & 6 & 0,525 & 1,992 & 4,95 \\
\hline $6-4$ & 0,2683 & 6 & 0,604 & 2,251 & 5,62 \\
\hline $7-1$ & 0,2692 & 6 & 0,572 & 2,125 & 5,29 \\
\hline $7-2$ & 0,2779 & 6 & 0,521 & 1,875 & 4,65 \\
\hline $7-3$ & 0,2762 & 6 & 0,492 & 1,781 & 4,41 \\
\hline
\end{tabular}

Legenda:

№ = Número do dosímetro

Abs = Absorbância
Espessura $=$ Espessura do dosímetro medido em $\mathrm{cm}$

$\mathbf{k}=$ Abs / Espessura
Dose-alvo = Quantidade de dose que o dosímetro recebeu em kGy

Dose $\mathbf{k G y}=$ Dose absorvida pelo dosímetro conforme equação da curva de calibração 
A FIG. 24 apresenta os pontos correspondes aos valores obtidos na TAB.13.

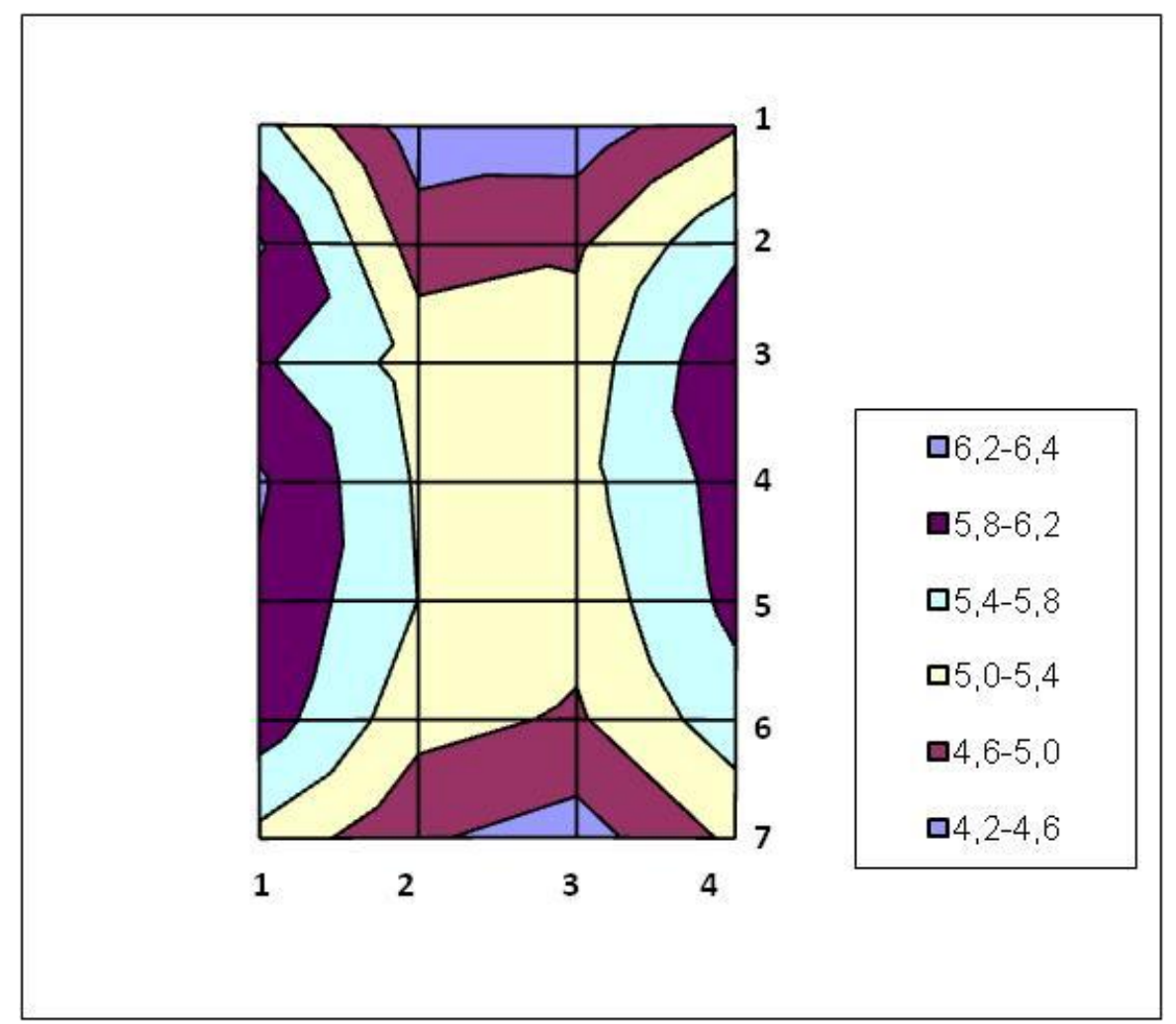

FIGURA 24 - Representação gráfica do dosímetro PMMA na posição 45은

Na distribuição de dose do Gammacell 220 do CTR para a posição 0ํㅡ, o valor do fator de uniformidade de dose (razão entre o maior e o menor valor de dose absorvida pelos produtos durante o mapeamento) foi 1,50. Para a posição de $90^{\circ}$, o fator de uniformidade de dose foi 1,45 e para a posição de $45^{\circ}$, o fator de uniformidade de dose foi 1,47 .

Os valores são inferiores ao fator de uniformidade de dose estabelecido por normas para irradiação de sangue, que é de 25 Gy a 50 Gy, ou seja, fator 2 . Estes valores permitem assegurar que o irradiador Gammacell 220 pode ser utilizado na irradiação de sangue. Por exemplo, ao se fixar a dose mínima de 25 Gy multiplicando-se o maior fator de uniformidade de dose 1,5 (posição $0^{\circ}$ ), o valor máximo da dose seria 37,5 Gy, o qual está dentro do intervalo estabelecido. 


\subsubsection{Dosímetros Gafchromic HD-810}

Conforme TAB.14, foram obtidos os resultados de leitura de dose absorvida para a posição 0 utilizando-se os dosímetros Gafchromic.

TABELA 14 - Posição 0ำ do dosímetro Gafchromic

\begin{tabular}{|c|c|c|c|c|c|c|c|}
\hline \multicolumn{2}{|r|}{ Dosímetros } & \multirow{2}{*}{$\begin{array}{c}\text { Dose-alvo } \\
\text { (Gy) }\end{array}$} & \multirow{2}{*}{$\begin{array}{c}\text { A0 } \\
\text { (média) }\end{array}$} & \multirow{2}{*}{$\begin{array}{c}\text { A0 } \\
\text { (LE LD) }\end{array}$} & \multirow{2}{*}{ A } & \multirow{2}{*}{$\mathrm{k}\left(\mathrm{cm}^{-1}\right)$} & \multirow{2}{*}{ Dose Gy } \\
\hline № & Espessura (cm) & & & & & & \\
\hline $1-1$ & 0,0104 & 25 & 0,0998 & 0,1012 & 0,1886 & 8,543 & 20,11 \\
\hline $1-2$ & 0,0103 & 25 & 0,0998 & 0,0983 & 0,1764 & 7,442 & 17,07 \\
\hline $1-3$ & 0,0103 & 25 & 0,0998 & & 0,1744 & 7,248 & 16,54 \\
\hline $1-4$ & 0,0103 & 25 & 0,0998 & & 0,1692 & 6,743 & 15,15 \\
\hline $1-5$ & 0,0100 & 25 & 0,0998 & & 0,1805 & 8,075 & 18,82 \\
\hline $2-1$ & 0,0102 & 25 & 0,0984 & 0,1006 & 0,1996 & 9,926 & 23,95 \\
\hline $2-2$ & 0,0102 & 25 & 0,0984 & 0,0961 & 0,1805 & 8,054 & 18,76 \\
\hline $2-3$ & 0,0107 & 25 & 0,0984 & & 0,1770 & 7,350 & 16,82 \\
\hline $2-4$ & 0,0102 & 25 & 0,0984 & & 0,1731 & 7,328 & 16,76 \\
\hline $2-5$ & 0,0102 & 25 & 0,0984 & & 0,1897 & 8,956 & 21,25 \\
\hline $3-1$ & 0,0101 & 25 & 0,0995 & 0,1014 & 0,2004 & 9,995 & 24,14 \\
\hline 3-2 & 0,0101 & 25 & 0,0995 & 0,0975 & 0,1829 & 8,262 & 19,33 \\
\hline 3-3 & 0,0106 & 25 & 0,0995 & & 0,1813 & 7,722 & 17,84 \\
\hline 3-4 & 0,0103 & 25 & 0,0995 & & 0,1779 & 7,617 & 17,55 \\
\hline 3-5 & 0,0105 & 25 & 0,0995 & & 0,1949 & 9,090 & 21,62 \\
\hline $4-1$ & 0,0101 & 25 & 0,0981 & 0,0997 & 0,2062 & 10,708 & 26,13 \\
\hline $4-2$ & 0,0104 & 25 & 0,0981 & 0,0964 & 0,1885 & 8,697 & 20,53 \\
\hline $4-3$ & 0,0108 & 25 & 0,0981 & & 0,1877 & 8,301 & 19,44 \\
\hline $4-4$ & 0,0103 & 25 & 0,0981 & & 0,1853 & 8,471 & 19,91 \\
\hline $4-5$ & 0,0103 & 25 & 0,0981 & & 0,1957 & 9,481 & 22,71 \\
\hline $5-1$ & 0,0103 & 25 & 0,0991 & 0,1017 & 0,2054 & 10,325 & 25,06 \\
\hline $5-2$ & 0,0103 & 25 & 0,0991 & 0,0964 & 0,1890 & 8,733 & 20,63 \\
\hline $5-3$ & 0,0103 & 25 & 0,0991 & & 0,1854 & 8,383 & 19,67 \\
\hline $5-4$ & 0,0106 & 25 & 0,0991 & & 0,1920 & 8,769 & 20,73 \\
\hline 5-5 & 0,0104 & 25 & 0,0991 & & 0,2019 & 9,889 & 23,84 \\
\hline $6-1$ & 0,0106 & 25 & 0,0987 & 0,1011 & 0,2159 & 11,057 & 27,11 \\
\hline $6-2$ & 0,0103 & 25 & 0,0987 & 0,0963 & 0,1903 & 8,893 & 21,08 \\
\hline $6-3$ & 0,0105 & 25 & 0,0987 & & 0,1797 & 7,714 & 17,82 \\
\hline $6-4$ & 0,0103 & 25 & 0,0987 & & 0,1790 & 7,796 & 18,05 \\
\hline $6-5$ & 0,0102 & 25 & 0,0987 & & 0,1948 & 9,422 & 22,54 \\
\hline $7-1$ & 0,0101 & 25 & 0,0993 & 0,1003 & 0,1992 & 9,891 & 23,85 \\
\hline 7-2 & 0,0104 & 25 & 0,0993 & 0,0983 & 0,1785 & 7,615 & 17,55 \\
\hline 7-3 & 0,0101 & 25 & 0,0993 & & 0,1705 & 7,050 & 15,99 \\
\hline $7-4$ & 0,0104 & 25 & 0,0993 & & 0,1731 & 7,096 & 16,12 \\
\hline $7-5$ & 0,0106 & 25 & 0,0993 & & 0,1898 & 8,538 & 20,09 \\
\hline
\end{tabular}

Legenda:

№ = Número do dosímetro de A0 (LE LD)

$\mathbf{k}=(\mathrm{A}-\mathrm{A} 0) /$ Espessura
Espessura $=$ Espessura do dosímetro medido em $\mathrm{cm}$

A0 (LE LD) = Leitura média do dosímetro da lateral esquerda e direita

Dose Gy = Dose absorvida pelo dosímetro conforme equação da curva de calibração
Dose-alvo = Quantidade de dose que o dosímetro recebeu em Gy

A = Absorbância 
A FIG. 25 apresenta os pontos correspondes aos valores obtidos na TAB.14 e representados por meio de cores.

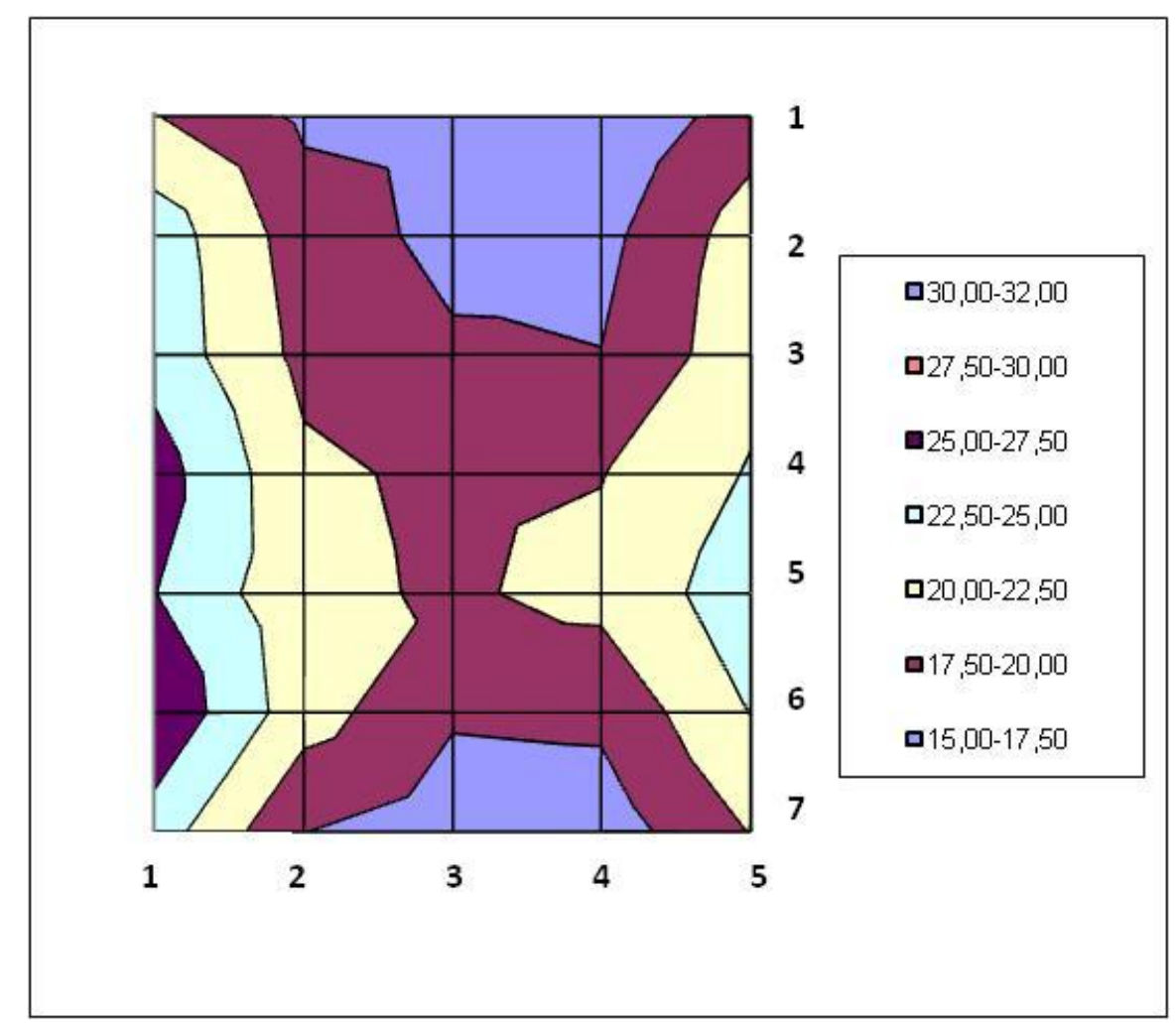

FIGURA 25 - Representação gráfica do dosímetro Gafchromic na posição 0ํำ

Na TAB.14 o menor valor da dose absorvida foi 15,15 Gy (mostrada com fundo de cor laranja) e o maior valor de dose absorvida, 27,11 Gy (mostrada com fundo de cor verde-claro).

No dosímetro situado na posição central, a dose lida foi de 19,44 Gy que é mostrado na tabela em negrito.

Nas linhas seguintes apresentam-se os resultados obtidos na posição $90^{\circ}$ conforme TAB. 15. 
TABELA 15 - Posição 90 do dosímetro Gafchromic

\begin{tabular}{|c|c|c|c|c|c|c|c|}
\hline \multicolumn{2}{|r|}{ Dosímetros } & \multirow{2}{*}{$\begin{array}{c}\text { Dose-alvo } \\
\text { (Gy) }\end{array}$} & \multirow{2}{*}{$\begin{array}{c}\text { A0 } \\
\text { (média) }\end{array}$} & \multirow{2}{*}{$\begin{array}{c}\text { A0 } \\
\text { (LE LD) }\end{array}$} & \multirow{2}{*}{ A } & \multirow{2}{*}{$\mathrm{k}\left(\mathrm{cm}^{-1}\right)$} & \multirow{2}{*}{$\begin{array}{c}\text { Dose } \\
\text { Gy }\end{array}$} \\
\hline № & Espessura (cm) & & & & & & \\
\hline $1-1$ & 0,0109 & 25 & 0,0983 & 0,0994 & 0,1980 & 9,147 & 21,78 \\
\hline $1-2$ & 0,0109 & 25 & 0,0983 & 0,0972 & 0,1853 & 7,982 & 18,56 \\
\hline $1-3$ & 0,0102 & 25 & 0,0983 & & 0,1819 & 8,196 & 19,15 \\
\hline $1-4$ & 0,0105 & 25 & 0,0983 & & 0,1838 & 8,143 & 19,00 \\
\hline $1-5$ & 0,0104 & 25 & 0,0983 & & 0,1937 & 9,173 & 21,85 \\
\hline $2-1$ & 0,0105 & 25 & 0,1030 & 0,1029 & 0,2173 & 10,886 & 26,63 \\
\hline $2-2$ & 0,0105 & 25 & 0,1030 & 0,1031 & 0,1946 & 8,724 & 20,61 \\
\hline $2-3$ & 0,0103 & 25 & 0,1030 & & 0,1897 & 8,417 & 19,76 \\
\hline $2-4$ & 0,0103 & 25 & 0,1030 & & 0,1925 & 8,689 & 20,51 \\
\hline $2-5$ & 0,0100 & 25 & 0,1030 & & 0,2135 & 11,050 & 27,09 \\
\hline $3-1$ & 0,0100 & 25 & 0,1057 & 0,1028 & 0,2203 & 11,465 & 28,26 \\
\hline 3-2 & 0,0104 & 25 & 0,1057 & 0,1085 & 0,1985 & 8,928 & 21,17 \\
\hline 3-3 & 0,0101 & 25 & 0,1057 & & 0,1986 & 9,203 & 21,94 \\
\hline 3-4 & 0,0100 & 25 & 0,1057 & & 0,2035 & 9,785 & 23,55 \\
\hline 3-5 & 0,0108 & 25 & 0,1057 & & 0,2339 & 11,875 & 29,42 \\
\hline 4-1 & 0,0104 & 25 & 0,1002 & 0,0997 & 0,2092 & 10,481 & 25,49 \\
\hline $4-1$ & 0,0103 & 25 & 0,1002 & 0,1007 & 0,1970 & 9,398 & 22,48 \\
\hline $4-3$ & 0,0101 & 25 & 0,1002 & & 0,1760 & 7,505 & 17,24 \\
\hline $4-4$ & 0,0106 & 25 & 0,1002 & & 0,2035 & 9,745 & 23,44 \\
\hline $4-5$ & 0,0106 & 25 & 0,1002 & & 0,2234 & 11,623 & 28,70 \\
\hline 5-1 & 0,0108 & 25 & 0,0990 & 0,0981 & 0,2128 & 10,537 & 25,65 \\
\hline $5-2$ & 0,0109 & 25 & 0,0990 & 0,0999 & 0,1949 & 8,798 & 20,81 \\
\hline $5-3$ & 0,0107 & 25 & 0,0990 & & 0,1935 & 8,832 & 20,91 \\
\hline $5-4$ & 0,0102 & 25 & 0,0990 & & 0,1980 & 9,706 & 23,33 \\
\hline $5-5$ & 0,0101 & 25 & 0,0990 & & 0,2222 & 12,198 & 30,33 \\
\hline $6-1$ & 0,0101 & 25 & 0,0992 & 0,1005 & 0,1985 & 9,832 & 23,68 \\
\hline $6-2$ & 0,0103 & 25 & 0,0992 & 0,0979 & 0,1802 & 7,864 & 18,23 \\
\hline 6-3 & 0,0102 & 25 & 0,0992 & & 0,1803 & 7,951 & 18,47 \\
\hline $6-4$ & 0,0109 & 25 & 0,0992 & & 0,1835 & 7,734 & 17,88 \\
\hline $6-5$ & 0,0104 & 25 & 0,0992 & & 0,2159 & 11,221 & 27,57 \\
\hline $7-1$ & 0,0100 & 25 & 0,0998 & 0,1005 & 0,1885 & 8,875 & 21,03 \\
\hline 7-2 & 0,0101 & 25 & 0,0998 & 0,0990 & 0,1716 & 7,114 & 16,17 \\
\hline 7-3 & 0,0100 & 25 & 0,0998 & & 0,1796 & 7,985 & 18,57 \\
\hline $7-4$ & 0,0105 & 25 & 0,0998 & & 0,1782 & 7,471 & 17,15 \\
\hline $7-5$ & 0,0102 & 25 & 0,0998 & & 0,2028 & 10,103 & 24,44 \\
\hline
\end{tabular}

Legenda:

№ = Número do dosímetro

A0 $=$ Média dos dois valores de A0 (LE LD)

$\mathbf{k}=(\mathrm{A}-\mathrm{A} 0) /$ Espessura
Espessura $=$ Espessura do dosímetro medido em $\mathrm{cm}$

A0 (LE LD) = Leitura média do dosímetro da lateral esquerda e direita

Dose Gy = Dose absorvida pelo dosímetro conforme equação da curva de calibração
Dose-alvo = Quantidade de dose que o dosímetro recebeu em Gy

A = Absorbância 
Na FIG. 26 apresentam-se os pontos correspondes aos valores obtidos na TAB.15.

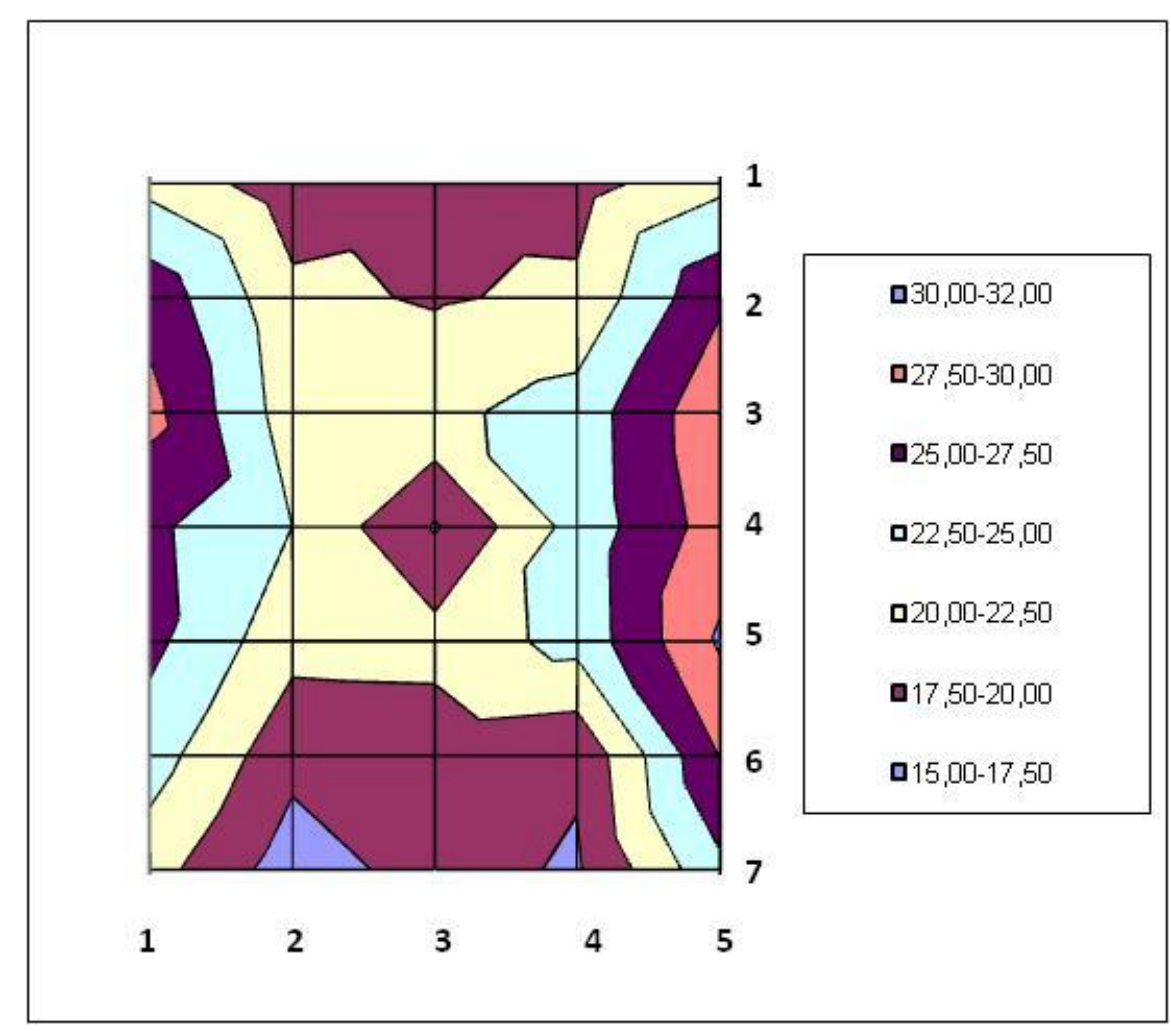

FIGURA 26 - Representação gráfica do dosímetro Gafchromic na posição 90ํำ

Na TAB. 15 o menor valor de dose absorvida foi 16,17 Gy (mostrada com fundo de cor laranja) e o maior valor de dose absorvida, 30,33 Gy (mostrada com fundo de cor verde-claro).

No dosímetro situado na posição central, a dose lida foi de 17,24 Gy que é mostrado na tabela em negrito.

No passo seguinte, apresentam-se os resultados obtidos na posição $45^{\circ}$ conforme apresentado na TAB. 16. 
TABELA 16 - Posição 45 do dosímetro Gafchromic

\begin{tabular}{|c|c|c|c|c|c|c|c|}
\hline \multicolumn{2}{|r|}{ Dosímetros } & \multirow{2}{*}{$\begin{array}{c}\text { Dose-alvo } \\
\text { (Gy) }\end{array}$} & \multirow{2}{*}{$\begin{array}{c}\text { A0 } \\
\text { (média) }\end{array}$} & \multirow{2}{*}{$\begin{array}{c}\text { A0 } \\
\text { (LE LD) }\end{array}$} & \multirow{2}{*}{ A } & \multirow{2}{*}{$\mathrm{k}\left(\mathrm{cm}^{-1}\right)$} & \multirow{2}{*}{$\begin{array}{c}\text { Dose } \\
\text { Gy }\end{array}$} \\
\hline № & Espessura (cm) & & & & & & \\
\hline $1-1$ & 0,0104 & 25 & 0,0979 & 0,0972 & 0,1841 & 8,293 & 19,42 \\
\hline $1-2$ & 0,0104 & 25 & 0,0979 & 0,0985 & 0,1855 & 8,428 & 19,79 \\
\hline $1-3$ & 0,0104 & 25 & 0,0979 & & 0,1735 & 7,274 & 16,61 \\
\hline $1-4$ & 0,0105 & 25 & 0,0979 & & 0,1787 & 7,700 & 17,78 \\
\hline $1-5$ & 0,0103 & 25 & 0,0979 & & 0,1863 & 8,587 & 20,23 \\
\hline $2-1$ & 0,0103 & 25 & 0,0996 & 0,0970 & 0,1964 & 9,403 & 22,49 \\
\hline $2-2$ & 0,0103 & 25 & 0,0996 & 0,1021 & 0,1788 & 7,694 & 17,77 \\
\hline $2-3$ & 0,0104 & 25 & 0,0996 & & 0,1791 & 7,649 & 17,64 \\
\hline $2-4$ & 0,0104 & 25 & 0,0996 & & 0,1846 & 8,178 & 19,10 \\
\hline $2-5$ & 0,0104 & 25 & 0,0996 & & 0,2051 & 10,149 & 24,57 \\
\hline 3-1 & 0,0103 & 25 & 0,0990 & 0,0968 & 0,1962 & 9,442 & 22,60 \\
\hline $3-2$ & 0,0103 & 25 & 0,0990 & 0,1011 & 0,1827 & 8,131 & 18,97 \\
\hline $3-3$ & 0,0106 & 25 & 0,0990 & & 0,1774 & 7,401 & 16,96 \\
\hline 3-4 & 0,0103 & 25 & 0,0990 & & 0,1874 & 8,587 & 20,23 \\
\hline 3-5 & 0,0104 & 25 & 0,0990 & & 0,2058 & 10,274 & 24,92 \\
\hline $4-1$ & 0,0104 & 25 & 0,0979 & 0,0956 & 0,1980 & 9,625 & 23,11 \\
\hline $4-1$ & 0,0104 & 25 & 0,0979 & 0,1002 & 0,1868 & 8,548 & 20,12 \\
\hline $4-3$ & 0,0103 & 25 & 0,0979 & & 0,1827 & 8,233 & 19,25 \\
\hline $4-4$ & 0,0103 & 25 & 0,0979 & & 0,1881 & 8,757 & 20,70 \\
\hline $4-5$ & 0,0103 & 25 & 0,0979 & & 0,2084 & 10,728 & 26,19 \\
\hline 5-1 & 0,0100 & 25 & 0,0979 & 0,0955 & 0,2020 & 10,415 & 25,31 \\
\hline $5-2$ & 0,0100 & 25 & 0,0979 & 0,1002 & 0,1857 & 8,785 & 20,78 \\
\hline $5-3$ & 0,0098 & 25 & 0,0979 & & 0,1819 & 8,577 & 20,20 \\
\hline $5-4$ & 0,0101 & 25 & 0,0979 & & 0,1886 & 8,985 & 21,33 \\
\hline $5-5$ & 0,0103 & 25 & 0,0979 & & 0,2065 & 10,549 & 25,68 \\
\hline $6-1$ & 0,0099 & 25 & 0,1001 & 0,0984 & 0,2023 & 10,323 & 25,05 \\
\hline $6-2$ & 0,0101 & 25 & 0,1001 & 0,1018 & 0,1875 & 8,653 & 20,41 \\
\hline $6-3$ & 0,0102 & 25 & 0,1001 & & 0,1775 & 7,588 & 17,47 \\
\hline 6-4 & 0,0101 & 25 & 0,1001 & & 0,1832 & 8,228 & 19,24 \\
\hline $6-5$ & 0,0099 & 25 & 0,1001 & & 0,2128 & 11,384 & 28,03 \\
\hline 7-1 & 0,0100 & 25 & 0,1013 & 0,0991 & 0,194 & 9,275 & 22,14 \\
\hline 7-2 & 0,0102 & 25 & 0,1013 & 0,1034 & 0,1775 & 7,475 & 17,16 \\
\hline 7-3 & 0,0099 & 25 & 0,1013 & & 0,1732 & 7,268 & 16,59 \\
\hline $7-4$ & 0,0100 & 25 & 0,1013 & & 0,1752 & 7,395 & 16,94 \\
\hline $7-5$ & 0,0105 & 25 & 0,1013 & & 0,2019 & 9,586 & 23,00 \\
\hline
\end{tabular}

Legenda:

№ = Número do dosímetro

$\mathbf{A 0}=$ Média dos dois valores de A0 (LE LD)

$\mathbf{k}=(\mathrm{A}-\mathrm{A} 0) /$ Espessura
Espessura $=$ Espessura do dosímetro medido em $\mathrm{cm}$

A0 (LE LD) = Leitura média do dosímetro da lateral esquerda e direita

Dose Gy = Dose absorvida pelo dosímetro conforme equação da curva de calibração
Dose-alvo = Quantidade de dose que o dosímetro recebeu em Gy

A = Absorbância 
Na FIG. 27 pode-se observar os pontos correspondes aos valores obtidos na TAB.16 e representados por meio de cores.

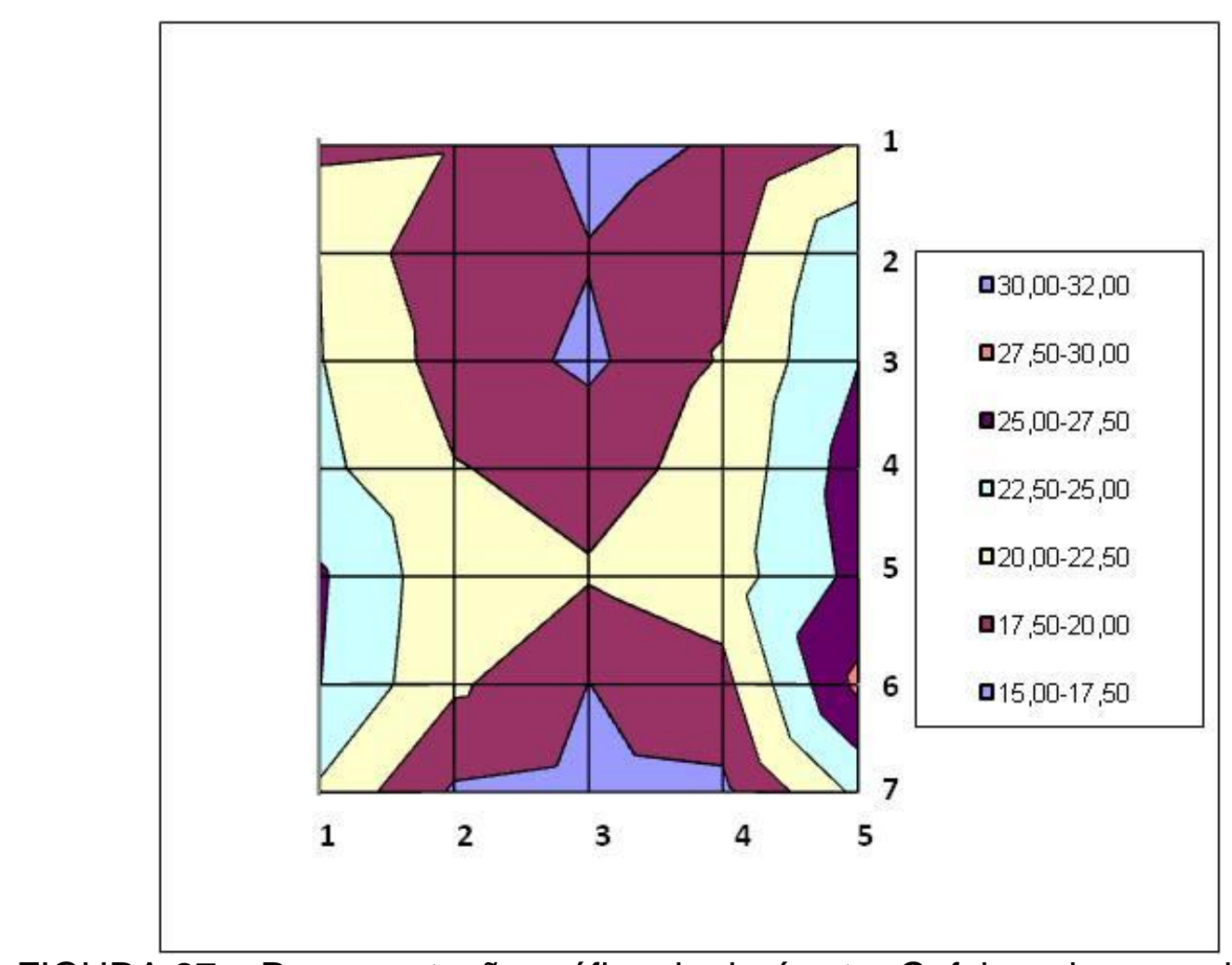

FIGURA 27 - Representação gráfica do dosímetro Gafchromic na posição 45ำ

$\mathrm{Na}$ TAB. 16, o menor valor de dose absorvida foi 16,59 Gy (mostrada com fundo de cor laranja) e o maior valor de dose absorvida, 28,03 Gy (mostrada com fundo de cor verde-claro).

No dosímetro situado na posição central, a dose lida foi de 19,25 Gy que é mostrado na tabela em negrito.

$\mathrm{Na}$ distribuição de dose do Gammacell 220 do CTR para a posição 0ํㅡ, o valor do fator de uniformidade de dose foi 1,79 (razão entre o maior e o menor valor pelos produtos durante o mapeamento). Para a posição de $90^{\circ}$, o fator de uniformidade de dose foi 1,88 e, para a posição de $45^{\circ}$, o fator de uniformidade de dose foi 1,69 . 
Os valores encontrados são inferiores a 2, o que permite assegurar que 0 irradiador Gammacell 220 pode ser utilizado na irradiação de sangue, uma vez que esse valor representa o fator de uniformidade de dose estabelecido pela norma AAMI/ISO11137(9) para irradiação de sangue, através da relação de 50 Gy dividido por 25 Gy.

\subsection{Certificação}

A certificação do processo das boas práticas de fabricação (BPF) na irradiação de sangue humano baseia-se na norma AAMI/ISO $11137^{(9)}$, na resolução $\mathrm{n}^{\circ} 153$ da $\mathrm{ANVISA}^{(6)}$, na literatura referenciada e nos resultados dos experimentos realizados no presente estudo.

Para garantir a certificação, todos os processos descritos no terceiro e quarto capítulo devem ser rigorosamente obedecidos.

As etapas de certificação são:

a) Controle de irradiação, conforme apêndice B;

b) Sistema dosimétrico correto;

c) Mapeamento de dose;

d) Controle do tempo do irradiador;

e) Calibração do sistema dosimétrico. 


\section{CONCLUSÃO}

No presente estudo foram desenvolvidos procedimentos e metodologias de controle para aplicação de BPF na irradiação de sangue humano, no Centro da Tecnologia das Radiações (CTR) - IPEN. Os procedimentos obedeceram ao mesmo rigor estabelecido na norma AAMI/ISO 11137.

Foram estudados três sistemas dosimétricos para serem utilizados na qualificação do irradiador. O sistema utilizando dosímetros TLD (Termoluminescence-Dosimetry) não apresentou uniformidade de resposta nas leituras para a faixa de dose requerida para irradiação de sangue. Os sistemas utilizando-se os dosímetros PMMA (Polimetil Metacrilato) e Gafchromic HD - 810 mostraram-se adequados para esta aplicação.

Foi escolhido o dosímetro Gafchromic HD - 810 pelo fato da faixa de aplicação para fótons estar entre 1 a $10^{3}$ Gy com taxas de dose de 0,001 a 1000 Gy/s. O sistema dosimétrico utilizando-se esse dosímetro mostrou-se de fácil utilização e os resultados do coeficiente de variação das leituras na faixa de dose entre 10 Gy e 50 Gy permitem que este sistema possa ser adotado, considerando-o como o mais adequado para os procedimentos de mapeamento de dose de irradiadores de sangue.

Os resultados do mapeamento de dose do irradiador Gammacell 220, fabricado pela Atomic Energy of Canada Limited (AECL), Ottawa-Canada e instalado na Coordenadoria de Aplicações na Engenharia e Indústria, IPENCNEN/SP-CTR, apresentou um fator de uniformidade de dose inferior a dois. Isso significa que o irradiador Gammacell 220 pode irradiar bolsas de sangue sem causar qualquer dano ao sangue. Quando o produto tem densidade próxima a $1 \mathrm{~g} / \mathrm{cc}$, este permite ser utilizado na irradiação de sangue humano, atendendo aos requisitos necessários de qualificação para este tipo de aplicação. 


\section{REFERÊNCIAS BIBLIOGRÁFICAS}

1. BASILE, Nívia Gomes.O que é sangue. VÉSPER. São Paulo. Disponível em: <http://www.escolavesper.com.br/sangue.htm.>. Acesso em: 15 out. 2004.

2. CAVALCANTE, Talvã Araripe. O sangue e seus constituintes. HEMONLINE. Salvador. Disponível em:<http://www.hemonline.com.br>.Acesso em: 15 out. 2004.

3. JUNQUEIRA, Luiz C; CARNEIRO, José. Histologia básica. Rio de Janeiro: Ed. Guanabara Koogan, 2004.

4. HARMENING, D. Técnicas modernas em banco de sangue e transfusão. Rio de Janeiro: Ed. Revinter Ltda, 1992.

5. LEITMAN, Susan F. Leukocyte inactivation by blood irradiation. In: Clinical Practice of Transfusion Medicine" PETZ, Swisher, KLEINMAN, Spence and STRAUSS. New York, 1997. p.375-382.

6. ANVISA - Agencia de Vigilância Sanitária, Resolução - RDC № 15314 de Julho de 2004. Regulamento Técnico para os procedimentos hemoterápicos, incluindo a coleta, o processamento, a testagem, o armazenamento, o transporte, o controle de qualidade e o uso humano do sangue e seus componentes, obtidos do sangue venoso, do cordão umbilical, da placenta e da medula óssea.

7. ARANHA, Fábio. Irradiação de sangue auxilia pacientes com deficiência imunológica. INSTITUTO DE ENERGIA NUCLEAR. Rio de Janeiro. Disponível em: <http://www.ien.gov.br/noticias/midia arquivo/bn a9 n25saude.htm>. Acesso em: 15 out. 2004.

8. BALDWIN, Michael L; JEFFERIES, Leigh C. Irradiation of blood components. Bethesda: American Association of Blood Bank (AABB) - Library of Congress Cataloging, 1992.

9. AAMI/ISO11137 - Sterilization of health care products - Requirements for validation and routine control - Radiation Sterilization. 1994. 
10. McLAUGHLIN, W.L.; BOYD, A.W.; CHADWICK, K.H.; McDONALD, J.C., MILLER, A. Dosimetry for radiation processing. London: Taylor \& Francis Ltd, 1989.

11. BELLINTANI, Sandra A. 2002. Noções básicas de proteção radiológica. IPEN - Cidade Universitária, São Paulo - SP. Diretoria de Segurança Nuclear. Divisão de Desenvolvimento de Recursos Humanos.

12. NETO, Miguel Bahiense; Carlos, Edison. Os produtos de PVC ajudam a salvar a vida de milhões de pessoas. INSTITUTO DO PVC. São Paulo. Disponível em < http://www.institutodopvc.org/areamedica.htm\#vant>. Acesso em: 25 jun. 2006.

13. ANVISA - Agencia de Vigilância Sanitária, Portaria - № 1376, 19 de novembro de 1993. Aprova alterações na Portaria n. 721/GM, de 09.08.89, que aprova Normas Técnicas para coleta, processamento e transfusão de sangue, componentes e derivados, e dá outras providências.

14. AAMI/ISO11140-1 - Sterilization of health care products - Chemical indicators - Part 1: General requirements - 2005.

15. RAD TAG TECHNOLOGIES. Canadá. Disponível em <http://www.radtagtech.com/index.html>. Acesso em: 12 fev. 2007.

16. SANTINI, A.G. Rfid - identificação por rádio freqüência. CENTRO UNIVERSITÁRIO DE VOTUPORANGA. São Paulo. Disponível em < http://www.santini.com.br/arthur/rfid/>. Acesso em: 16 abr. 2007.

17. GLOVER, B.;BHATT, H. Fundamentos de rfid. Rio de Janeiro: 2007. cap. 1, introdução e rfid. p. 1-17.

18. Guidance for Industry - Gamma irradiation of blood and blood components: a pilot program for licensing. Food and Drug Administration FDA, February 2000. 
19. Atomic Energy of Canada Limited, Instruction Manual. GAMMACELL 220. Cobalt-60 Irradiation Unit. Edition nº 6, July, 1968.

20. ASTM International. Designation: E 668 - 97. Standard Practice for application of thermoluminescence-dosimetry (tld) systems for determining absorbed dose in radiation-hardness testing of electronic devices.

21. Butson, Yu, Cheung, Carolan, Quach, Arnold \& Metcalfe. Dosimetry of blood irradiation with radiochromic film. BLACKWELL SYNERGY. Austrália. Disponível em < http://www.blackwell-synergy.com/doi/abs/10.1046/i.1365-3148.1999.00200.x >. Acesso em: 17 abr.2007.

22. ASTM International. Designation: E 1310 - 89. Standard Practice for use of radiochromic optical waveguide dosimetry system.

23. Dosimetry Gafchromic. INTENATIONAL SPECIALTY PRODUCTS. New Jersey. Disponível em <http://www.ispcorp.com/products/dosimetry/ content/gafchromic/index.html>. Acesso em 17 abr. 2007.

24. MARTINS, Petrônio G., LAUGENI, Fernando P. Administração da produção. São Paulo: 2001.

25. ASTM International. Designation: E 1276 - 93. Standard Practice for use of a polymethylmethacrylate dosimetry system.

26. ASTM International. Designation: E 1275 - 93. Standard Practice for use of radiochromic film dosimetry system. 


\section{APÊNDICES}

\section{APÊNDICE A - Fluxograma da rotina de coleta e irradiação de sangue}
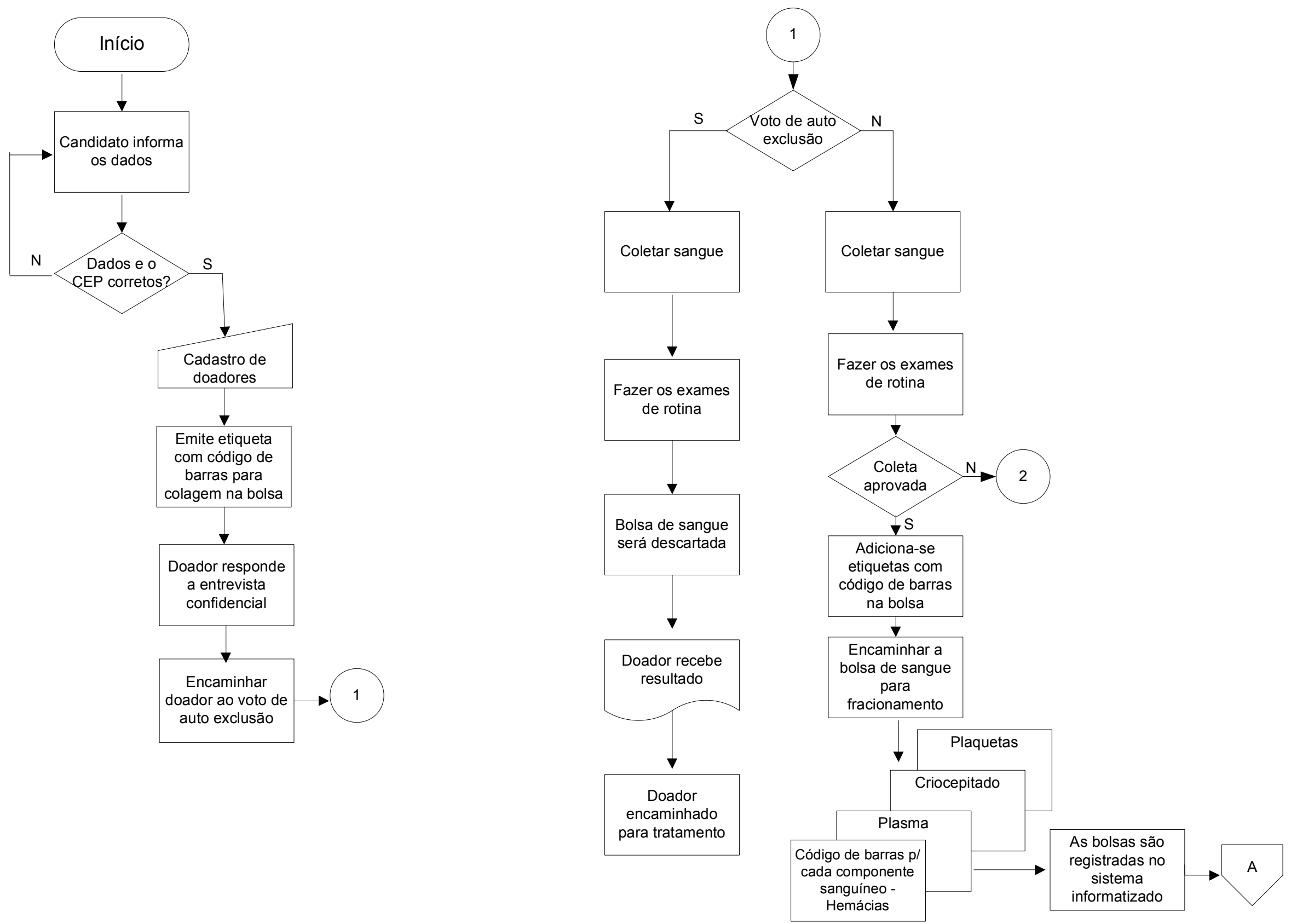

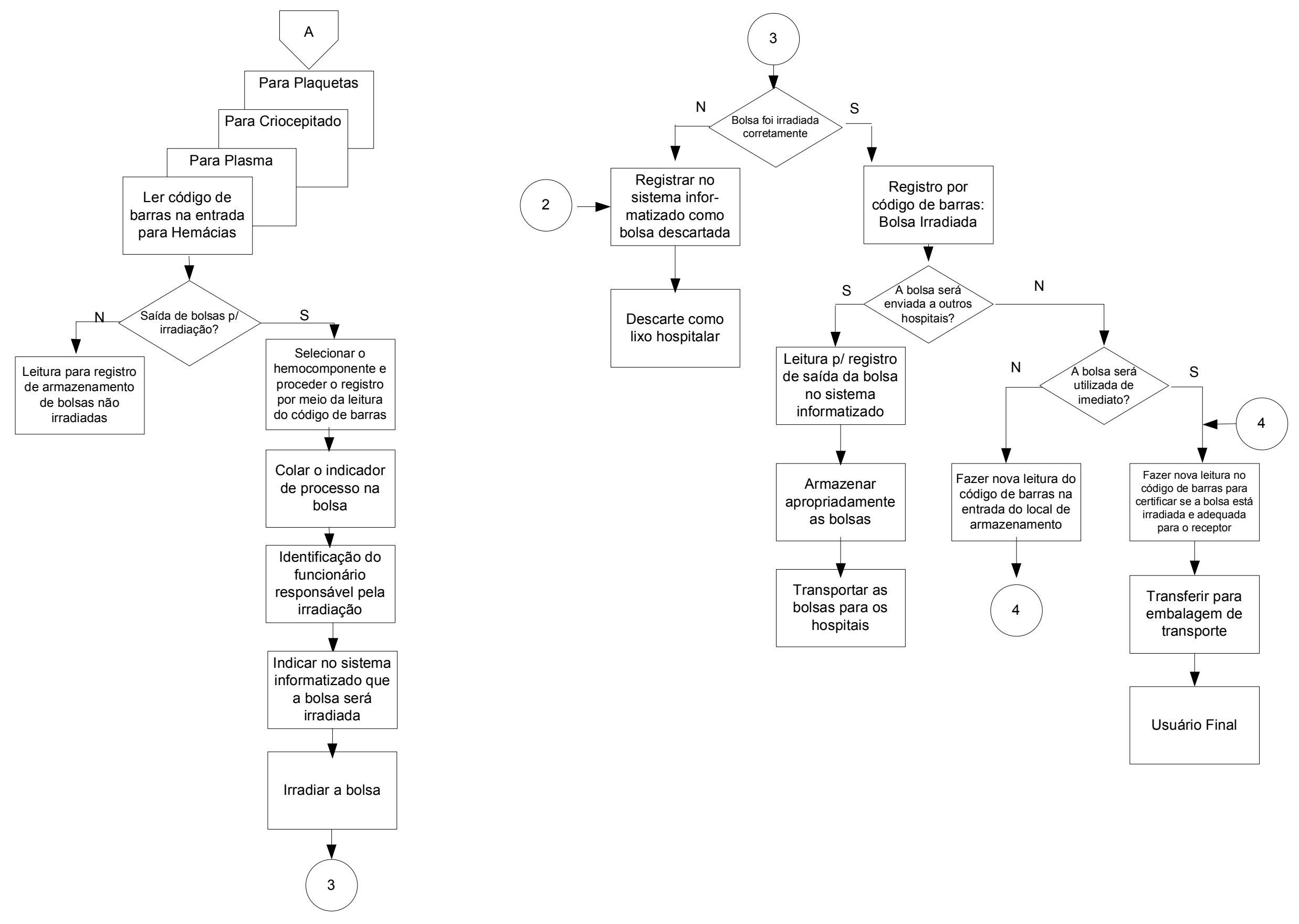
APÊNDICE B - Controle de Irradiação

\section{Controle de irradiação da bolsa de sangue}

№ de Identificação (código de barras)

Nome do Hemocomponente

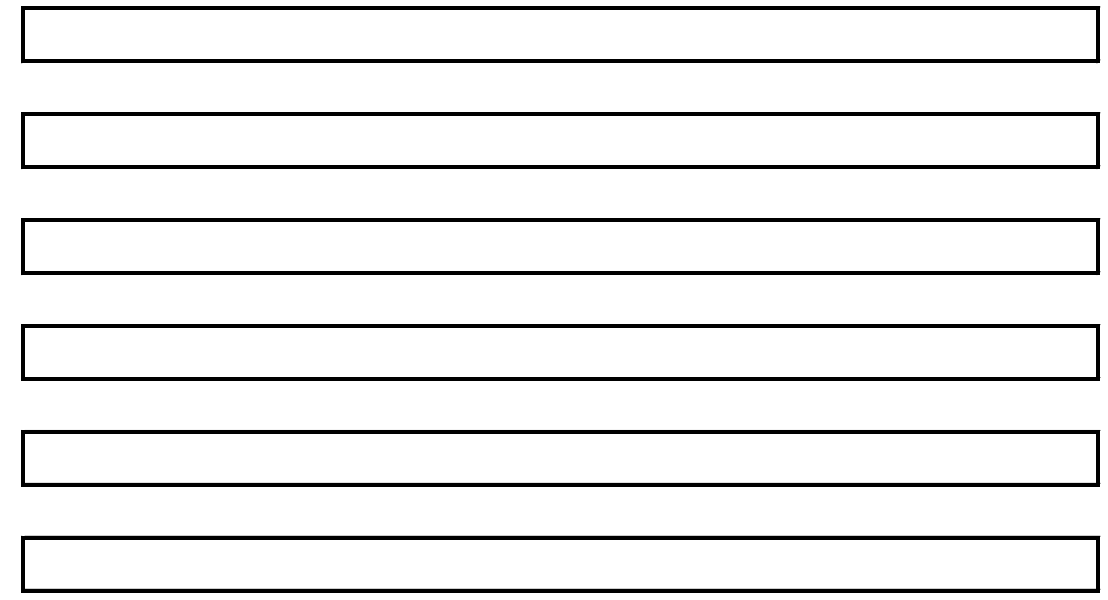

Data de Validade

Irradiação

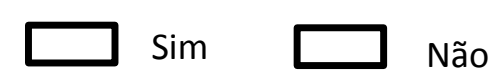

Dose (Gy)

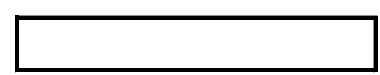

Assinatura do Responsável pela Irradiação

Entregar para outro hospital

$\square \operatorname{Sim} \square$ Não

Assinatura do Responsável pela Entrega 